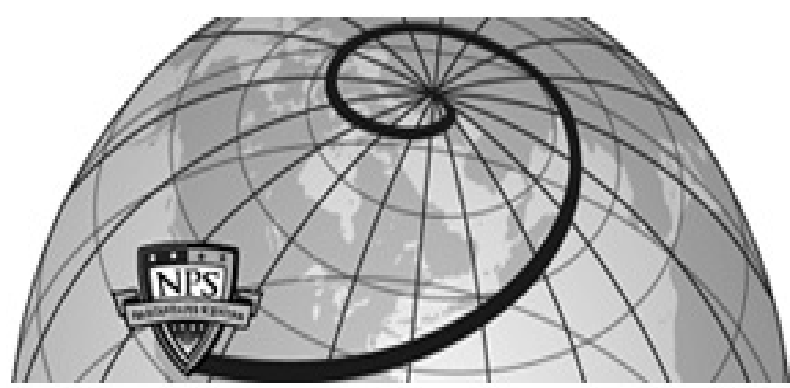

Calhoun: The NPS Institutional Archive DSpace Repository

1972-12

\title{
A study of time variability of surface currents at a point in Monterey Bay.
}

Howton, Harry Marshall.

Monterey, California. Naval Postgraduate School

http://hdl.handle.net/10945/16391

This publication is a work of the U.S. Government as defined in Title 17, United States Code, Section 101. Copyright protection is not available for this work in the United States.

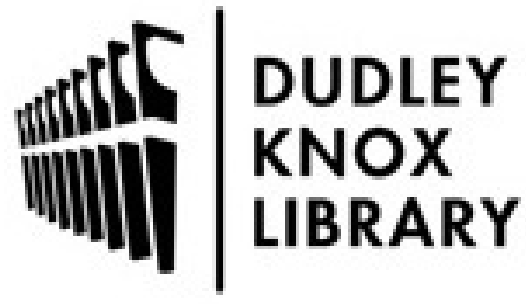

http://www.nps.edu/library
Calhoun is the Naval Postgraduate School's public access digital repository for research materials and institutional publications created by the NPS community. Calhoun is named for Professor of Mathematics Guy K. Calhoun, NPS's first appointed -- and published -- scholarly author.

Dudley Knox Library / Naval Postgraduate School 411 Dyer Road / 1 University Circle Monterey, California USA 93943 
A STUDY OF TIME VARIABILITY OF SURFACE CURRENTS

AT A POINT IN MONTEREY BAY

Harry Marshall Howton 


\section{NAVAL POSTORAWUNTE SGMOL Monterey, Galiónia}
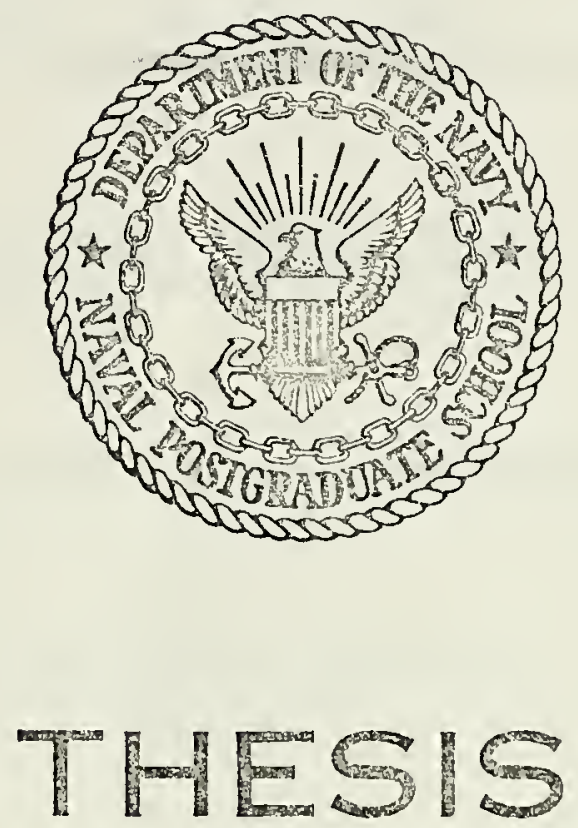

A Study of Time Variability of Surface Currents at a Point in Monterey Bay

Harry Marshall Howton
R. G. Paquette
J. J. von Schwind

December 1972

Approved for public release; distribution unlimited. 

A Study of Time Variability of Surface Currents

at a Point in Monterey Bay

$$
\text { by }
$$

>

Harry Marshall Howton

Lieutenant, United States Navy

B.S., United States Naval Academy 1966

Submitted in partial fulfillment of the requirements for the degree of

MASTER OF SCIENCE IN OCEANOGRAPHY

from the

NAVAL, POSTGRADUATE SCHOOL

December 1972 



\section{ABSTRACT}

The geomagnetic electrokinetograph (GEK) was used to measure surface currents near the center of Monterey Bay during six separate 24-hour periods from May through July, 1972. An average of 244 current vectors were derived for each cruise. The mean currents from these cruises are all southerly and ranged from $4.3 \mathrm{~cm} / \mathrm{sec}$ to $20.4 \mathrm{~cm} / \mathrm{sec}$. The average of these mean currents is $12.1 \mathrm{~cm} / \mathrm{sec}$ toward $163^{\circ} \mathrm{T}$. These values were compared with individual currents derived from dynamic topographies from the same period.

Diurnal and semi-diurnal variations of the current were studied after subjecting the data to a fourier analysis. It was concluded that there must be at least an indirect coupling of the ocean currents with the semi-diurnal tide at the data point. The diurnal component also is important; it may be tidal or inertial, or merely related to the passage of the sun. 

I. INTRODUCTION

II. THE ELECTROMAGNETIC METHOD OF MEASURING OCEAN CURRENTS

A. DEVELOPMENT 11

B. GEOMAGNETIC ELECTROKINETOGRAPH 11

1. Theory of Operation 11

2. Assumptions 17

$\begin{array}{ll}\text { III. EQUIPMENT } & 19\end{array}$

A. ELECTRODES 19

B. CABLE 19

C. RECORDING POTENTIOMETER 20

IV. SHIP PROCEDURES 22

A. PLATFORM 22

B. SAILING PLAN 22

C. NAVIGATION 24

V. DATA COLLECTION, REDUCTION, AND PRESENTATION 25

A. SURFACE CURRENTS 25

1. Collection 25

2. Reduction 26

3. Presentation 26

B. WINDS 27

$\begin{array}{ll}\text { C. TIDES } & 27\end{array}$

D. DISCUSSION OF ACCURACY 28 

VI. ANALYSIS OF CURRENT DATA 31

A. INTRODUCTION 31

B. GRAPHICAL PRESENTATION OF DATA BY CRUISES 32

1. Cruise I 32

2. Cruise II 37

3. Cruise III 42

4. Cruise IV 47

5. Cruise V . 52

6. Cruise VI 57

C. DISCUSSION $\quad 62$

1. General 62

2. Variability 65

VII. CONCLUSIONS 70

APPENDIX A COMPUTER PROGRAMS 71

APPENDIX B SAMPLE DATA FROM CRUISE I 83

APPENDIX C UNAVERAGED CURRENT DATA PLOTTED 92

VERSUS WINDS AND TIDES

BIBLIOGRAPHY

INITIAL DISTRIBUTION LIST '

$\begin{array}{ll}\text { FORM DD } 1473 & 115\end{array}$ 



\section{LIST OF FIGURES}

Figure

1. The Location of the Data Point in Monterey Bay

2. GEK Component Arrangement

3. Sailing Plan and Component Computation

4. Locations of Other Recent Current Measurements

5a. Cruise I, E-W Current Component, Tide Height, and Wind, versus Time; Averaged Current Data

5b. Cruise I, N-S Current Component, Tide Height, and Wind, versus Time; Averaged Current Data

5c. Cruise I, Total Current Magnitude, Tide Height, and Wind, versus Time; Averaged Current Data

5d. Cruise I, Progressive Vector Diagram, N-S Component versus E-W Component, Averaged Current Data

6a. Cruise II, E-W Current Component, Tide Height, and Wind, versus Time; Averaged Current Data

6b. Cruise II, N-S Current Component, Tide Height, and Wind, versus Time; Averaged Current Data

6c. Cruise II, Total Current Magnitude, Tide Height, and Wind, versus Time; Averaged Current Data

6d. Cruise II, Progressive Vector Diagram, N-S Component versus E-W Component; Averaged Current Data

7a. Cruise III, E-W Current Component, Tide Height, and Wind, versus Time; Averaged Current Data

7b. Cruise III, N-S Current Component, Tide Height, and Wind, versus Time; Averaged Current Data

7c. Cruise III, Total Current Magnitude, Tide Height, and Wind, versus Time; Averaged Current Data

7d. Cruise III, Progressive Vector Diagram, N-S Component versus E-W Component; Averaged Current Data 

8a. Cruise IV, E-W Current Component, Tide Height, and Wind, versus Time; Averaged Current Data

8b. Cruise IV, N-S Current Component, Tide Height, and Wind, versus Time; Averaged Current Data

8c. Cruise IV, Total Current Magnitude, Tide Height, and Wind, versus Time; Averaged Current Data

8d. Cruise IV, Progressive Vector Diagram, N-S Component versus E-W Component; Averaged Current Data

9a. Cruise V, E-W Current Component, Tide Height, and Wind, versus Time; Averaged Current Data

9b. Cruise V, N-S Current Component, Tide Height, and Wind, versus Time; Averaged Current Data

9c. Cruise V, Total Current Magnitude, Tide Height, and Wind, versus Time; Averaged Current Data

9d. Cruise V, Progressive Vector Diagram, N-S Component versus E-W Component; Averaged Current Data

10a. Cruise VI, E-W Current Component, Tide Height, and Wind, versus Time; Averaged Current Data

10b. Cruise VI, N-S Current Component, Tide Height, and Wind, versus Time; Averaged Current Data

10c. Cruise VI, Total Current Magnitude, Tide Height, and Wind, versus Time; Averaged Current Data

10d. Cruise VI, Progressive Vector Diagram, N-S Component versus E-W Component; Averaged Current Data

1la. Cruise I, E-W Current Component, Tide Height, and Wind, versus Time; Unaveraged Current Data

11b. Cruise I, N-S Current Component, Tide Height, and Wind, versus Time; Unaveraged Current Data

11c. Cruise I, Total Current Magnitude, Tide Height, and 95 Wind, versus Time; Unaveraged Current Data 

12a. Cruise II, E-W Current Component, Tide Height, and Wind, versus Time; Unaveraged Current Data

12b. Cruise II, N-S Current Component, Tide Height, and Wind, versus Time; Unaveraged Current Data

12C. Cruise II, Total Current Magnitude, Tide Height, and Wind, versus Time; Unaveraged Current Data

13a. Cruise III, E-W Current Component, Tide Height, and Wind, versus Time; Unaveraged Current Data

13b. Cruise III, N-S Current Component, Tide Height, and Wind, versus Time; Unaveraged Current Data

13c. Cruise III, Total Current Magnitude, Tide Height, and Wind, versus Time; Unaveraged Current Data

14a. Cruise IV, E-W Current Component, Tide Height, and 102 Wind, versus Time; Unaveraged Current Data

14b. Cruise IV, N-S Current Component, Tide Height, and Wind, versus Time; Unaveraged Current Data

14c. Cruise IV, Total Current Magnitude, Tide Height, and Wind, versus Time; Unaveraged Current Data

15a. Cruise V, E-W Current Component, Tide Height, and 105 Wind, versus Time; Unaveraged Current Data

15b. Cruise V, N-S Current Component, Tide Height, and Wind, versus Time; Unaveraged Current Data

15c. Cruise V, Total Current Magnitude, Tide Height, and Wind, versus Time; Unaveraged Current Data

16a. Cruise VI, E-W Current Component, Tide Height, and Wind, versus Time; Unaveraged Current Data

16b. Cruise VI, N-S Current Component, Tide Height, and Wind, versus Time; Unaveraged Current Data

16c. Cruise VI, Total Current Magnitude, Tide Height, and Wind, versus Time; Unaveraged Current Data 



\section{LIST OF TABLES}

Table

Page

I Other Recent Current Measurements Near the Data Point

II Results of Fourier Analysis 



\section{INTRODUCTION}

\section{INTRODUCTION}

This study was designed to use the Geomagnetic Electrokinetograph (GEK) to investigate the time variability of surface currents at one point in Monterey Bay .

Recent studies by Smith (1971) and McKay (1970) utilized the GEK to measure surface currents, but these measurements were taken singly, over large areas, and at different times. In order to determine the nature of the surface currents in Monterey Bay it was necessary to get data which was independent of spacial changes and of a sufficiently long duration to show tidal and inertial effects. The technique followed was to continually run squares with the GEK for approximately 24 hours. The squares averaged 0.5 nautical miles on a side and were repeated about every 24 minutes. Electrode zeros and current components were computed cyclically around the square.

Six experiments were conducted between 10 May and 22 July, 1972 at a point near the center of Monterey Bay $\left(36^{\circ} 46^{\prime} \mathrm{N} / 122^{\circ} 0 \mathrm{I}^{\prime} \mathrm{W}\right)$ in water 440 fathoms deep (Figure 1). The Naval Postgraduate School (NPS) research vessel ACANIA was used to tow the GEK array. Analysis of the data was facilitated by the use of the NPS IBM 360 computer. Causes of variability of surface currents were sought in tidal, wind, inertial, and seasonal effects. 



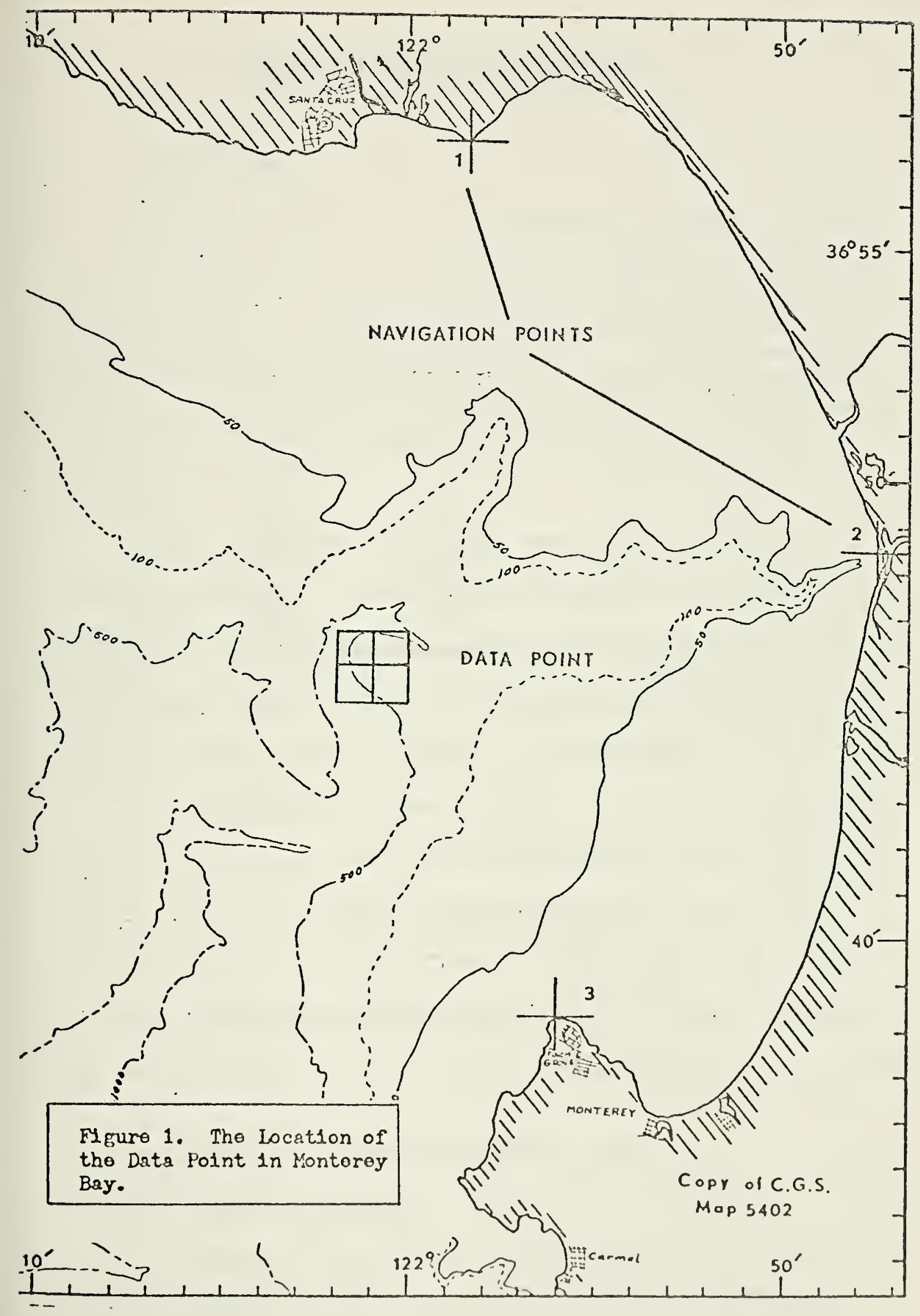





\section{THE ELECTROMAGNETIC METHOD OF MEASURING OCEAN CURRENTS}

\section{A. DEVELOPMENT}

When a part of the ocean moves relative to the earth's magnetic field, a voltage is induced in the sea water. Under certain conditions a voltage equal to the induced voltage may be measured between two identical electrodes introduced into the sea. Under other conditions, part or all of the induced voltage is dissipated through resistance in the sea water.

Faraday is credited with the first mention of and experimentation with this phenomenon. His experiments failed; however, in the late 1800 's broken trans-Atlantic cables showed the potential differences he had sought and led to the early 20 th contury experimentation in Dartmouth Harbor by Young, Gerrard, and Jevens (1920).

The electromagnetic method of towed electrodes is a continuation of this theory and is a result of work done between 1946 and 1954 by Longuet-Higgins and Barber (1946), Stommel (1948), von Arx (1950), and Longuet-Higgins, Stern, and Stommel (1954). The technique owes its name, Geomagnetic Electrokinetograph (GEK), to von Arx. Using the GEK method, surface currents can readily be measured from a ship underway.

B. GEOMAGNETIC ELECTROKINETOGRAPH (GEK)

\section{Theory of Operation}

The GEK is made up of a recording potentiometer, a twoconductor, neutrally buoyant cable, and a matched pair of silver-silver 

chloride electrodes of the order of 100 meters apart. The potentiometer records the difference in potential between two electrodes. A long cable is required to allow the electrodes to be towed beyond the magnetic effects of the ship's steel hull.

An extensive discussion of electromagnetic theory and the ocean's movement through the earth's magnetic field may be found in von Arx (1950) and Longuet-Higgins, Stern, and Stommel (1954) (hereafter referred to as L-HSS). The following summary of L-HSS's treatment of this subject is by McKay (1970) with large portions of the development based on work by Curtin (1970) .

The electrical field intensity along a conducting path that moves through a magnetic field is the difference between the two potential gradients. One potential gradient can be shown by application of Faraday's Law of Induction to be $\underline{V} \times \underline{H}$ as is done by L-HSS. In this expression, $\underline{V}$ is the vector velocity with which the conducting path is moved and $\underline{H}$ is the magnetic field intensity vector. The other potential gradient is given by Ohm's Law as $\rho \underline{1}$, where $\rho$ is the resistivity and $\underline{i}$ the electric current density vector along the conductor. If the potential is denoted $\Phi$, the negative of the electric force field in the moving conducting path can be expressed as

$$
\nabla \Phi=(\underline{V} \times \underline{H})-\rho \underline{i}
$$

When the electrodes are deployed, two distinct conducting paths are present: (a) the sea water, and (b) the long conductors to which the electrodes are attached. The potential in each of these paths is the 

difference of the two terms of equation (1). In the following discussion, a right-hand co-ordinate system is utilized with the following conventions: the positive $\mathrm{x}$-direction is that of the ship's head; $\mathrm{y}$ is the horizontal co-ordinate perpendicular to the course steered and $z$ is positive up.

Consider first the sea water path. When the electrodes are towed directly astern of the ship, as shown in Figure 2, they sense the potential difference along a path parallel to the direction of the ship's head. The component of potential gradient generated in this direction due to the $(\mathrm{V} \times \underline{\mathrm{H}})$ term is $\left(\mathrm{V}_{\mathrm{y}} \mathrm{H}_{\mathrm{z}}-\mathrm{V}_{\mathrm{z}} \mathrm{H}_{\mathrm{y}}\right)$, where $\mathrm{V}_{\mathrm{y}}$ is the component of water velocity perpendicular to the course steered (set of ship), $V_{z}$ is the vertical component of water velocity, $\mathrm{H}_{z}$ is the vertical intensity of the earth's magnetic field, and $\mathrm{H}_{\mathrm{y}}$ is the horizontal intensity of the geomagnetic field in a direction perpendicular to the ship's course. If $\mathrm{V}_{\mathrm{Z}}$ is assumed negligible in comparison with $\mathrm{V}_{\mathrm{y}^{\prime}}$, the measurable potential gradient generated by the water motion is $\mathrm{V}_{\mathrm{y}} \mathrm{H}$; that is, the potential gradient contributed by the $(\underline{V} \times \underline{H})$ term is due to the component of water velocity perpendicular to the ship's course. This water motion causes the ship's set (and the set of the electrodes) and is independent of the ship's velocity in the direction of the interelectrode line. The second potential gradient in the sea water path, $\rho \underline{i}$, is a direct function of the electric current density along the path betwcen the electrodes. The electric current density along this path depends on the clectrical characteristics (potential gradient's resistances) of all other surrounding 

paths, since it is only through the surrounding paths that a closed electric-current-carrying circuit can be completed.

Consider next the part of the closed conducting path formed by the two wires and the voltmeter. It can be seen, by application of reasoning identical to that used for the sea water path, that the velocity-induced potential gradient due to the $(\underline{\mathrm{V}} \times \underline{\mathrm{H}})$ term in equation (l) is again $\mathrm{V}_{\mathrm{y}} \mathrm{H}_{\mathrm{Z}}$. The second potential gradient $\rho \underline{i}$, is essentially zero in this path due to the low resistance of the wire and the small current drawn.

The potential differences sensed by the voltmeter and continuously recorded as GEK data are those developed in the wires leading to the electrodes and in the sea water between the electrodes. Traversing this path, as shown in Figure 2, and adding the potentials yields the following:

$$
\begin{aligned}
E=\left(V_{y} H_{z}\right) \overline{A B}+\left(V_{y} H_{z}\right) \overline{B C} & +\left[\left(-V_{y} H_{z}\right) \overline{C B}-\left(\rho i_{n}\right) \overline{C B}\right] \\
& +\left(-V_{y} H_{z}\right) \overline{B A}
\end{aligned}
$$

where $\mathrm{E}$ is the emf per unit distance and $\mathrm{A}, \mathrm{B}$, and $\mathrm{C}$ are the points shown in Figure 2. The sumbol $\overline{\mathrm{AB}}$ represents the distance between $\mathrm{A}$ and $\mathrm{B}$. The term in brackets represents the potential gradient in the sea water between the electrodes; the remaining terms represent the induced emf in the indicated sections of the wire. Equation (2) reduces to:

$$
E=\left(\rho i_{x}\right) \overline{C B}
$$

where the direction is that of the electrode line, or, in the case of electrodes towed directly astern, the direction of the ship's head. 



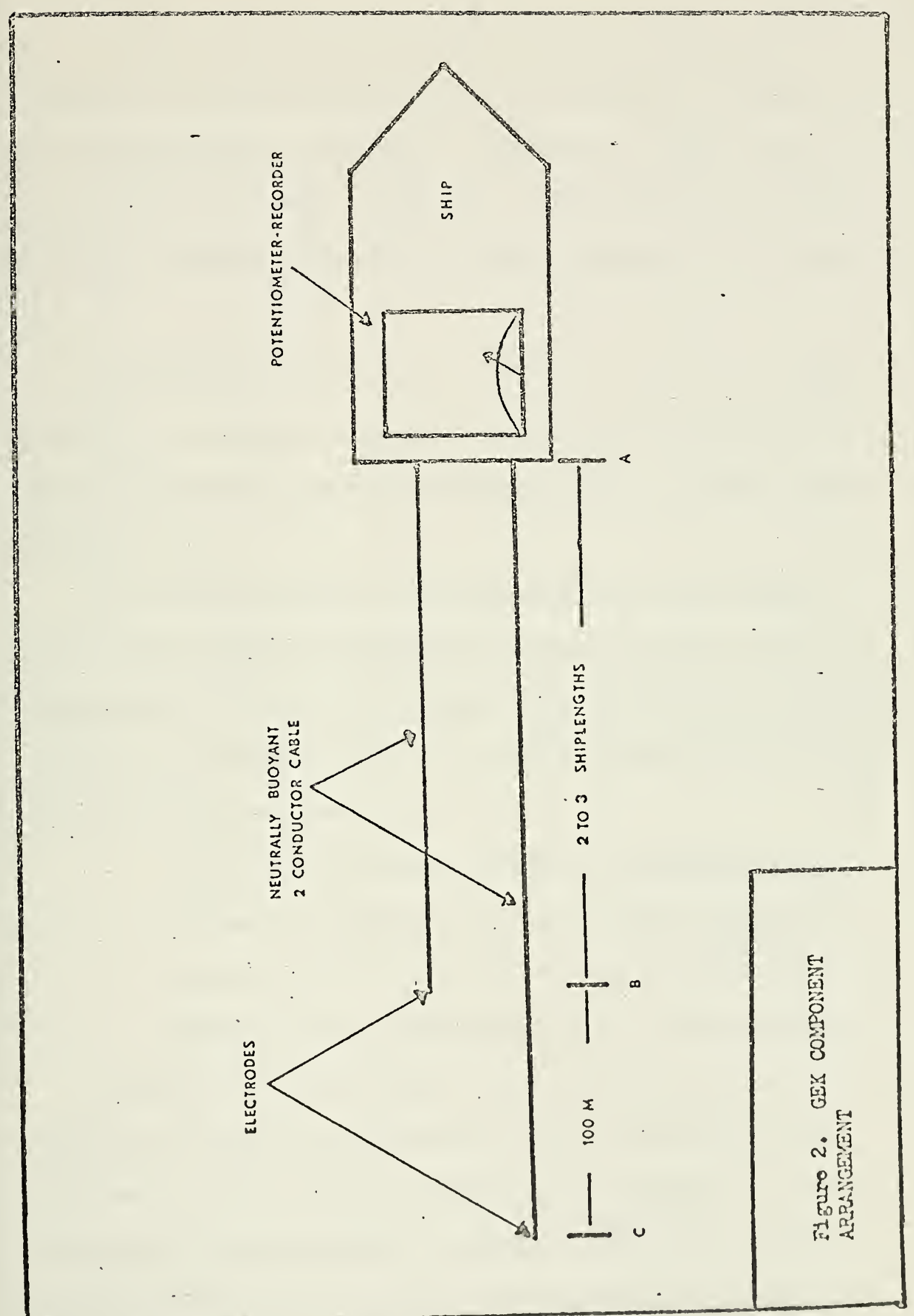



For most currents in the deep ocean the potential gradient is completely short-circuited by the deep layer of relatively still water underlying the moving surface layer. In this case $\nabla \Phi=0$ and $\rho \underline{i}=\underline{V} \times \underline{H}$. Under these conditions, if the interelectrode distance is s units, the horizontal potential difference measured by the voltmeter is:

$$
E=\left(\mathrm{ksH}_{\mathrm{z}} \mathrm{V}_{\mathrm{h}}\right) \times 10^{-8}
$$

where $\mathrm{V}_{\mathrm{h}}$ is the horizontal component of water motion perpendicular to the interelectrode line and $k$ is a constant near unity, to be discussed in Section III C.

The positive direction of $\mathrm{E}$ is taken as that of the ship's head and the current velocity is determined by adding the electric vectors, $\mathrm{E}$, obtained on two courses, at right angles. The following example indicates the relationship between the direction of the current component measured and that of the interelectrode line:

If $\mathrm{V}_{\mathrm{h}}$ is positive toward the east, $\mathrm{H}_{\mathrm{Z}}$ is directed downward, and the interelectrode line is parallel with a meridian of longitude, E will have a positive polarity at the southern electrode and a negative polarity at the northern electrode.

Since $\mathrm{H}_{\mathrm{z}}$ is positive downward in the northern hemis phere, the following convention must be observed to obtain the true direction of the current velocity: In order that the deflection recorded by the instrument be in the same direction as the set of the electrodes, the conductor leading to the more distant electrode must be connected to 

the voltmeter input terminal which, when made positive, gives a deflection of the recorder current indicator to the right. The necessity of observing this convention can be seen from the example given above. This convention must be reversed in the southern magnetic hemisphere, where $\mathrm{H}_{z}$ is directed upward.

\section{Assumptions}

As has been stated above, the electric current density, $\underline{i}$, is a function of the conducting path in which it exists. Thus, with an assumption of uniform resistivity, the current density integrated along any line is directly dependent on the emf's in the available sea water paths surrounding that line. These emf's as indicated by Equation (1), are directly related to the water velocity in the region. Therefore, any electric current density measured at the surface is a reflection, in part, of the velocity field in the entire water column below the surface and in adjacent waters .

Recognition of this fact is essential for a meaningful interpretation of GEK data. It is only in the case of true oceanic currents that GEK data, unsupplemented by information derived from other sources, can be considered representative of the true surface current velocity. In this case the following conditions generally prevail:

(i) the vertical component of water velocity is negligible in comparison with the horizontal component,

(ii) the flow is broad compared with the depth of the water,

(iii) the current is stcady in the $x$-direction, while a current "fix" is being obtained, 

(iv) a deep layer of still water underlies the moving surface layer.

If condition (iv) is not obtained, the voltage is usually less than the theoretical and it is customary to multiply by a correction factor $k$ determined by a simultaneous measurement with a current meter. 



\section{EQUIPMENT}

\section{A. ELECTRODES}

A complete operating assemblage of GEK equipment was inherited from Smith (1971) at the onset of this project.

The matched set of silver-silver chloride electrodes was supplied by Woods Hole Oceanographic Institute and attached to the cable 100 meters apart by direct soldering. Von Arx (1950) describes the process by which electrode pairs are matched. The electrodes were padded and housed in a water permeable tube as shown by Smith (1971).

During the three-month period of data collection, it was not necessary to change the electrode installation.

To eliminate the electrochemical potential, the "zero point" must be obtained and subtracted out of the actual current vectors. This is normally done by reversing the electrodes end for end. In this case, the ship used a square sailing plan and the zero point was taken from opposite sides of each square. This is described in detail in Section VA.

\section{B. CABLE}

A neutrally buoyant cable (Type B-3088) 329 meters long, made by the Vector Cable Company, was utilized during this investigation. The cable's function is to transmit to the recorder the electrode-generated signals from far enough astern ( $1.5-3.0$ shiplengths) of the ship that the electrodes are not affected by the ship's magnetic field and wake. 



\section{RECORDING POTENTIOMETER}

The Geomagnetic Electrokinetograph Model V recording potentiometer based on a Speedomax Type G recorder was used to record the potential differences delivered from the electrodes by the cable. A photograph and a thorough description of the operation of the GEK Model V is contained in $\mathrm{H} . \mathrm{O}$. Publication 607.

The vertical intensity of the earth's magnetic field in gauss for the ship's location was taken from H. O. Chart Number 1702 and the rounded value was set into the recorder to the nearest tenth. A multiplication factor was later used to adjust the data to the exact magnetic vertical intensity at the data point. The multiplier includes compensation for annual variation, and is the ratio of the rounded vertical intensity to the correct local magnetic intensity. In this instance it was 0.91 $(0.40 / 0.44)$

As noted by Smith (1971) it is essential to isolate the power for the recorder from the ship's ground. This is done with an isolation transformer which must not be by-passed by the ground lead of a 3-wire power cord. Hence, a conventional two-prong plug is necessary. The recorder also requires a signal multiplier setting. This $k$ value is the ratio of the water speed observed by a non-electromagnetic method to the water speed measured by the electromagnetic method. An open ocean value of 1.04 is suggested by von Arx (1950) with the caution that higher values might be needed in areas where tidal currents and water shear occur. 

The $k$ factor was set at 1.10 , following the recommendation of H. O. Publication 607 (1970 Ch. 1) for water deeper than 75 fathoms. This factor was derived from experjence in open ocean conditions along the Atlantic coast. An unusual structure like Monterey Canyon may behave anomalously, a possibility which will be considered in the discussion of accuracy (Section V D). An incorrect choice of $k$ does not lead to an error in direction. 



\section{SHIP PROCEDURES}

\section{A. PLATFORM}

The research vessel ACANIA was acquired by the Naval Postgraduate School in 1971 and refitted as an oceanographic research vessel. She was launched in 1929 and for many years took part in research activities under the Stanford Rescarch Foundation.

$\mathrm{R} / \mathrm{V}$ ACANIA's length is 126 feet, maximum speed is ten knots, and she carries a crew of five. Of the standard equipment aboard ACANIA, the Decca RM 416 radar was the most important to this study as noted in Section IV C. The UQN - 1 depth finder was also used briefly to confirm charted depths at the data point.

\section{B. SAILING PLAN}

Both clockwise and counterclockwise squares were traversed during the cruise series, allowing the ship to remain within 1000 meters of the data point in calm weather and within 1500 meters during heavier weather.

Ship's speed was held at five knots for all cruises, but the time on each leg was varied between four and nine minutes, depending upon wind and current conditions. In order to maintain position within 1000 meters of the data point the downwind leg might take four minutes, while the upwind leg (opposite side of the squarc) might take eight minutes. All legs were at least four minutes long to insure that the cable had straightened out and a good signal was being received. 



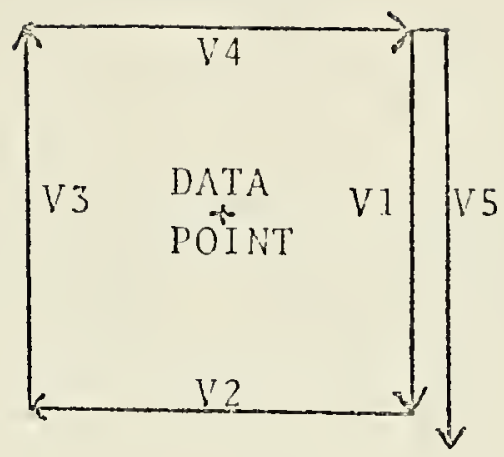

FIGURE 3. SALING PLAN AND COMPONENT COMPUTATION

FIRST VECTOR:

$\mathrm{ZERO}=\frac{\mathrm{VI}+\mathrm{V} 3}{2}$

$\mathrm{E}-\mathrm{W}$ COMPONENT $=\mathrm{V} 1-\mathrm{ZERO}$

$N-S$ COMPONENT $=V 2-Z E R O$

CURRENT MAGNITUDE $=\left[(E-W)^{2}+(N-S)^{2}\right]^{1 / 2}$

CURRENT DIRECTION $=\arcsin \frac{\mathrm{E}-\mathrm{W}}{\mathrm{MAGN}}$

SECOND VECTOR: $\quad$ ZERO $=\frac{\mathrm{V} 2+\mathrm{v} 4}{2}$

$\mathrm{E}-\mathrm{W}$ COMPONENT $=\mathrm{V} 3-\mathrm{ZERO}$

$\mathrm{N}-\mathrm{S}$ COMPONENT $=\mathrm{V} 2-\mathrm{ZERO}$

THIRD VECTOR: $\quad$ ZERO $=\frac{\mathrm{V} 3+\mathrm{V} 5}{2}$

$\mathrm{E}-\mathrm{W}$ COMPONENT $=\mathrm{V} 3-\mathrm{ZERO}$

$\mathrm{N}-\mathrm{S}$ COMPONENT $=V 4-Z E R O$ 

Only cardinal headings were steered during this series of cruises. The sailing plan is shown in Figure 3.

\section{NAVIGATION}

The data point for this project was located close to the center of Monterey Bay over the Canyon. Navigation was by radar at ranges of roughly 11 miles from well-defined landmarks. These points are noted on Figure 1. Visual bearings were also used to augment the radar range information. The positioning accuracy is estimated to be $\pm 0.1 \mathrm{~nm}$. 



\section{DATA COLLECTION, REDUCTION, AND PRESENTATION}

A. SURFACE CURRENTS

\section{Data Collection}

During each cruise approximately twenty-four hours of consecutive surface current readings were obtained. All data was taken at one point near the center of both Monterey Bay and the Monterey Canyon. An average of 244 current vectors were obtained from each of the six cruises .

The GEK recording potentiometer was continuously manned in order that the strip chart could be annotated and the potentials logged for each leg of the sailing plan. The ship's speed was five knots with each leg of the square being between four and nine minutes in duration. The average duration was six minutes. Longer and shorter legs were run to compensate for the ship's drift.

The primary items logged on the data sheet were: ship's heading $\left({ }^{\circ} \mathrm{T}\right)$, velocity $(\mathrm{cm} / \mathrm{sec})$, and time. Weather, position, depth, speed, and other pertinent data were also logged on each data shcet.

The strip chart was marked and the time was noted for each change of course. The date, segment of cruise and cruise number were also recorded on the chart.

Breaks in the data of about ten to fifteen minutes occurred when the direction sailed around the square was changed from clockwise to counterclockwise or vice versa. Several breaks in the data sets of up to forty-five minutes occurred due to stecring casualties. 



\section{Data Reduction}

The IBM 360/67 computer at the Naval Postgraduate School computer center was used to reduce the rough data to current magnitudes and directions.

As can be seen from Figure 3 , there is an interdependence of current vectors in each square since one of the current vector components is calculated from a leg of the square which will take part in the next zero computation. This procedure allowed for the calculation of approximately ten current vectors per hour.

The outputs of the data reduction computer program included east-west (E-W) and north-south $(\mathrm{N}-\mathrm{S})$ components, time, and the magnitude and direction of each current vector. This computer program is listed in Appendix A with suitable comments and explanations. Appendix B lists sample current data for Cruise I.

Sharply alternating speeds were present in the data after reduction. These variations were removed by averaging alternate pairs of data. A full discussion of these variations is to be found in Section V D.

\section{Data Presentation}

To produce a clear presentation of current magnitudes versus winds and tides, a computer program was written which utilized the plotting package for the CALCOMP Model 765 plotting equipment along with the IBM 360 computer. 

For each cruise this graphing program produced the plots of $\mathrm{E}-\mathrm{W}$ and $\mathrm{N}-\mathrm{S}$ components and resultants versus time. Corresponding tide heights and wind speeds were plotted on the same graph. Northerly and easterly sets were taken to be positive. Both unaveraged and averaged data were handled in this fashion. The graphing program is included after the reduction program in Appendix $\mathrm{A}$.

The data is also presented in a progressive vector diagram format for each cruise. The progressive vector diagram again utilized the plotting package and may be found with explanations in Appendix A.

\section{B. WINDS}

Estimations of wind speed and direction were recorded aboard $R / V$ ACANIA at various times (normally every two or three hours) during each cruise. These estimates were compared with the hourly readings logged at the U.S. Coast Guard lighthouse on Point Pinos. A composite of these two sources forms the basis for the wind magnitude and direction utilized for each cruise. Appendix $\mathrm{C}$ contains the resulting hourly wind data for Cruise I.

\section{TIDES}

Tide records from Pier Number 1 at Monterey were made available by the NPS Occanographic Department. This data was used to plot directly the tidal curve for each cruise. These tides compare favorably with the high and low tidal heights as calculated from the U. S. Coast and Geodetic Survey Tide Tables. The hourly tidal heights utilized are contained in Appendix D. 

A tide prediction computer program was also written, based on harmonic constants for San Francisco and corrected to the data point in Monterey Bay. The results from this effort did not correlate well with either the tide gauge measurements or the tide tables, and were, therefore, not considered further.

\section{DISCUSSION OF ACCURACY}

In discussing the accuracy of the current data the following potential errors must be considered:

(i) Errors in the observed voltage due either to reading inaccuracies or to the failure of the trace to steady to a constant value after a turn.

(ii) Errors due to inadcquate depth or effects of the canyon walls not compensated for by the $k$ factor.

(iii) Errors due to substantial velocity gradients across the square.

Since the trace could be read to $\pm 1 \mathrm{~cm} / \mathrm{sec}$, and at least four minutes were always given to steady out this trace, the errors in Group (i) are small. They are not systematic and in the long term average to zero.

It is not known how great the crrors of Group (ii) may be. There may not be a thick layer of static water near the bottom (current shears, internal waves may exist) and the lateral dimensions of the parcel of deep water are relatively small. Because of the sharply sloping walls 

of the canyon, bottom effects may affect different legs unequally and cause aberrations. In these circumstances it is unwise to be categorical about the adequacy of using $k=1.10$. On the other hand, the speeds measured are plausible and not notably at variance with the few available measurements obtained in various locations in Monterey Bay.

The sharply alternating speeds described in Section V A 2 may best be explained by the existence of large velocity gradients across the square. These gradients may be caused by variations of depth or by actual currents or eddics. This is contrary to the assumption that the current is broad and therefore the same on both sides of the sajling plan. This breakdown, coupled with the circular and redundant method by which the currents were computed, produces oscillations in a scquence highmedium-low-medium-high in the $\mathrm{N}-\mathrm{S}$ and $\mathrm{E}-\mathrm{W}$ components of current and in the resultant. (See Appendix $\mathrm{C}$ for an example.) If the current component actually present on one $\mathrm{N}-\mathrm{S}$ leg has a magnitude $\mathrm{E}$ and on the opposite side has the magnitude $\mathrm{E}+\triangle \mathrm{E}$, and likewise the remaining two sides of the square have magnitudes $N$ and $N+\Delta N$, then it may be shown that the peak-to-peak range of the resulting zigzag will be the absolute value of $\triangle E-\Delta N$. (Sec एigure 3 for method of computation.) A maximum peak-to-peak range of $60 \mathrm{~cm} / \mathrm{sec}$ occurs in the E-W component of Cruise I, though most peak-to-peak variations are of the order of $30 \mathrm{~cm} / \mathrm{sec}$. These variations were mostly removed from the data by averaging alternate pairs of values. Variations after averaging are of the order of $5 \mathrm{~cm} / \mathrm{sec}$. The process of averaging 

alternate pairs would produce a speed corresponding to some point within the square, if the first explanation of the alternation is valid. It can be seen from comparing the graphs of averaged and unaveraged data, in Section VI and Appendix C, that the averaging process produces a plausible, smoothly varying curve. 



\section{ANALYSIS OF CURRENT DATA}

\section{A. INTRODUCTION}

Various presentations were used to show different aspects of the current data, and to correlate this data with winds, tides, and ocean currents. A summary of results of the fourier analysis with mean current values and a table of contemporary current data are included in this chapter (Tables I and II).

The graphical presentations are contained in Section B of this chapter in the following order:

(i) East-west current component versus wind and tide.

(ii) North-south current component versus wind and tide.

(iii) Total current magnitude versus wind and tide.

(iv) Progressive vector diagram with the cumulative transport past the data point marked every five "fixes" (approximately 30 minutes) with a cross.

Each set of graphs is prefaced with a short summary of sea and weather conditions for that particular period. 

B. GRAPHICAL PRESENTATION OF DATA BY CRUISE

\section{Cruise I}

Period: 10 - 11 May 1972

Latitude: $36^{\circ} 46^{\prime} \mathrm{N}$

Longitude: $122^{\circ} 01^{\prime} \mathrm{W}$

Depth: 440 fathoms

Ship's Speed: 5 knots

Sea and Weather: Winds were from the WNW during this cruise, with a diurnal variation in wind speed caused partly by a land-sea breeze pattern. Velocities of up to 22 knots occurred in the late afternoon and virtual calm prevailed in the early morning hours. Seas varied from 0.5 to 2.0 feet with the wind velocity, while the swell was between 3 feet in the early morning and 8 feet in the early evening. Both were from the WNW. The sky was partly cloudy. Note that only the averaged current data is presented in this section. The unaveraged current data is presented in Appendix C. The start of the progressive vector diagram is labelled " $\mathrm{S}$ " and the end is labelled "E". 



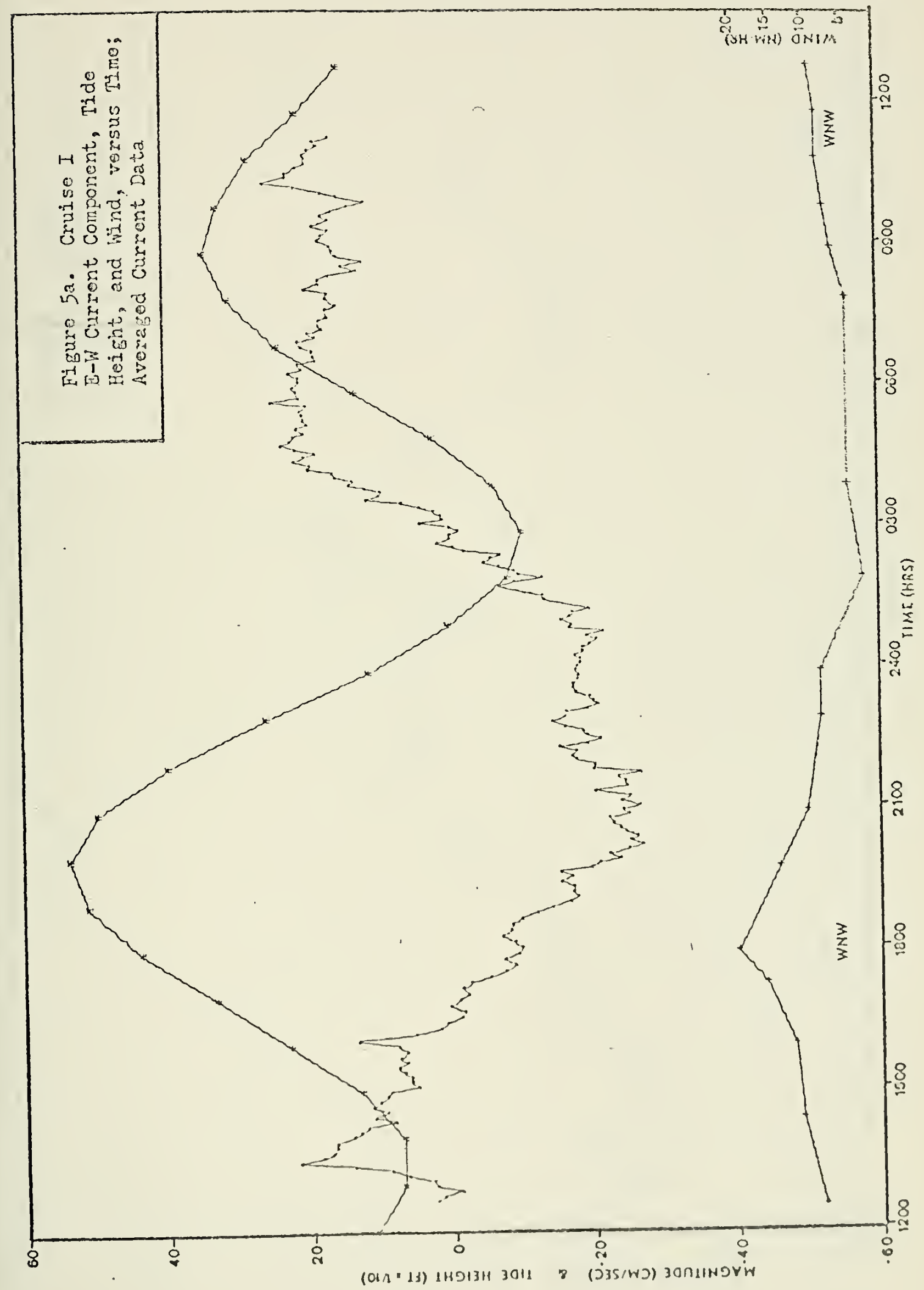





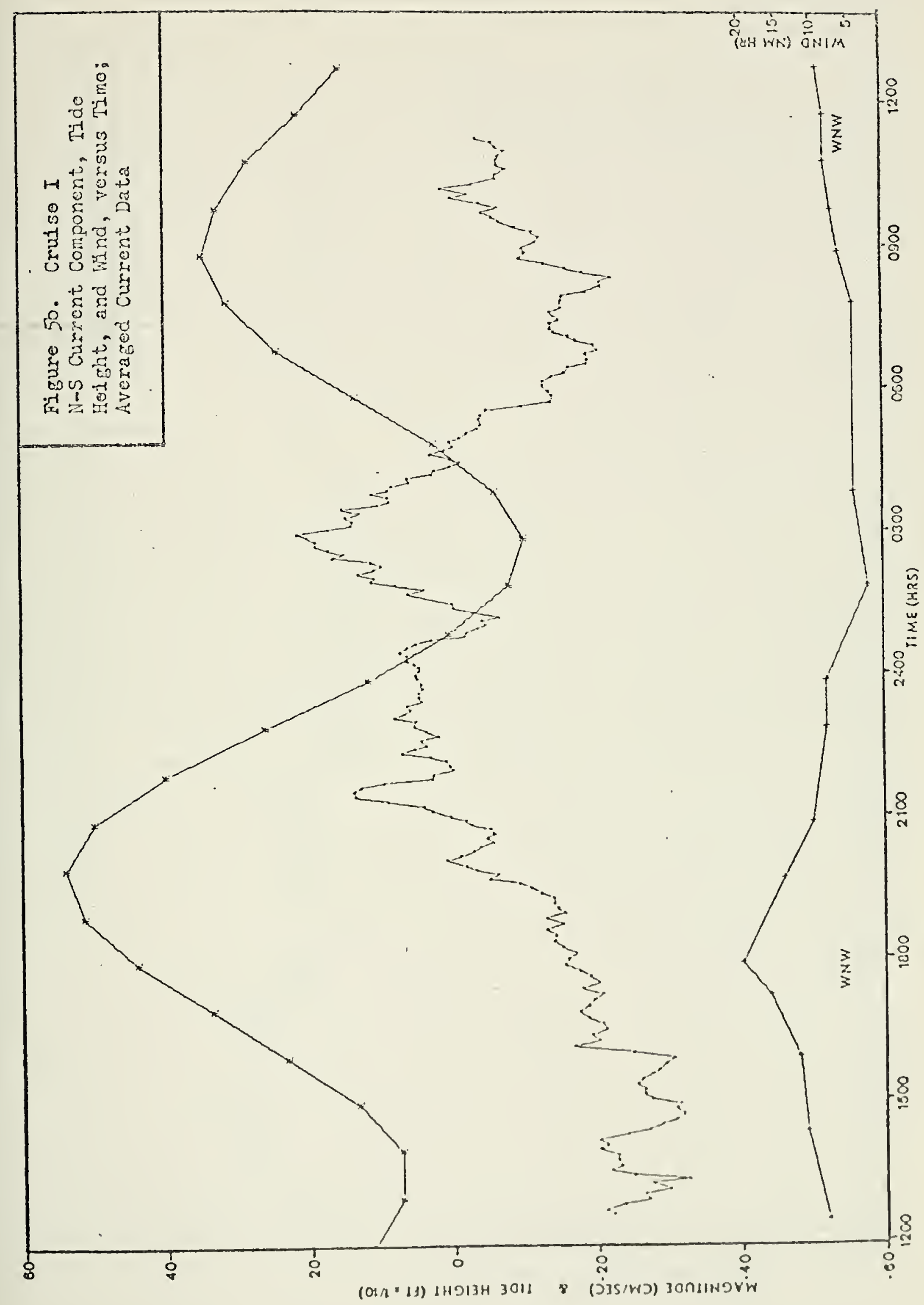





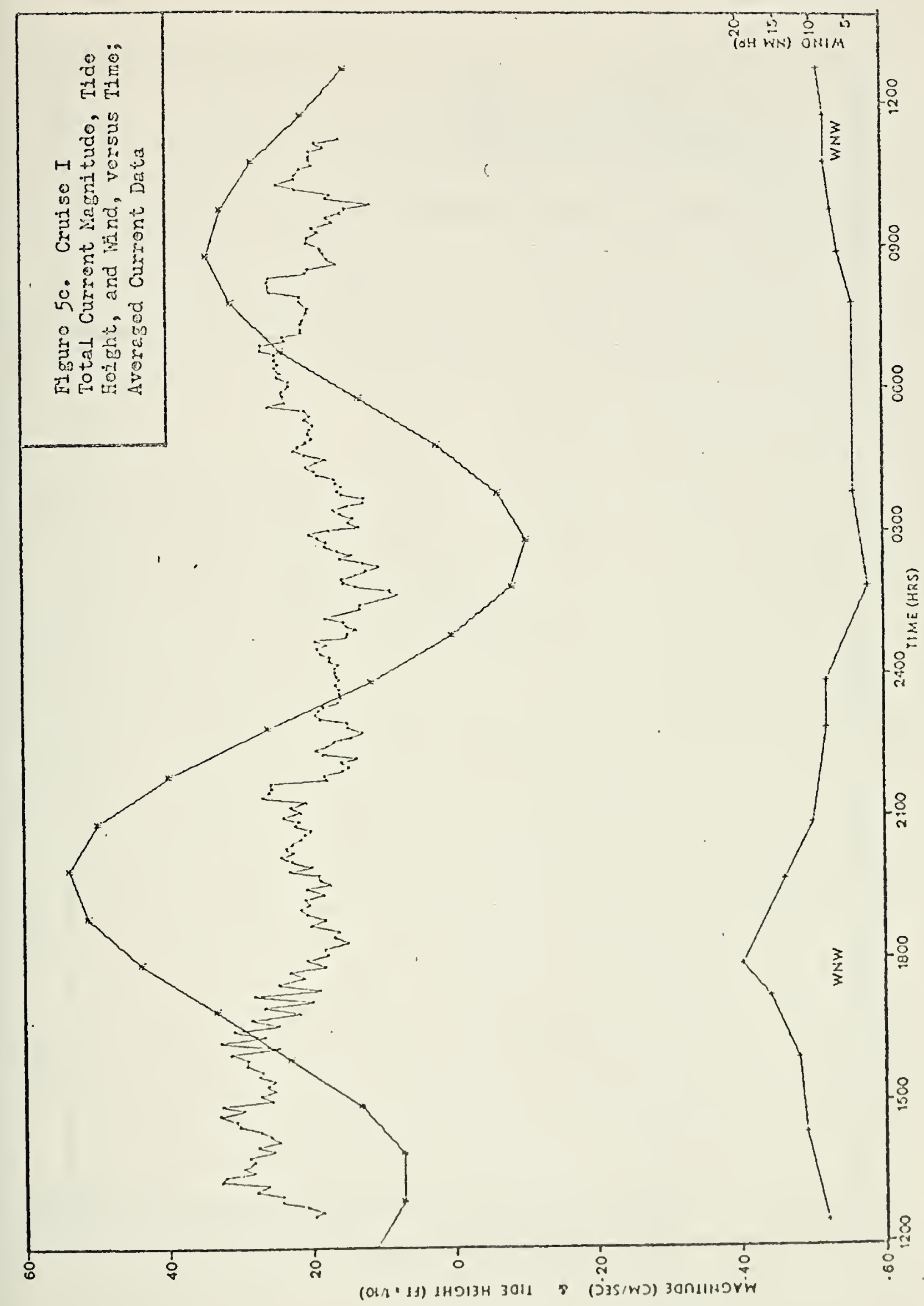





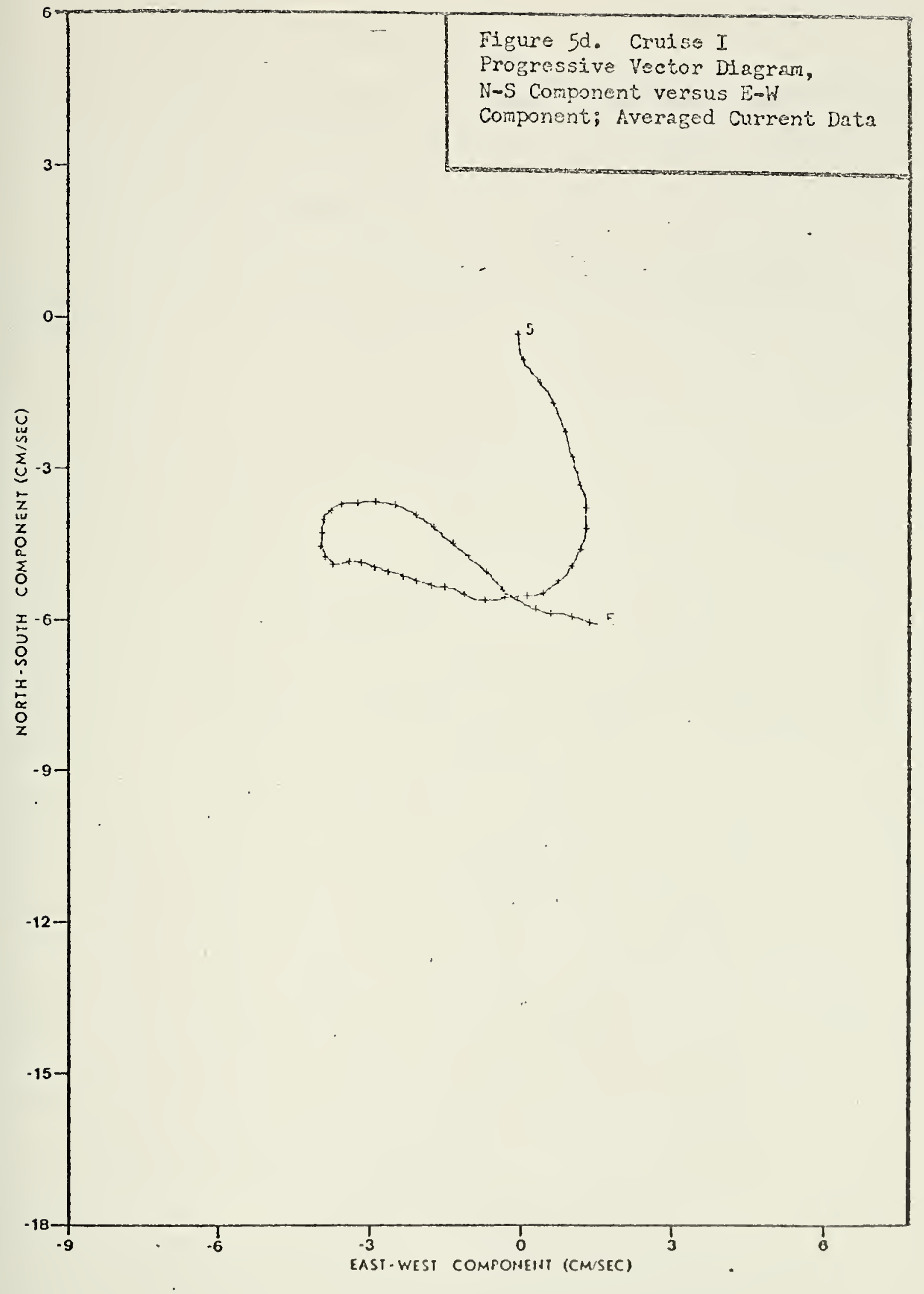



2. Cruise II

Period: 30 - 31 May 1972

Sea and Weather: Same pattern and magnitude as in Cruise I, but with fog and overcast skies in the morning, clearing by mid-afternoon

Note: All other information is the same as for Cruise I. 



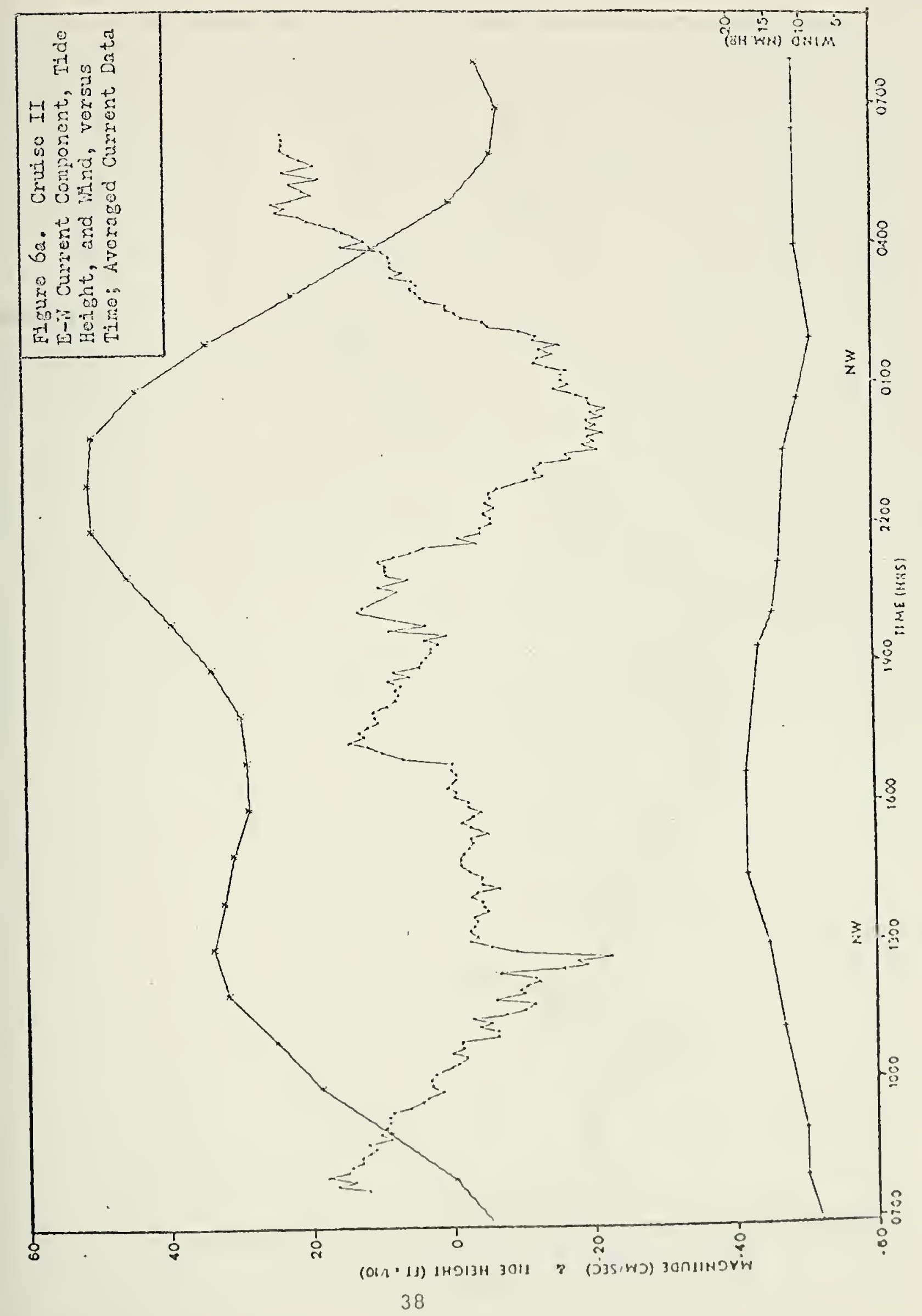





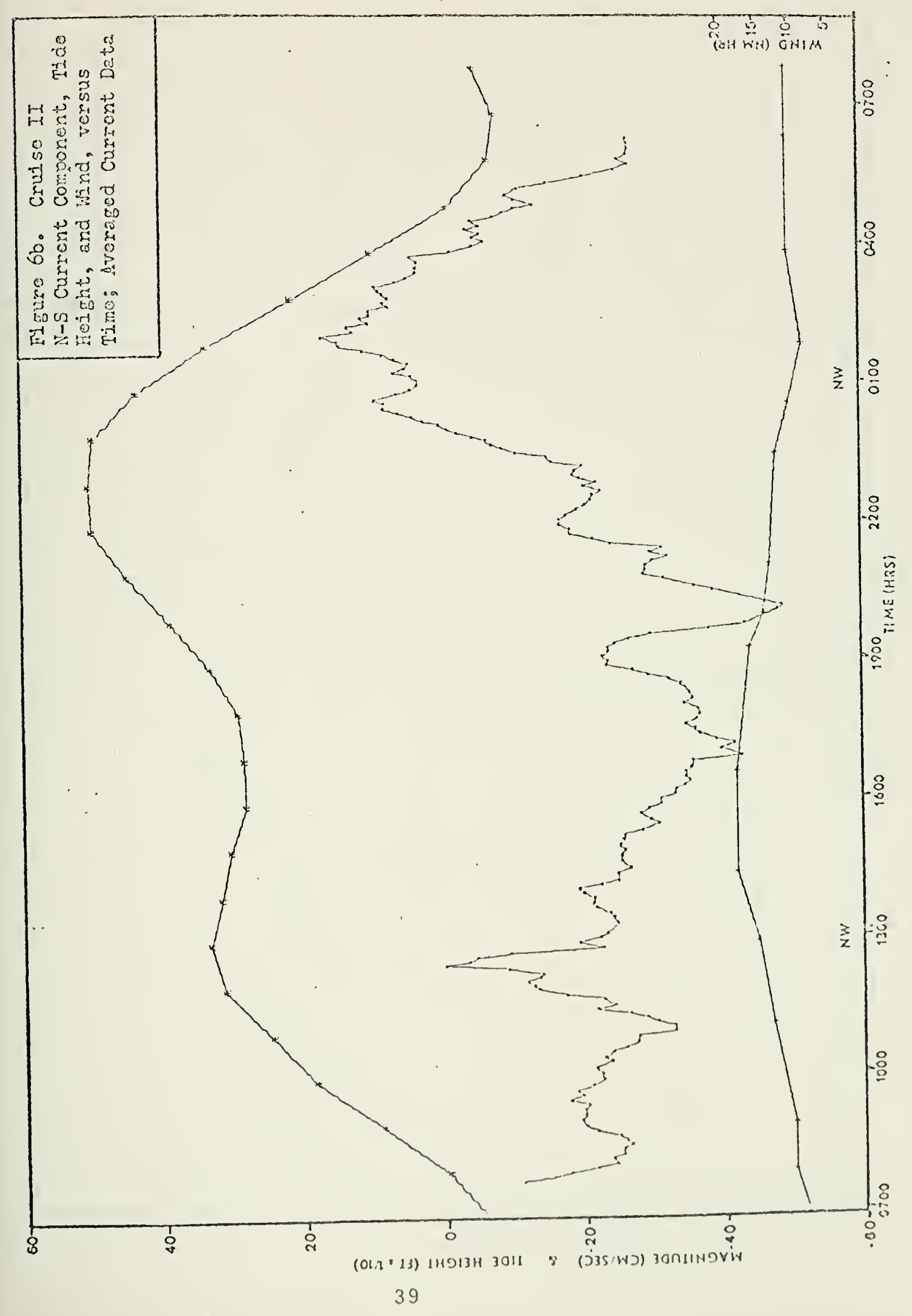





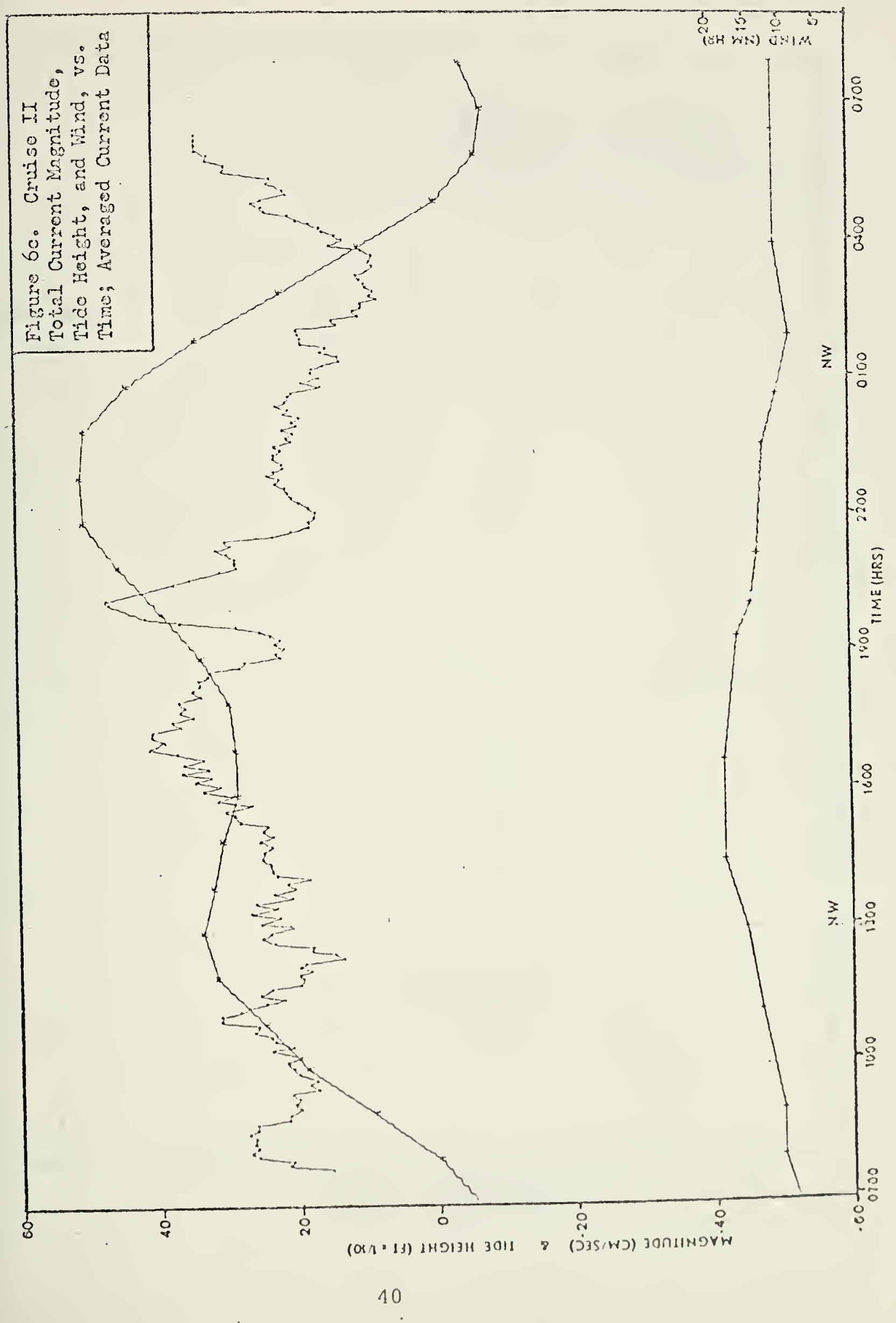





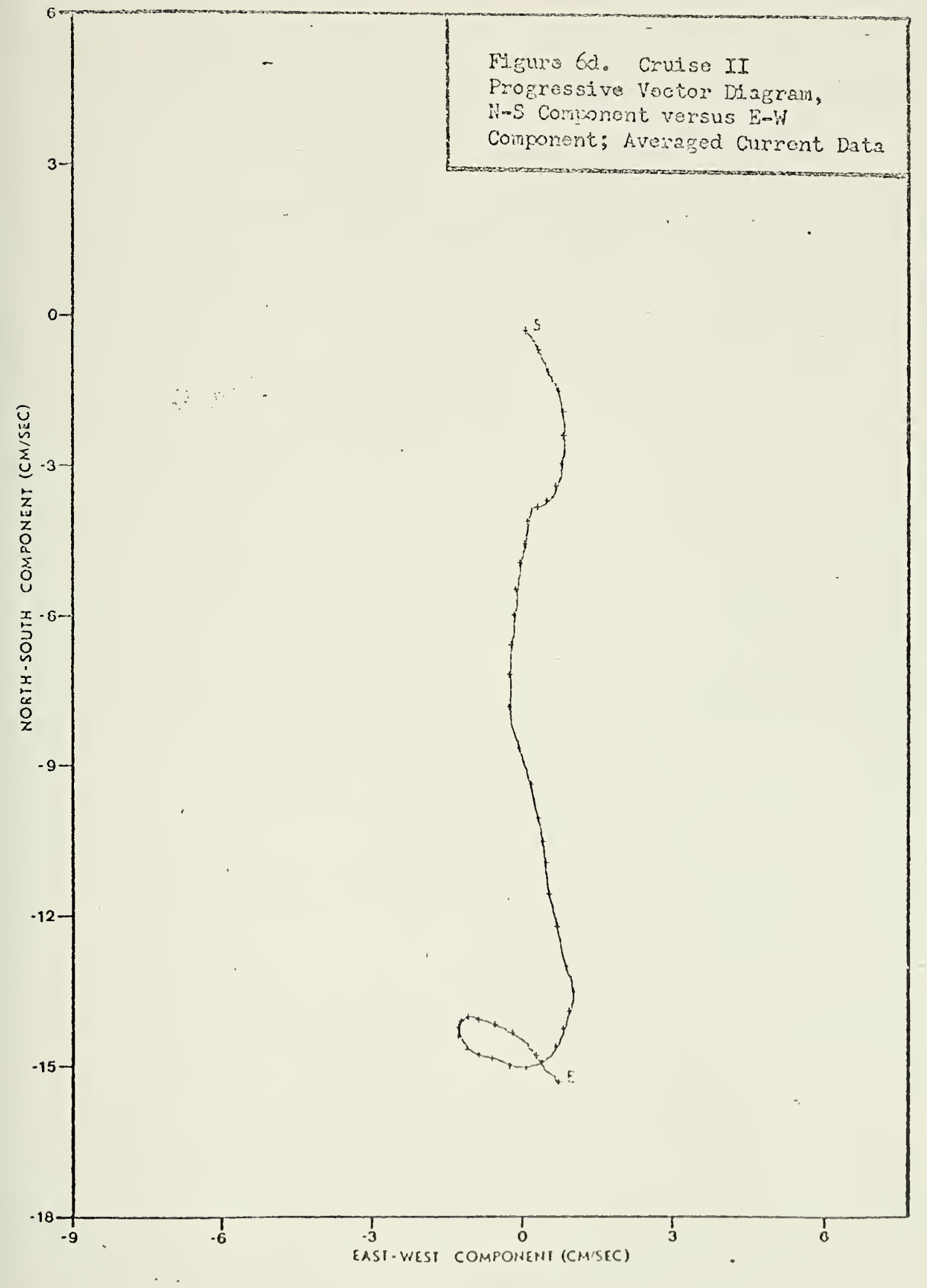





\section{Cruise III}

Period: $19-20$ June 1972

Sea and Weather: Weak and variable winds with a maximum velocity of 8 knots were the rule, with a 1 foot sea and 3 foot swell throughout the cruise. The sky was overcast and some drizzle fell in the morning. 




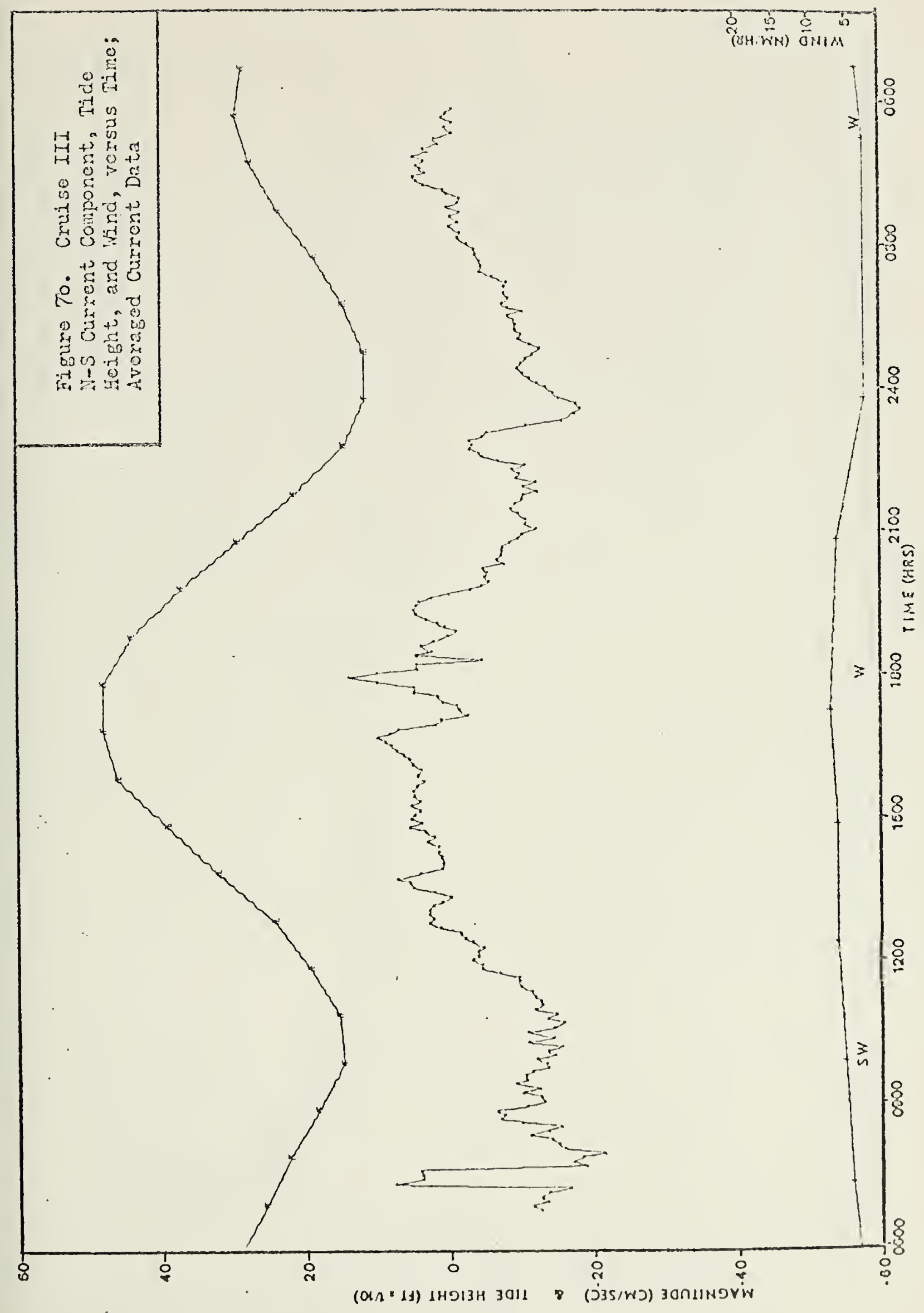





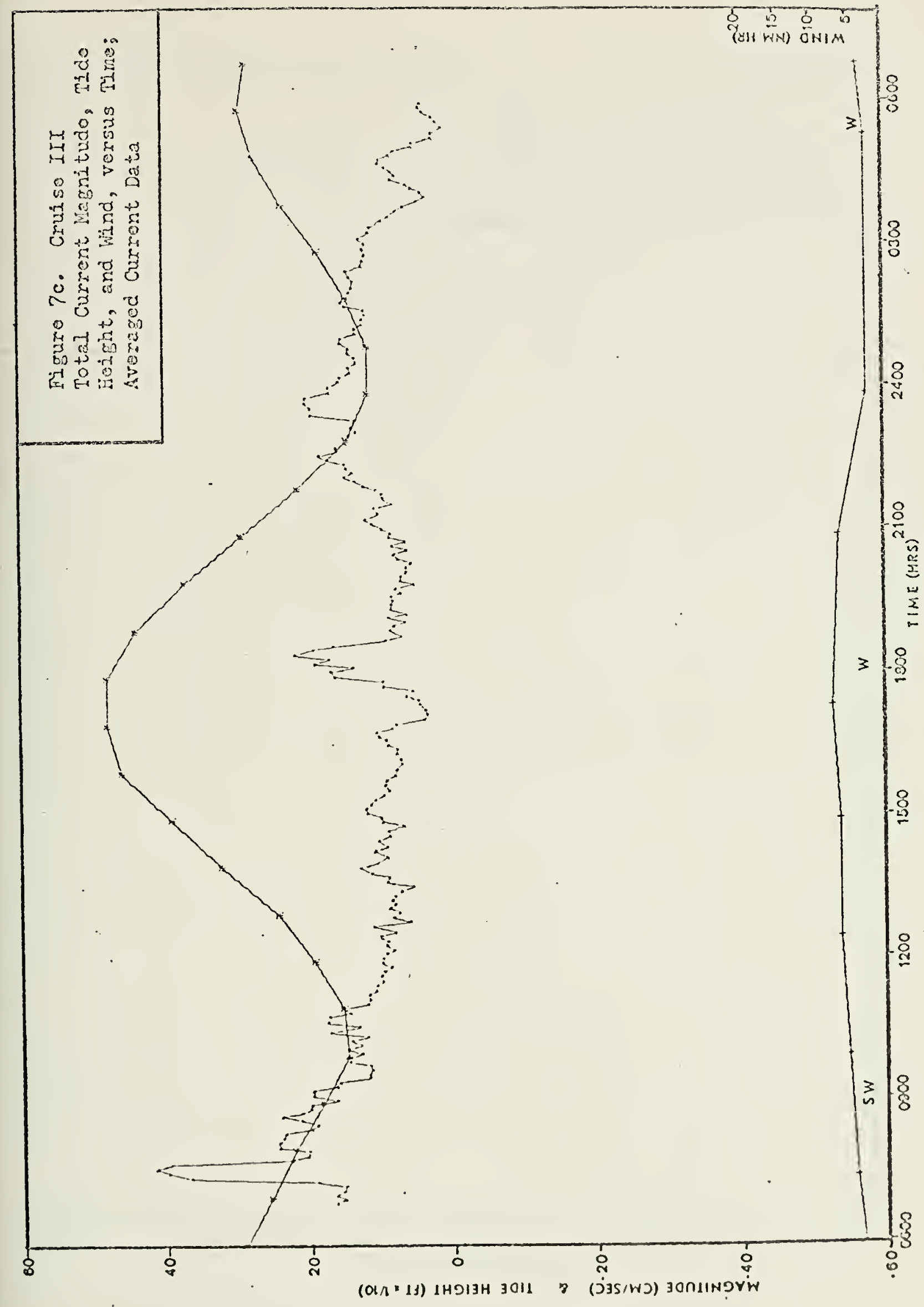





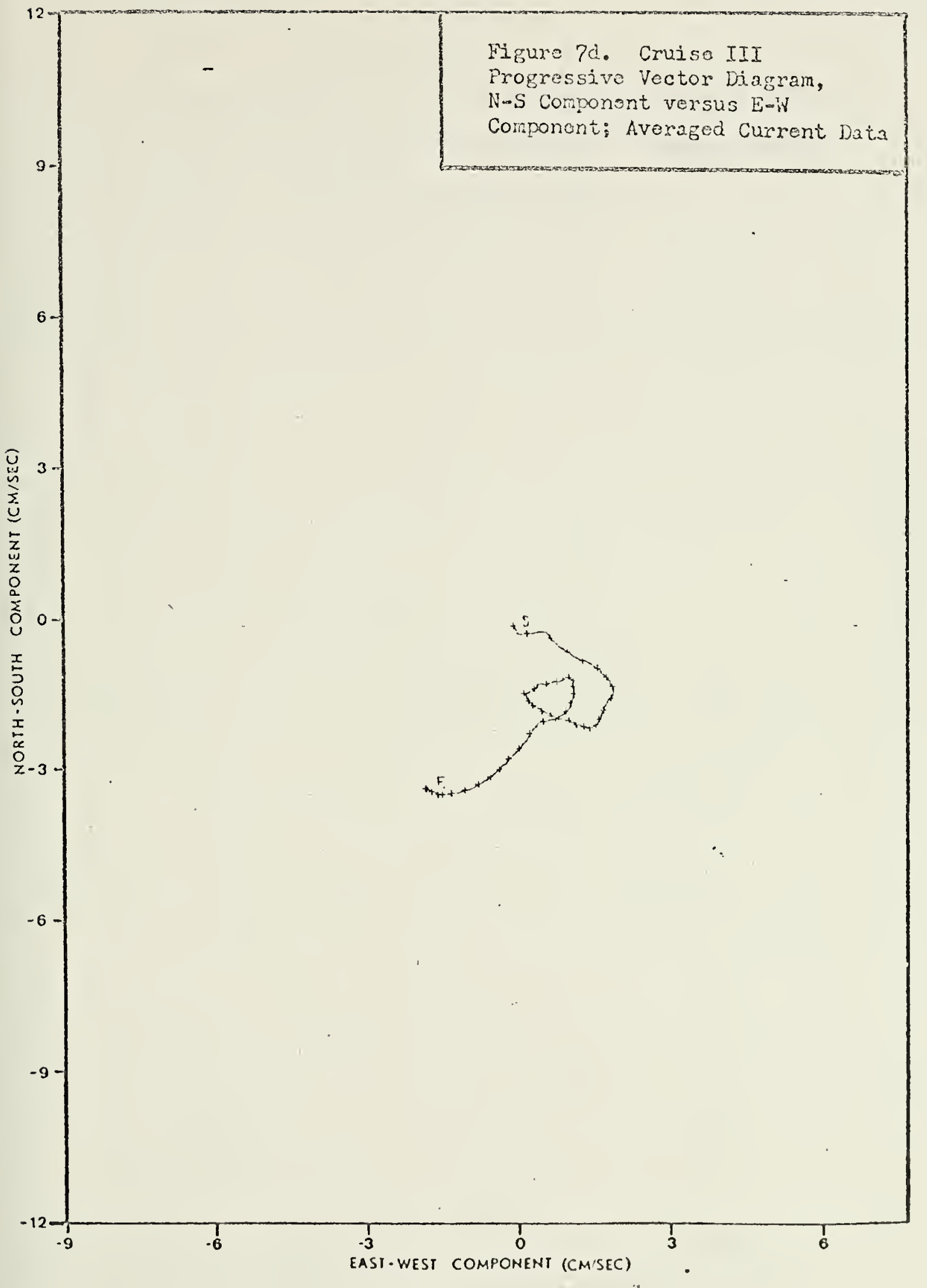

46 

4. Cruise IV

Period: $22^{\circ}-23$ June 1972

Sea and Weather: Very similar to Cruise I with a maximum wind of 16 knots and overcast skies. Winds varied from west to southwest during this period. 



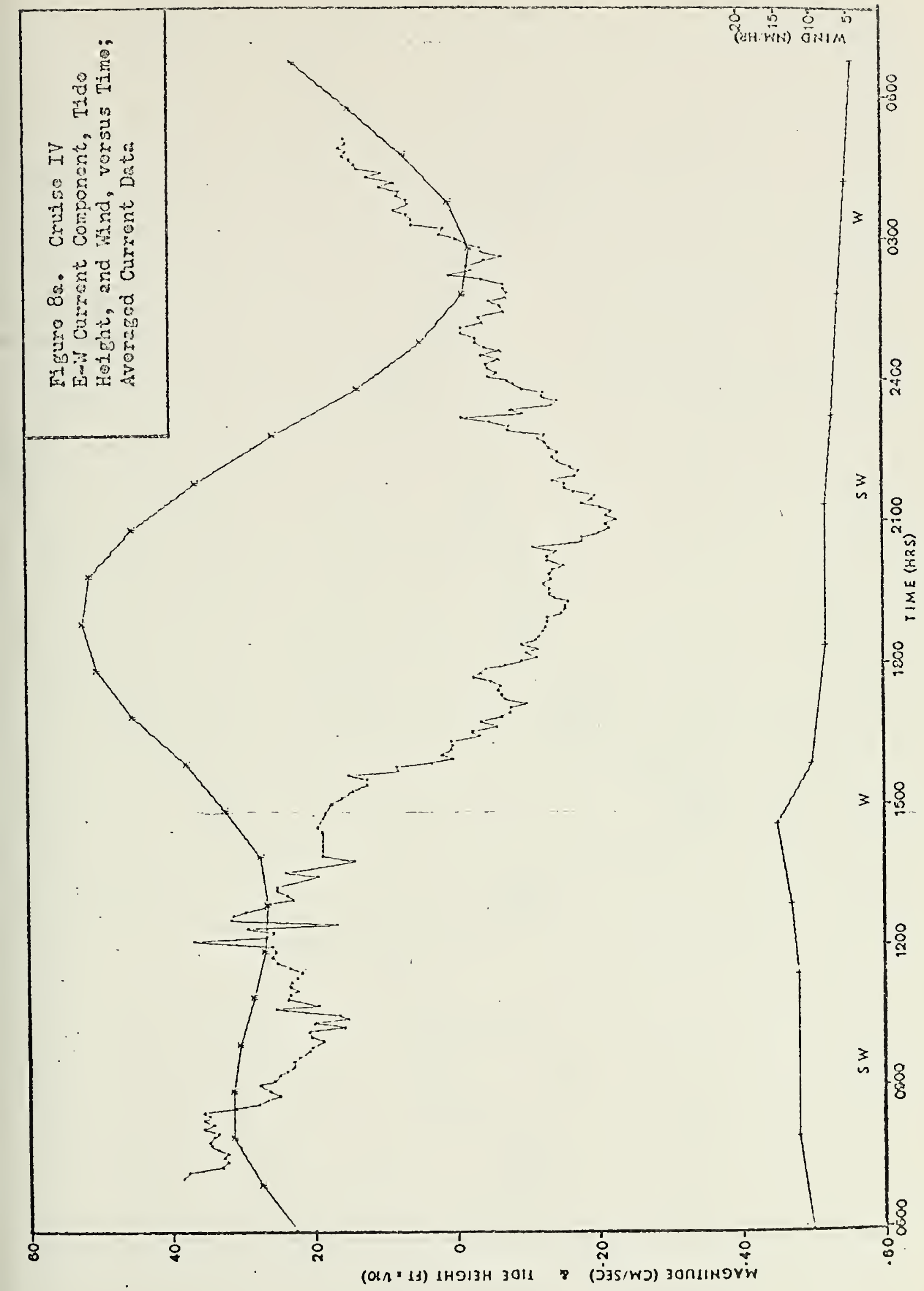





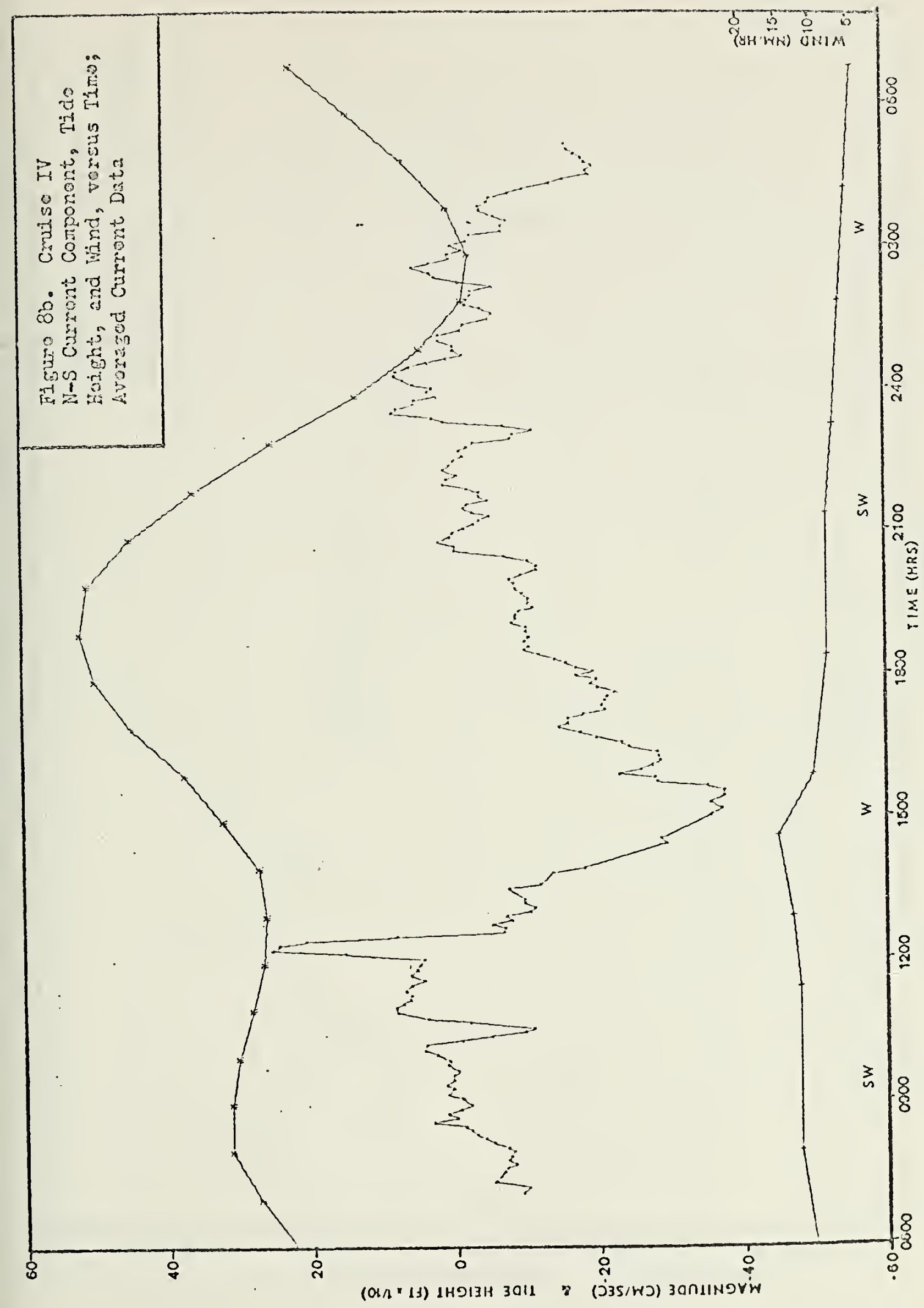





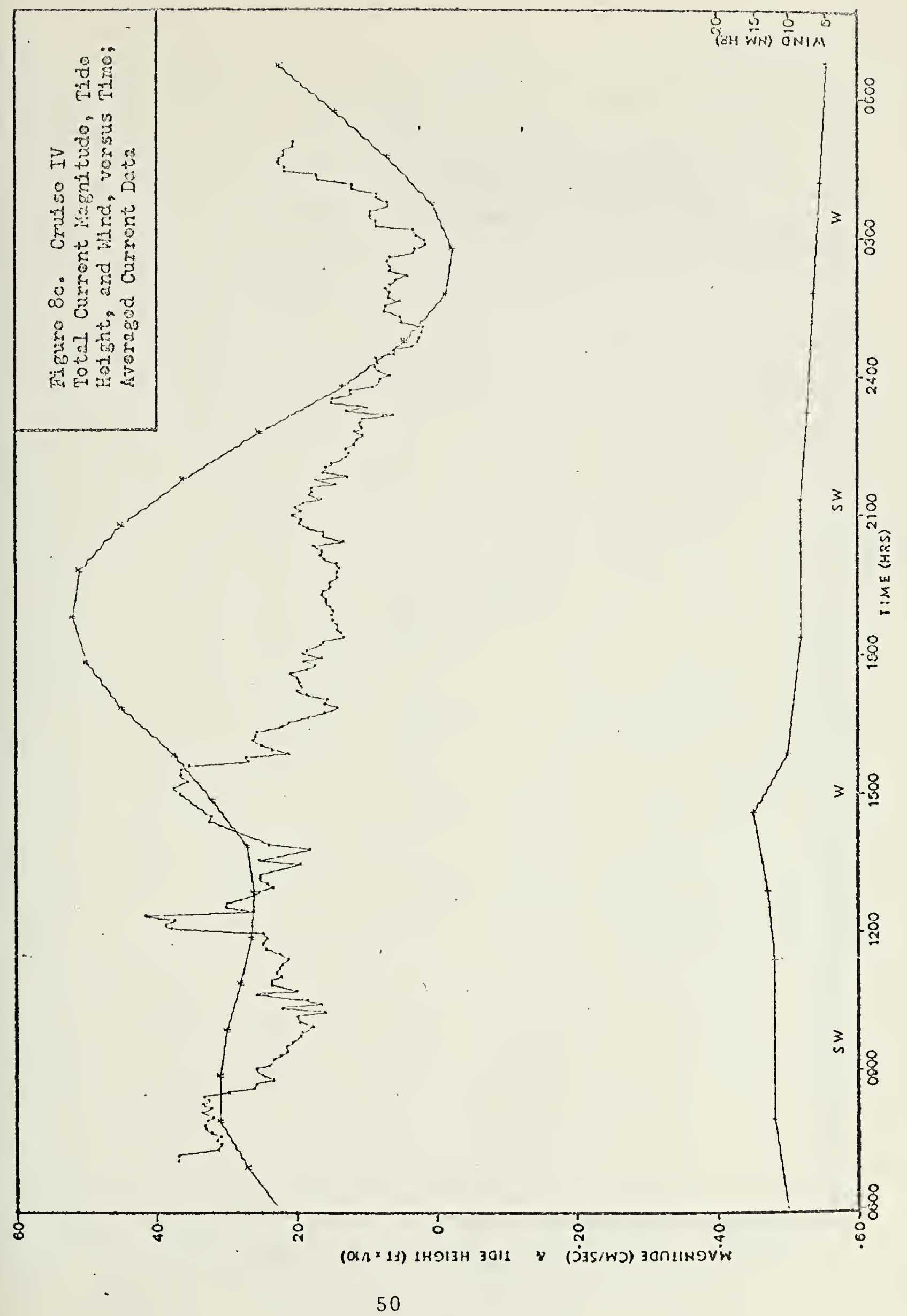





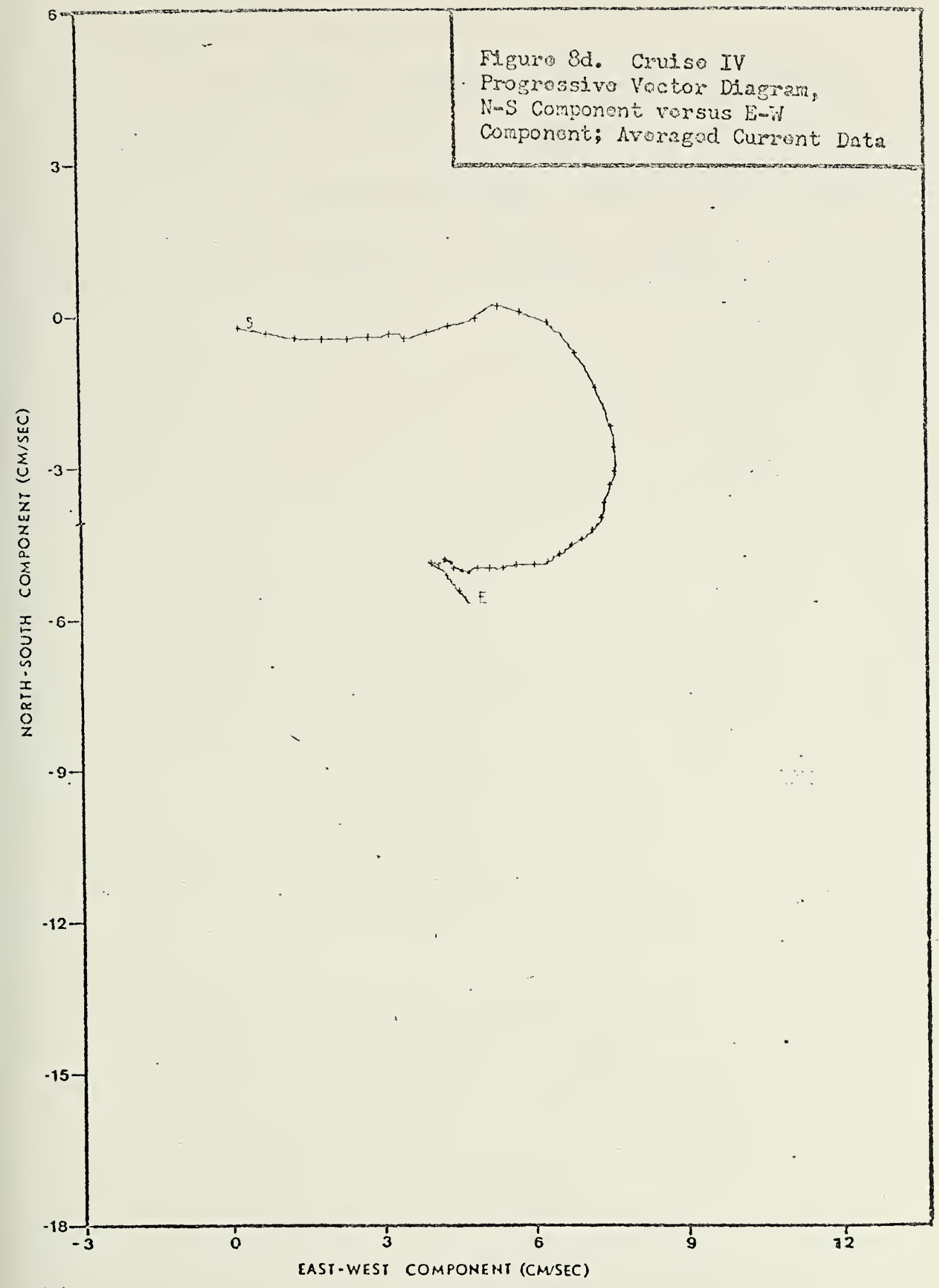





\section{Cruise V}

Period: $10-11$ July 1972

Sea and Weather: Wind was fairly steady from the west to northwest at 5 to 18 knots with the same diurnal pattern as Cruise I. The skies were clear. Seas and swell were from the WNW with the same magnitude as Cruise I. 



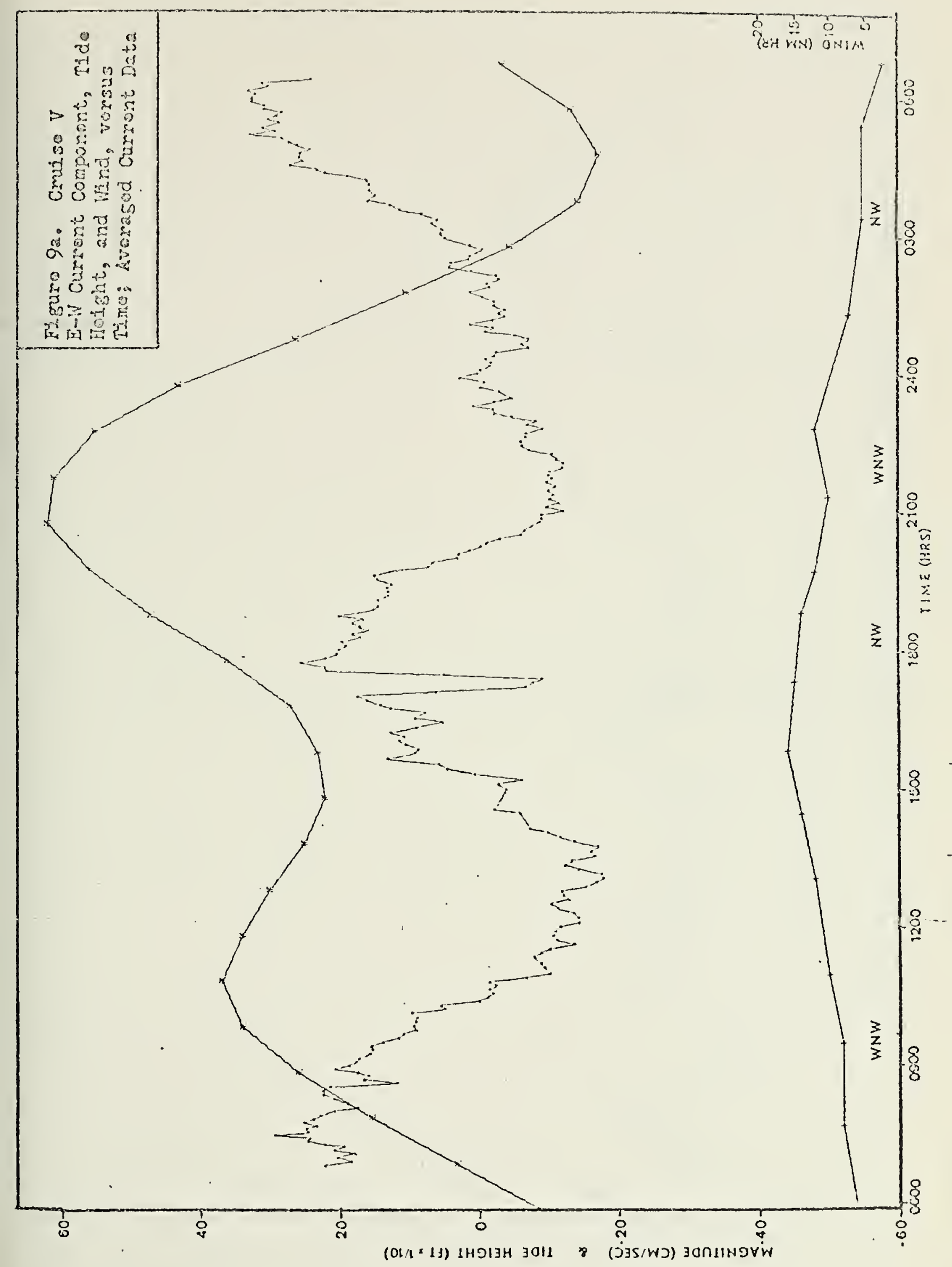







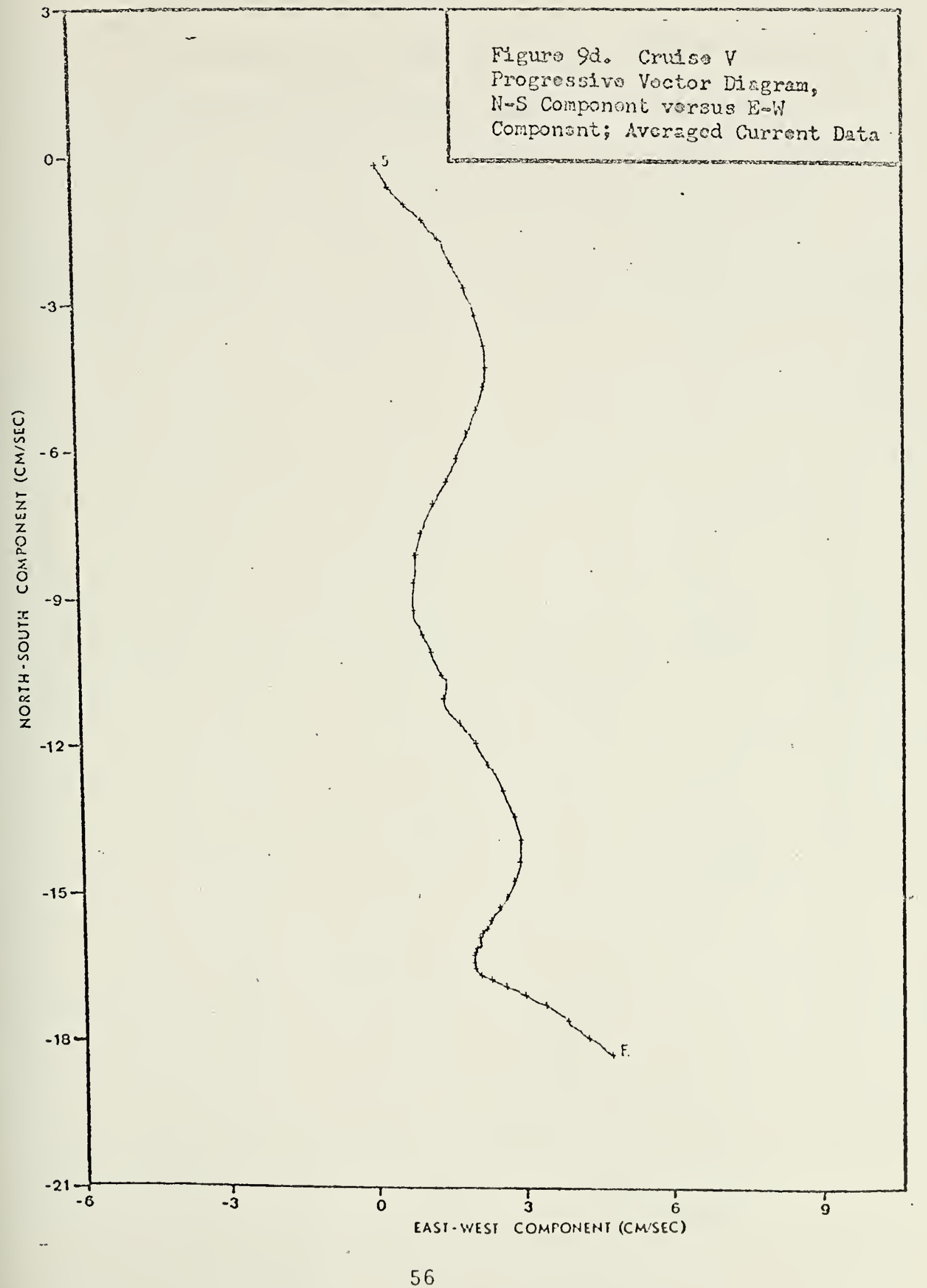



6. $\quad$ Cruise VI

Period: $20-21$ July 1972

Sea and Weather: Winds were predominantly southerly with velocities below 10 knots. There was a mixed swell, but it was mostly from the west and southwest with a southerly sea of 1 to 2 feet. It was overcast during much of this cruise. 



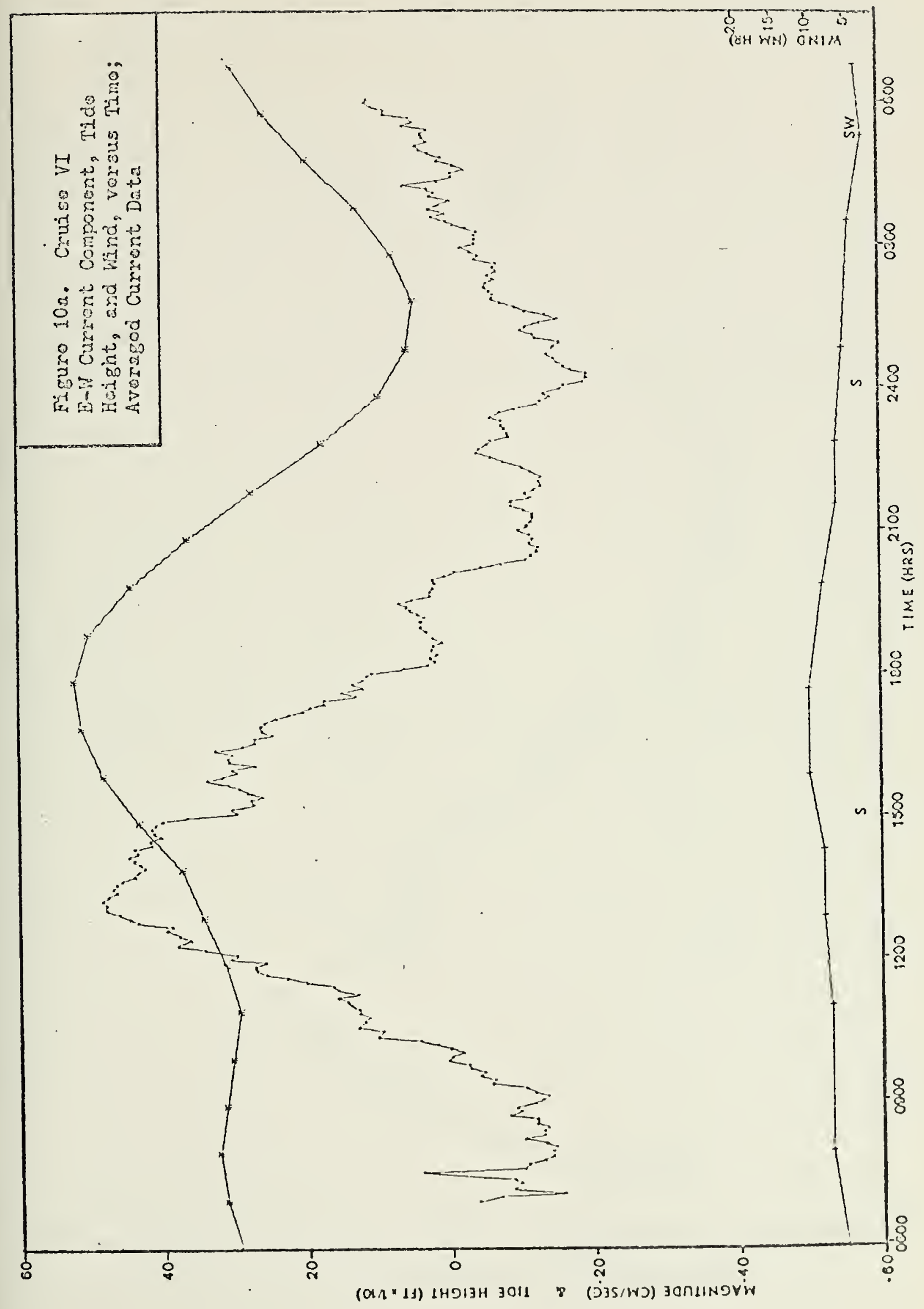





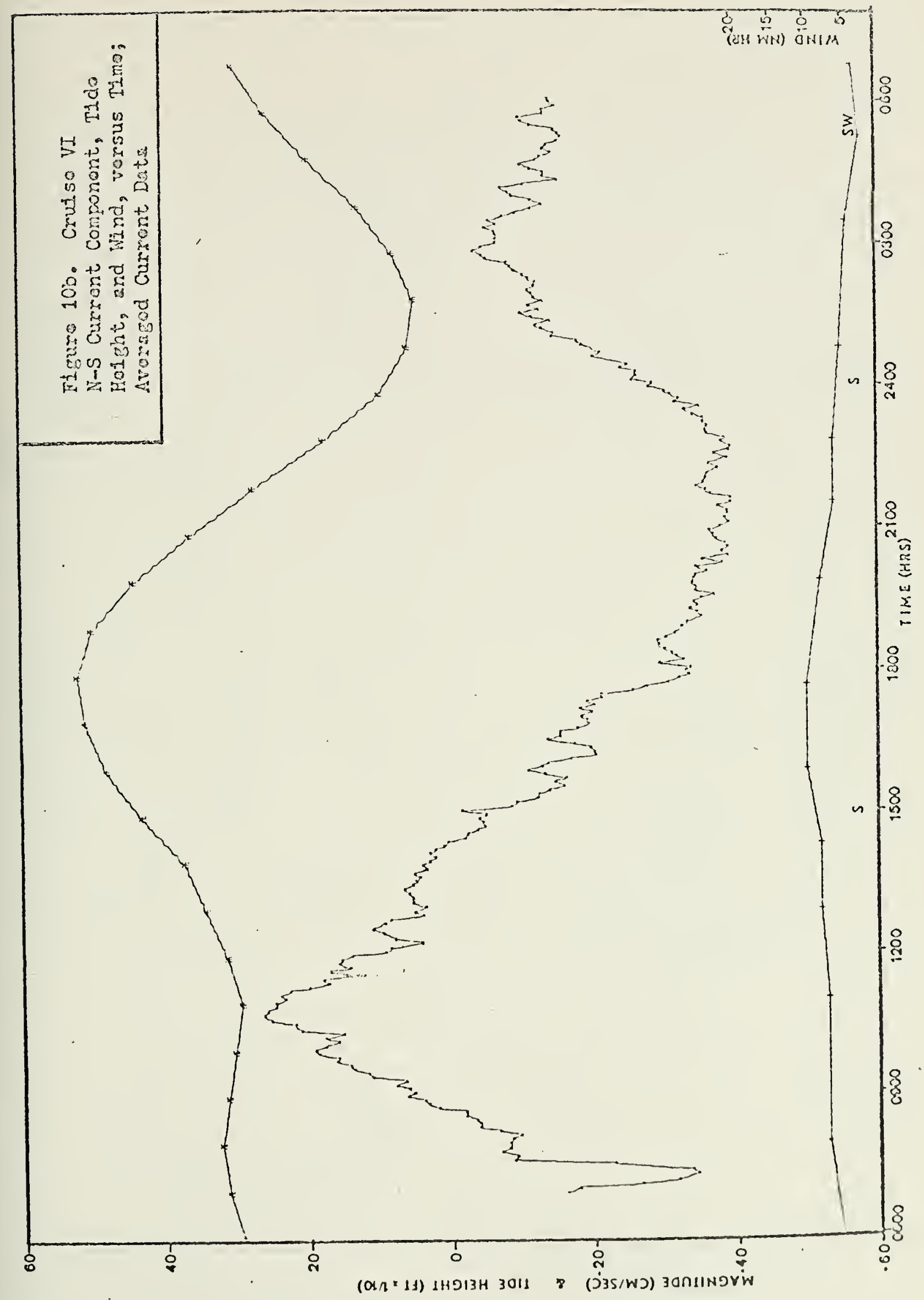





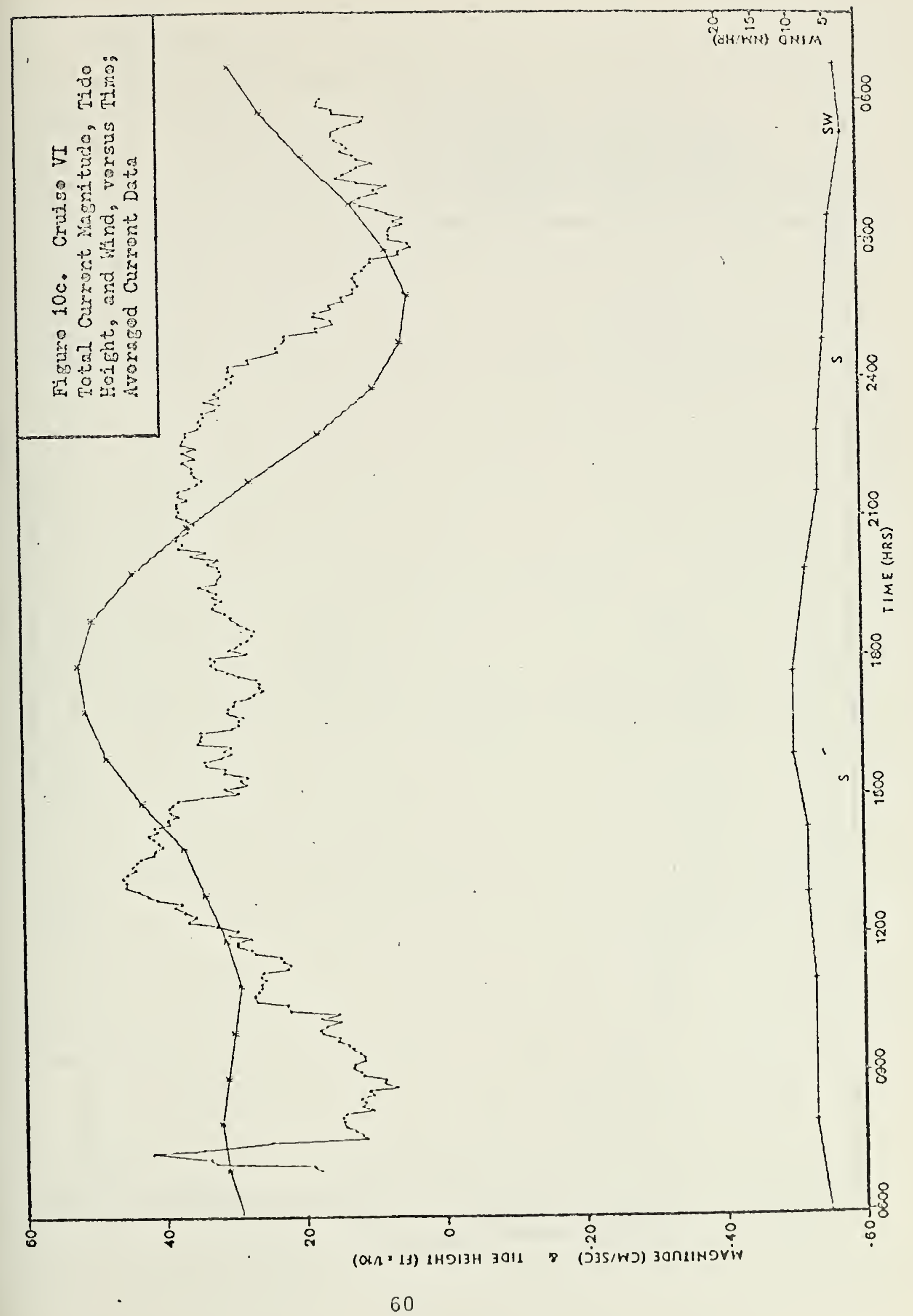





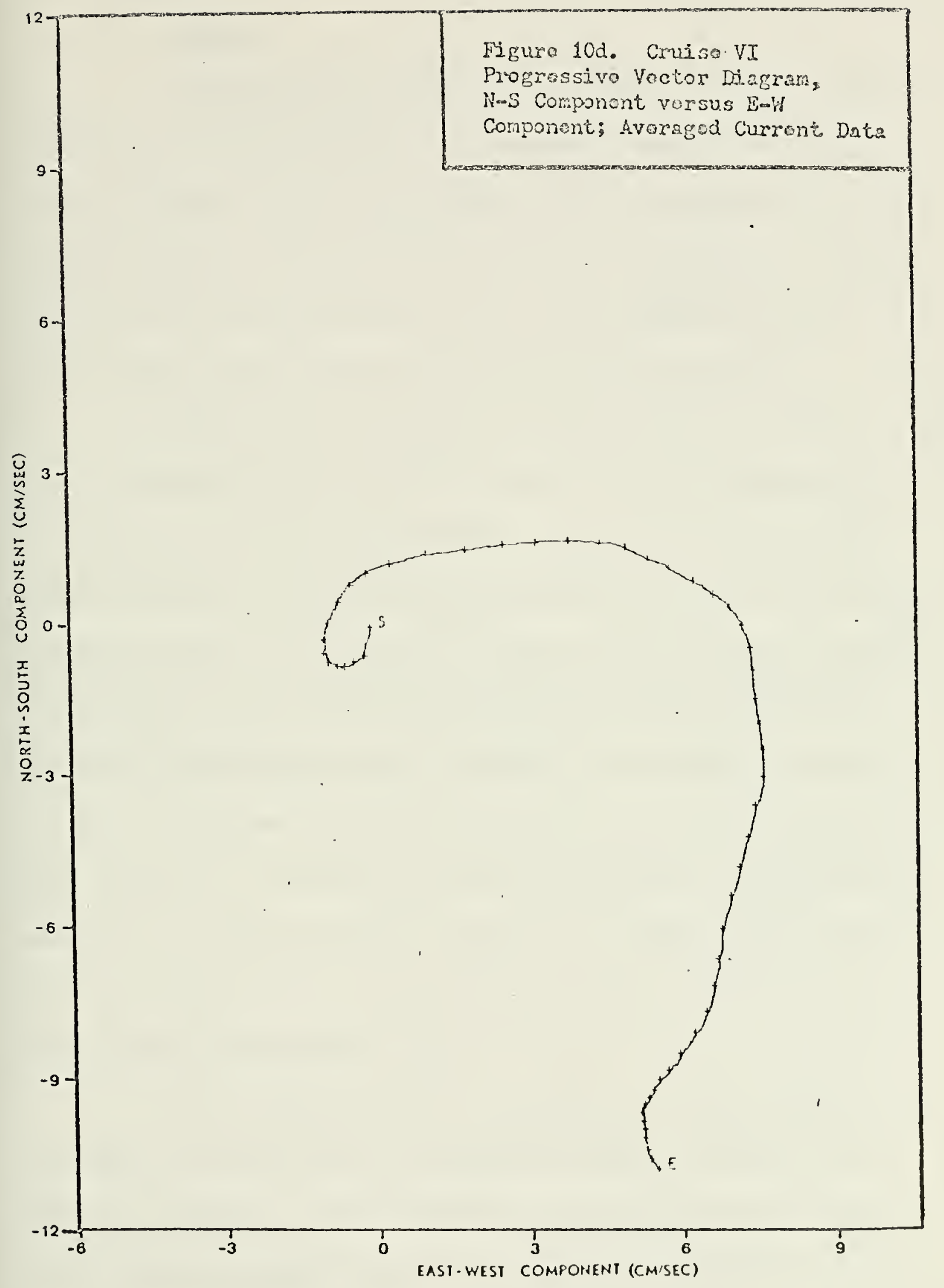



C. DISCUSSION

\section{General}

This section deals with the mean currents and their relation to the wind and seasonal effects. The currents in Monterey Bay are weak and variable and have as yet defied accurate description. The current data gathered during this research and its relationship to oceanic currents, the winds, and seasonal effects may, together with other investigations, lead to a viable picture of the bay's circulation.

The averages of the mean components for the six cruises are $11.6 \mathrm{~cm} / \mathrm{sec}$ to the south and $3.6 \mathrm{~cm} / \mathrm{sec}$ to the east. These yield a resultant of $12.1 \mathrm{~cm} / \mathrm{sec}$ toward $163^{\circ} \mathrm{T}$. No data are available which may be compared accurately to the present results. However, for purposes of rough comparison, Table I gives the mean for each cruise and currents derived from dynamic heights by Moomy (results yet to be published). The points between which Moomy's transports are computed are shown in Figure 4. The mean of Moomy's data is $15 \mathrm{~cm} / \mathrm{sec}$, and of the present data, $12 \mathrm{~cm} / \mathrm{sec}$. However, the standard deviations are relatively large and the close agreement probably is fortuitous. However, the generally southerly trend of all the mean directions of the time series data is in good agreement with Moomy's data.

The "upwelling period," during which this current data was collected, has been described by Skogsberg (1936) as extending from February to September, and as having the same prevailing northwesterly winds as were experienced during this research. Lammers (1971) noted 

TABLE 1

COMPARISON OF RECENT OCEAN CURRTNT MEASUREMENTS

\begin{tabular}{|c|c|c|c|c|c|}
\hline \multicolumn{3}{|c|}{ 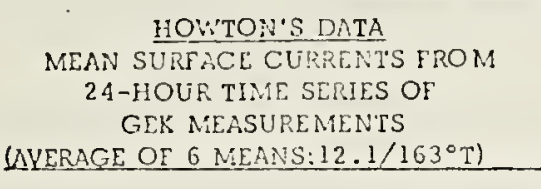 } & \multicolumn{3}{|c|}{$\begin{array}{l}\text { MOOMY'S DATA } \\
\text { SIORT DERIVED FROM } \\
\text { DYNAMIC UEIGHTS }\end{array}$} \\
\hline DATE & STATION & $\begin{array}{c}\mathrm{VEI} / \mathrm{DIRC} \\
\mathrm{CM} / \mathrm{SEC} /{ }^{\circ} \mathrm{T}\end{array}$ & DATE & STATION & $\begin{array}{r}\text { VEL/DIRC } \\
\mathrm{CM} / \mathrm{SEC} /{ }^{\circ} \mathrm{T}\end{array}$ \\
\hline 30/31 May & $\begin{array}{l}\text { Data } \\
\text { Point } \\
\text { (Near } \\
\text { Station \#S) }\end{array}$ & $\begin{array}{l}7.2 / 164 \\
17.1 / 175\end{array}$ & $\begin{array}{c}9 \text { May } \\
\text {. } \\
16 \text { May } \\
17 \text { May }\end{array}$ & $\begin{array}{lll}3 & \& & 5 \\
3 & \& & 4 \\
4 & \& & 5 \\
2 & \& & 4 \\
2 & \& & 3 \\
2 & \& & 3 \\
2 & \& & 3\end{array}$ & $\begin{array}{c}21 / \mathrm{SE} \\
26 / \mathrm{SE} \\
3 / \mathrm{NE} \\
8 / \mathrm{S} \\
27 / \mathrm{S} \\
13 / \mathrm{N} \\
2 / \mathrm{S}\end{array}$ \\
\hline $\begin{array}{l}19 / 20 \text { June } \\
22 / 23 \text { June }\end{array}$ & $\begin{array}{l}\text { Data } \\
\text { Point }\end{array}$ & $\begin{array}{r}4.1 / 198 \\
11.3 / 135\end{array}$ & 2 June & $2 \& 3$ & $11 / \mathrm{s}$ \\
\hline 10/11 July & $\begin{array}{l}\text { Data } \\
\text { Point }\end{array}$ & $21.9 / 154$ & $\begin{array}{l}6 \text { July } \\
19 \text { July }\end{array}$ & $\begin{array}{l}2 \& 3 \\
2 \& 3\end{array}$ & $\begin{array}{l}22 / S \\
7 / s\end{array}$ \\
\hline $20 / 21$ July & & $11.9 / 158$ & 25 July & $2 \& 3$ & $14 / S$ \\
\hline
\end{tabular}

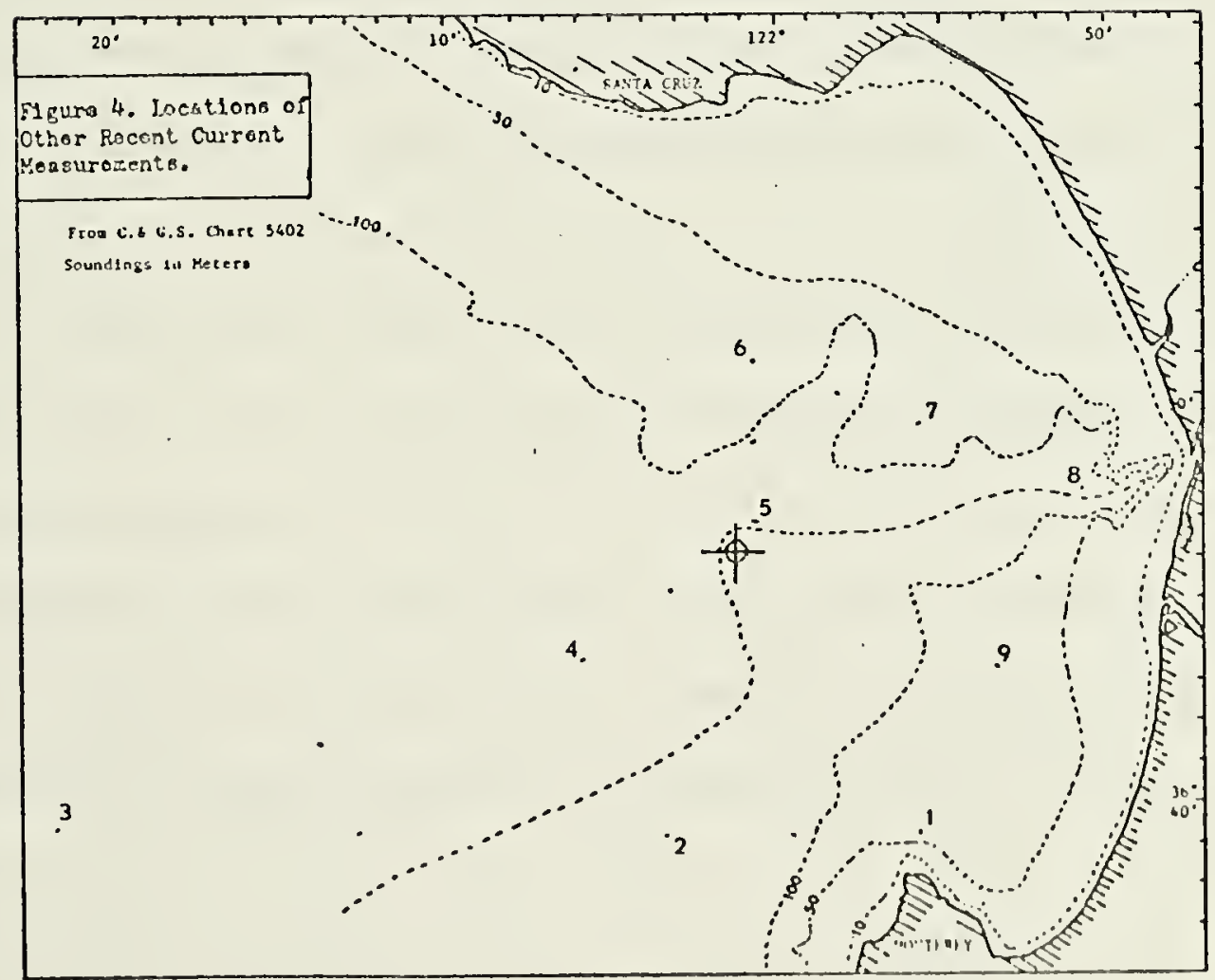



that the southern flow of the California Current exists at the seaward edge of Monterey Bay from mid-February to November, while the northerly Davidson Current persists during the balance of the year. Lammers also observed that during the upwelling period the mean velocity of the California Current in this region is from 1.0 to $6.7 \mathrm{~nm} /$ day with a mean of $5 \mathrm{~nm} /$ day. This generally agrees in both direction and speed with the average of the mean currents from each cruise $(5.9 \mathrm{~nm} /$ day $)$.

During this set of cruises the wind blew fairly steadily from the west northwest with the exception of Cruise VI, when the wind was from the south and southwest at ten knots or less. If the general southerly flow is due to the prevailing wind, this cruise would be expected to show northerly flows. However, during Cruise VI the mean current maintained its mean southerly flow with only slightly more than the usual easterly component. In checking the progressive vector diagram for Cruise VI it was seen that almost due easterly current flow occurred during the daylight hours when the southerly wind was at its peak. A further study of weather charts for the period showed that the south wind was only a local phenomenon and that west northwest winds prevailed along the coast to the north. The local south wind did have some temporary effect on the surface currents, but the California Current maintained by the prevailing northwest winds along the coast persisted in its steady southerly flow across the mouth of the bay. 



\section{Variability}

By inspection of the unaveraged Total Current Magnitude

Graphs (Appendix C) it can be seen that the range of variability over 24 hours is from $2 \mathrm{~cm} / \mathrm{sec}$ to around $40 \mathrm{~cm} / \mathrm{sec}$. The Cruise V Total Current Magnitude graph (Figure 15c) is a good example of this variation and also shows two unusually high magnitudes of over $50 \mathrm{~cm} / \mathrm{sec}$. The spacings of the crosses on the Progressive Vector Diagram also give an indication of this current variability (each cross represents five current vectors, or approximately 30 minutes of time) as well as the changeability of the current direction. The Cruise I Progressive Vector Diagram (Figure $5 \mathrm{~d}$ ) shows the clockwise rotation (which may vary through more than 180 degrees) that is typical of all cruises except Cruise V. This directional oscillation is superimposed on a moderate mean southerly flow.

In order to produce numerical estimates of the cyclic components of the currents and to determine their origins; the data was subjected to a fourier analysis. It was recognized that with so short a series ( 24.8 hours) the diurnal component would not be separated from the inertial component ( 20 hours at this latitude), and that if there were a substantial amount of noise it would have its usual effect in reducing the reliability of the coefficients. The $\mathrm{N}-\mathrm{S}$ and $\mathrm{E}-\mathrm{W}$ components separately were prepared by filling gaps, extrapolating to 24.8 hours total length, and by subtracting the mean. Fourier coefficients, magnitudes, and phase angles were then computed, using the Subroutine 

FORIT from the IBM Scientific Subroutines Package (included in Appendix A). This program expresises the coefficients $A_{m}$ and $B_{m}$ as those in the equation

$$
f(t)=A_{0}+\sum A_{m} \cos m \omega_{0} t+\sum B_{m} \sin m \omega_{0} t
$$

where $f(t)$ represents the time series being analyzed, $m$ is the integer specifying the particular harmonic being calculated and $\omega_{0}$ is the fundamental angular frequency, which is related to the time duration of the series, $\mathrm{T}$, by

$$
\omega_{0}=\frac{2 \pi}{T}
$$

The power present in the mth component is then

$$
\mathrm{P}_{\mathrm{m}}=1 / 2\left(\mathrm{~A}_{\mathrm{m}}^{2}+\mathrm{B}_{\mathrm{m}}^{2}\right)
$$

and the magnitude of current speed in that component is

$$
C_{m}=\left(A_{m}^{2}+B_{m}^{2}\right)^{1 / 2}
$$

Equivalently, Equation (1) may be expressed as

$$
f(t)=c_{m} \cos \left(m \omega_{o} t-\alpha_{m}\right)
$$

where

$$
A_{0}=0 \text { and } \quad \alpha_{m}=\sin ^{-1} \frac{B m}{C_{m}}
$$

Here $\alpha_{m}$ is the phase angle, the number of degrees after the start of each series at which component maximum occurs.

The mean velocity and the phase differences between the diurnal component and the transit of the sun, and the semi-diurnal component 

and the transit of the moon are contained in Table II, along with the results of the fourier analysis. The total power present in all the calculable frequencies is also tabulated in this table to facilitate a comparison of this value with the amount of power present in the diurnal and semi-diurnal components. The conclusions to be drawn from this table are the following:

(i) The amplitudes of the diurnal and semi-diurnal components are comparable with the mean velocity.

(ii) The power in the diurnal plus semi-diurnal components is about three-fourths of the total variable power.

(iii) Diurnal components are not consistently more important than the semi-diurnal and vice-versa.

(iv) The variable effects are generally larger in the $\mathrm{E}-\mathrm{W}$ components than in the $\mathrm{N}-\mathrm{S}$ components, while for the mean velocities the reverse is true.

(v) The diurnal and semi-diurnal terms in both the $\mathrm{N}-\mathrm{S}$ and $\mathrm{E}-\mathrm{W}$ portions of the current have a fairly consistent phase relationship with the meridional transit of the sun and moon respectively.

The phase stability of the fourier components may be seen by comparing the phase angles relative to lunar and solar transit with the res pective means .

The variations from the mean of the semi-diurnal does not exceed \pm 2.5 hours in either the $\mathrm{E}-\mathrm{W}$ or the $\mathrm{N}-\mathrm{S}$ component except for 

TABLE II. FOURIER ANALYSIS RESULTS

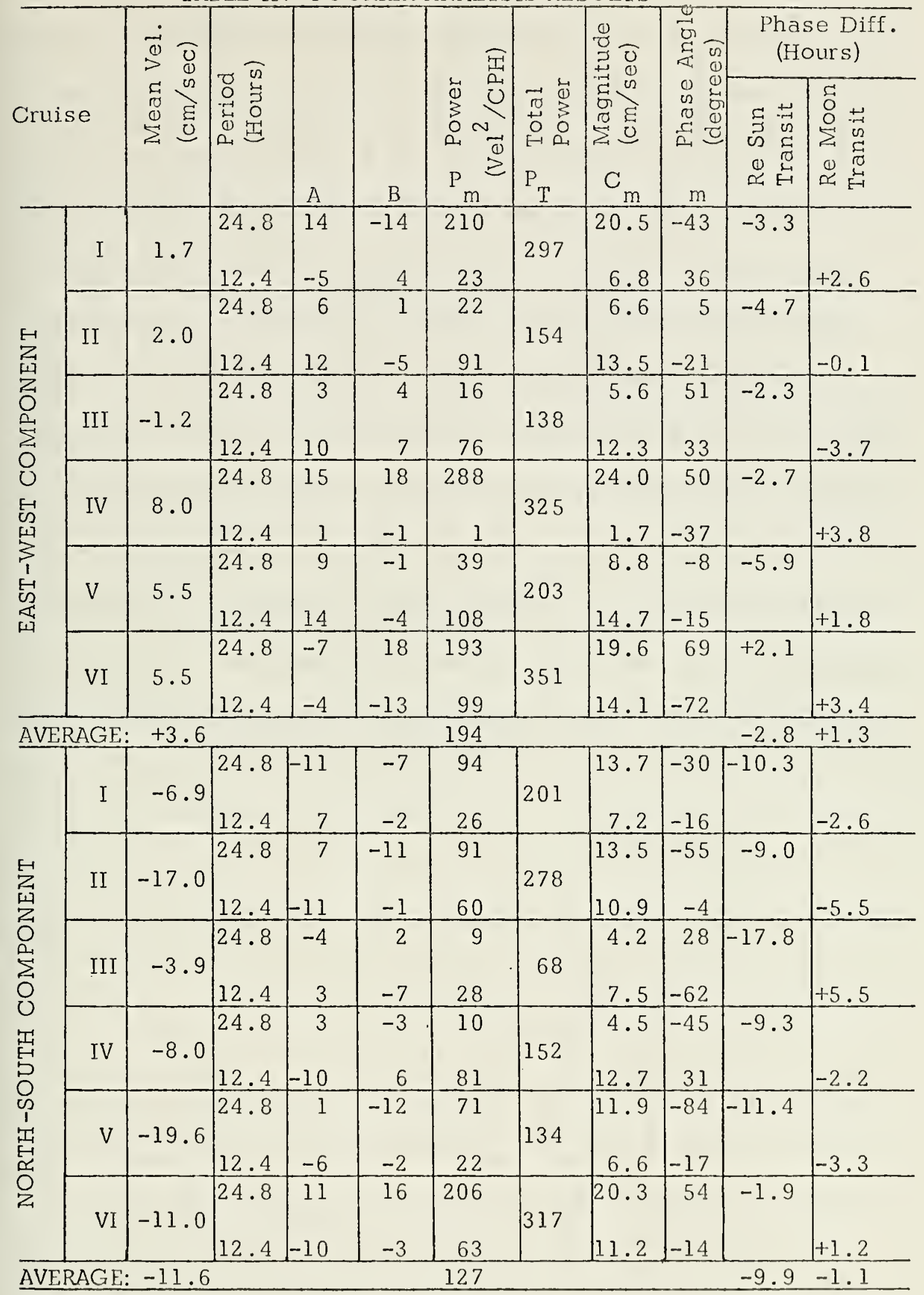



Cruise III in the E-W and Cruises II and III in the N-S. Similarly, the variation from the mean of the diurnal phase does not exceed \pm 1.9 hours except on Cruises V and VI in the E-W and III and VI in the N-S. Only four out of the 24 variations from the mean exceed one-third of the associated period. Since we are dealing with a time series which is both non-stationary and short, such agreement may be regarded as good. However, the fact that there is not a constant relation between the amplitudes of these two components, and the fact that the phase angles occasionally vary widely from the mean leads to either of two inferences: (a) the currents are driven indirectly by the tides and are considerably modified by some unknown oceanic processes, or (b) inertial rotations are important. This makes one unwilling to say that the coupling of the tide and current is direct, but does indicate that a relationship exists. 



\section{CONCLUSIONS}

Currents in Monterey Bay are quite variable in both velocity and direction. Therefore, one cannot describe the mean flow by means of a short-term measurement.

All six cruises yielded mean southerly currents. The average of these means is a current directed $163^{\circ} \mathrm{T}$ at a speed of $12.1 \mathrm{~cm} / \mathrm{sec}$ $(5.9 \mathrm{~nm} /$ day $)$. This result supports Lammers' analysis that the California Current sweeps close to the mouth of Monterey Bay (and the data point) during the upwelling period.

It has been established that there are substantial diurnal and semi-diurnal components which, with a few notable exceptions, have a consistent phase relation with the sun and moon. There obviously must be at least an indirect coupling with the semi-diurnal tide. The diurnal component may be tidal or inertial or merely related to the passage of the sun. 

APPENDIX A

COMPUTER PROGRAMS

1. Reduction of GEK Data to Current Vectors

2. Graphing of Ocean Current Data versus Winds and Tides

3. Progressive Vector Diagram of Current Vectors

4. Fourier Analysis of Ocean Current Components 



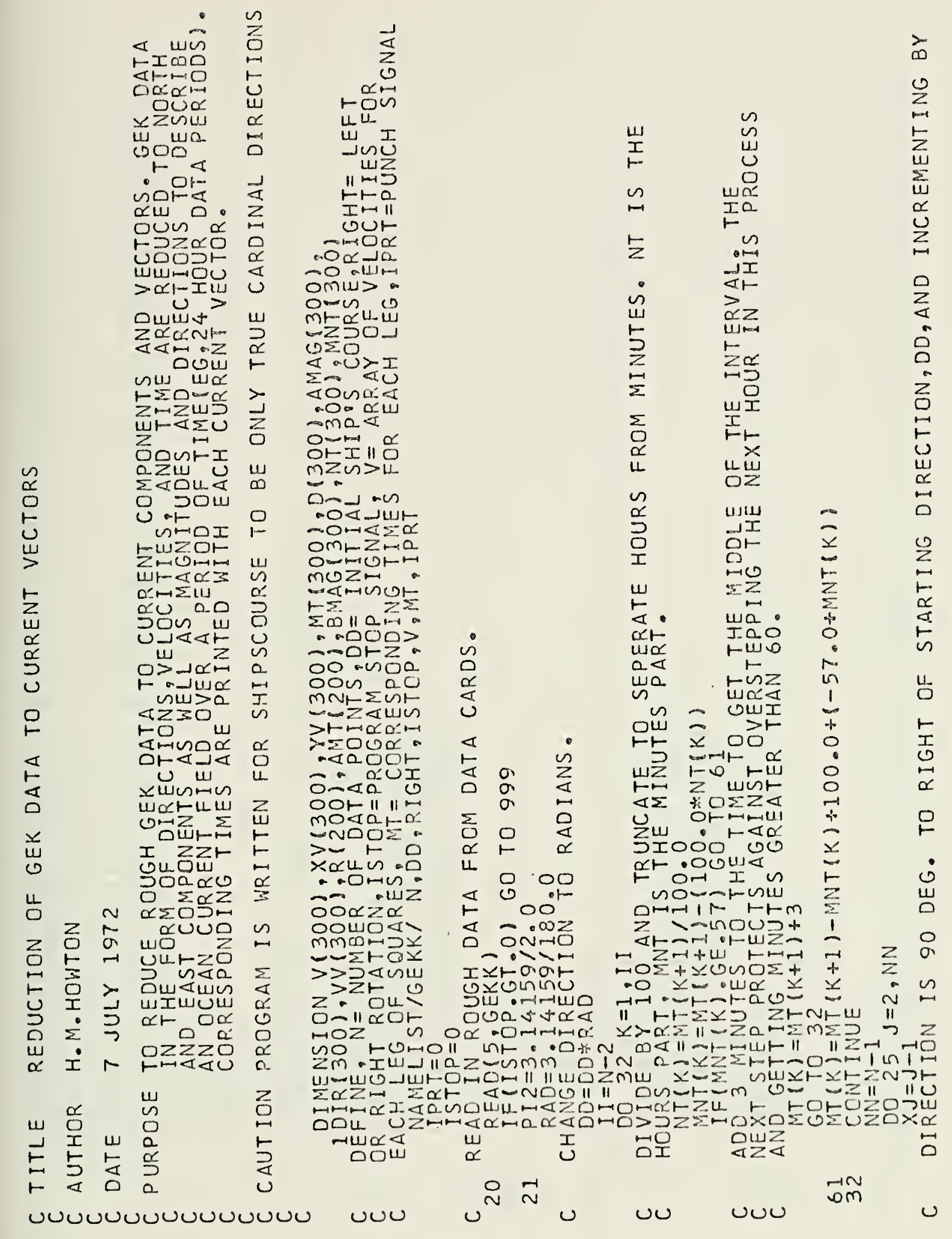





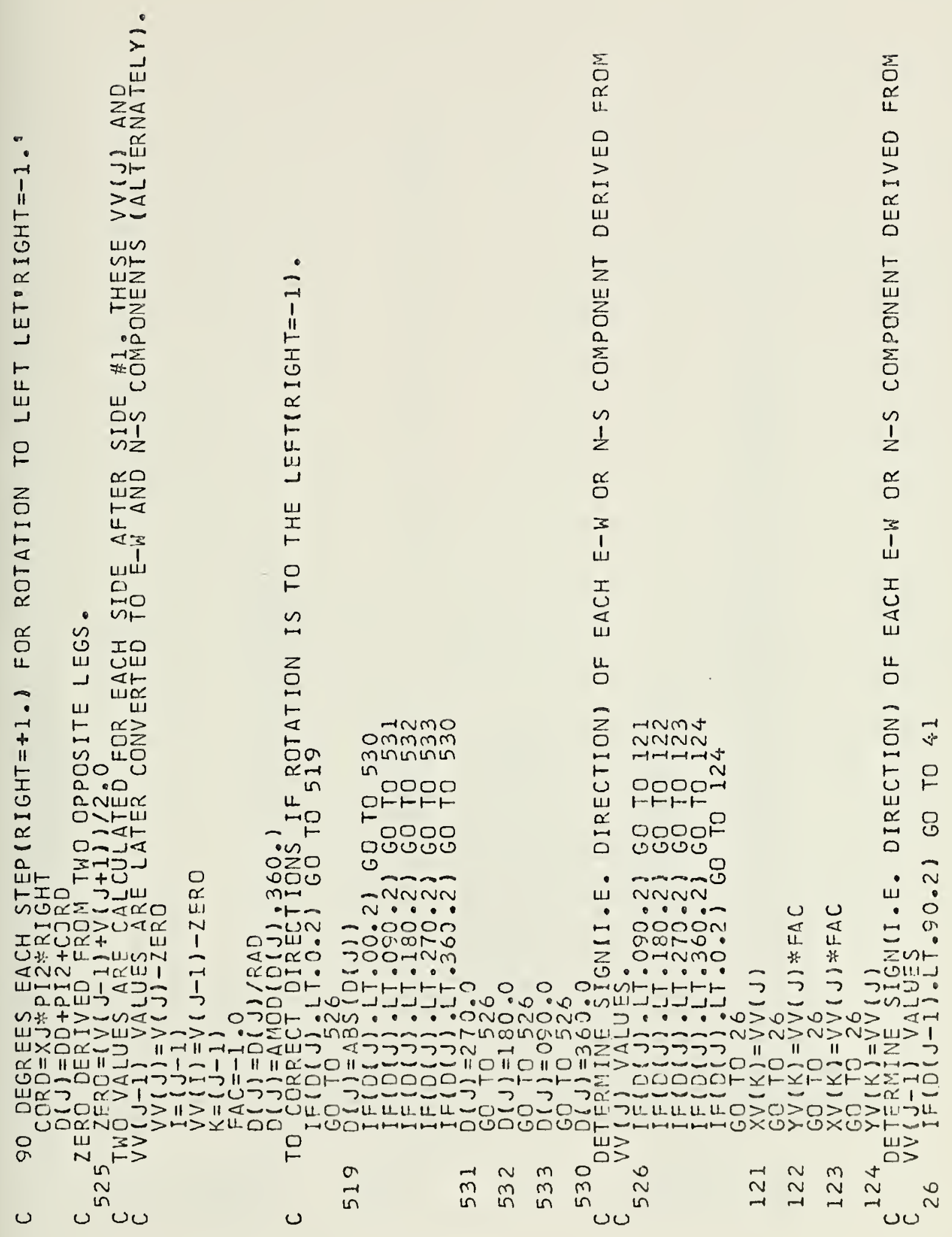





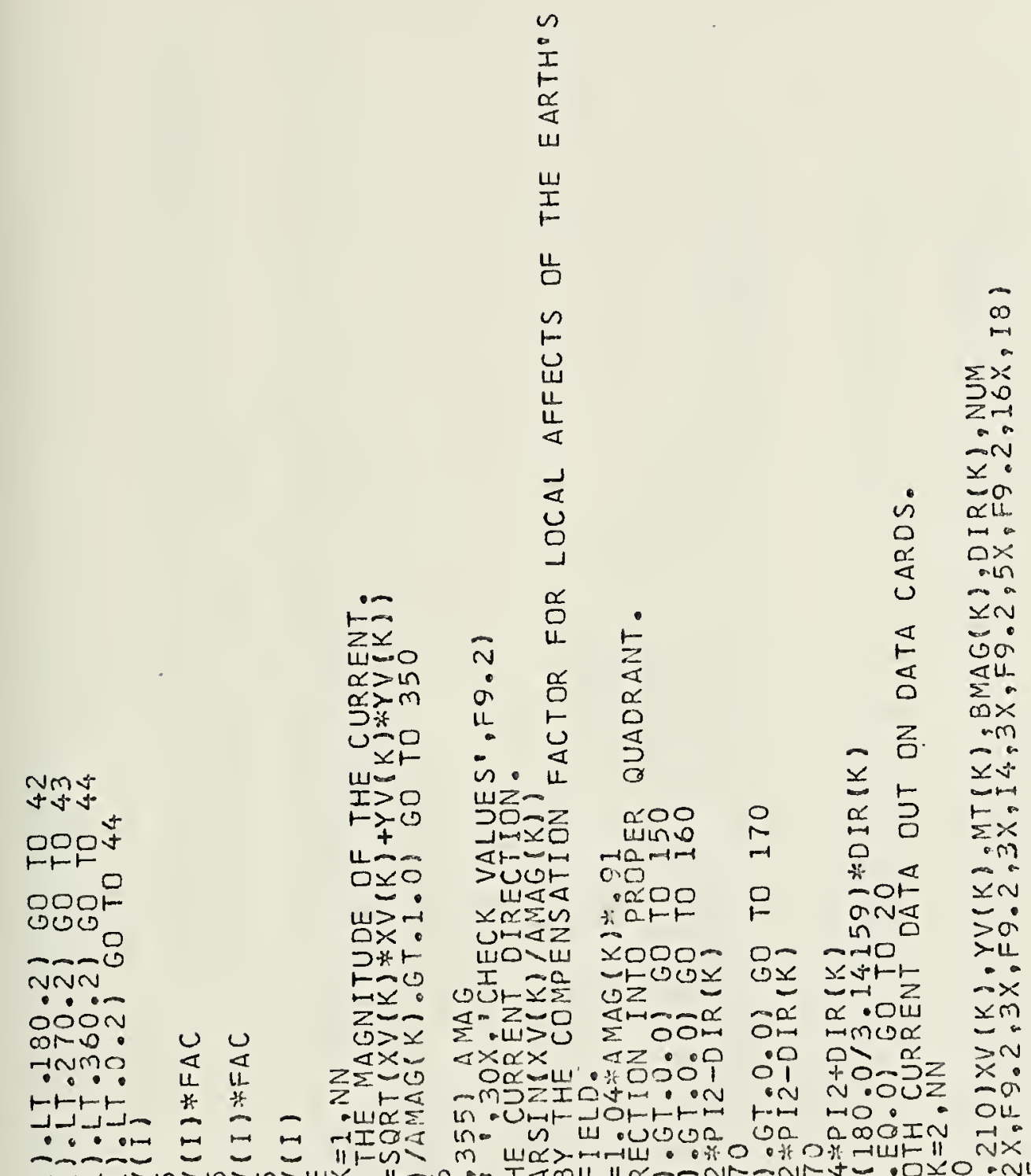

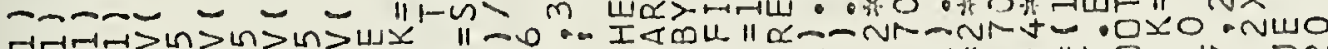
$1111>N>N>N>2$ w-xmo-1 11 -

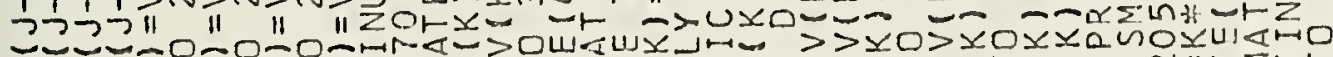

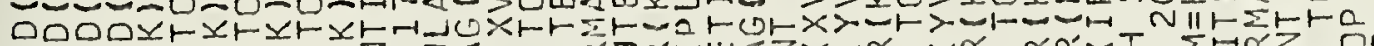

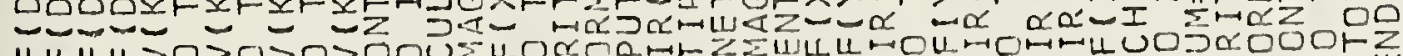

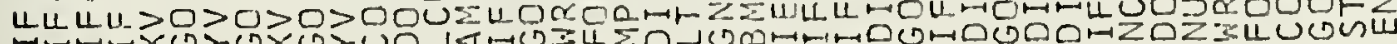

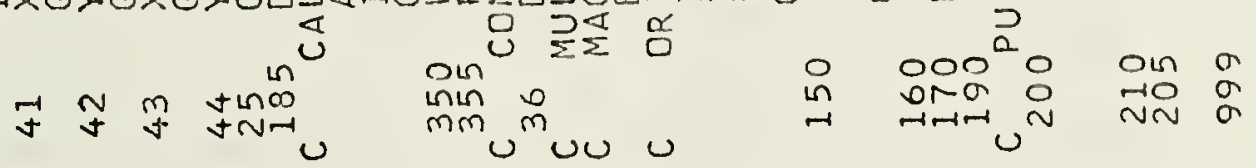






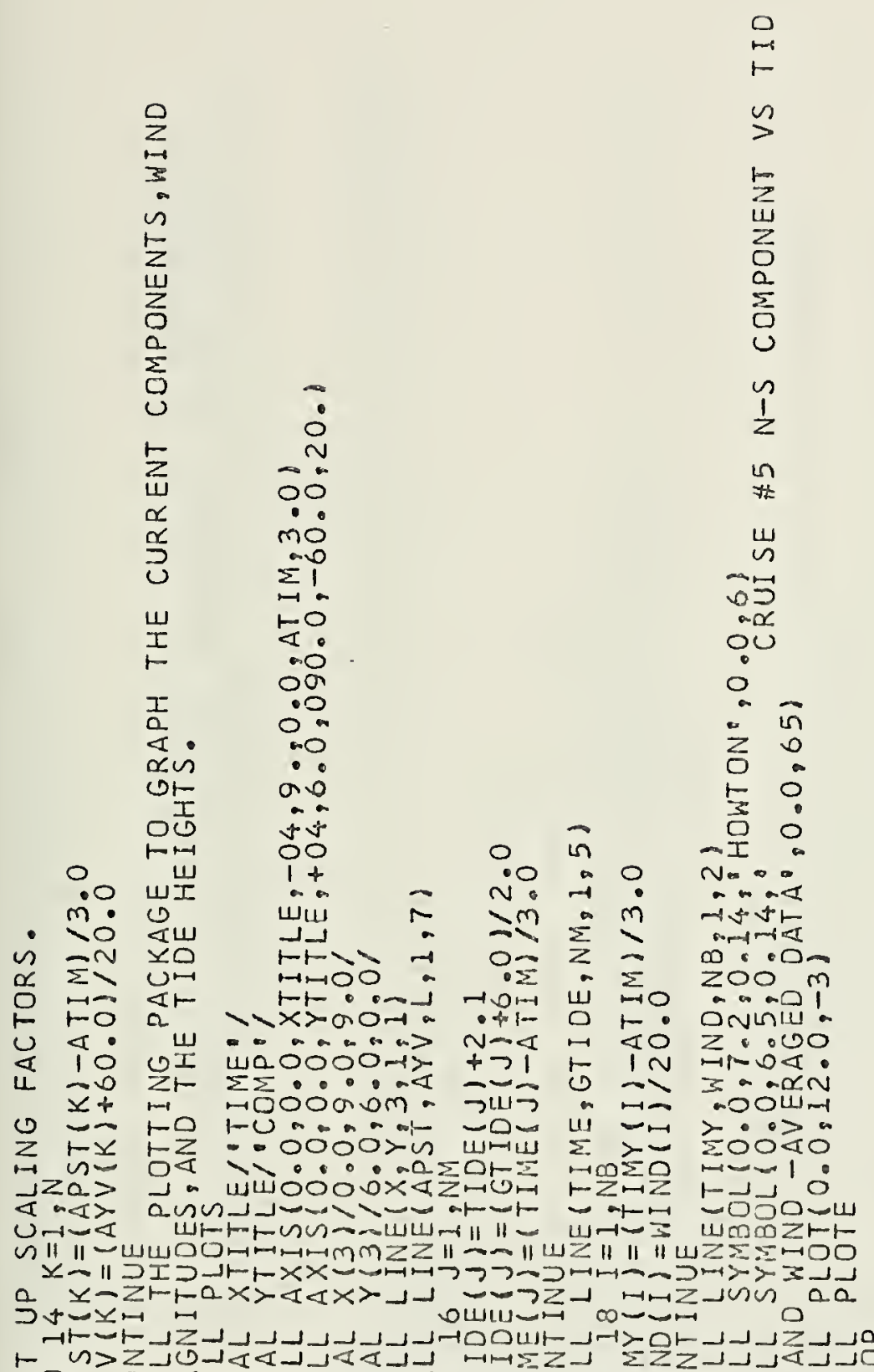

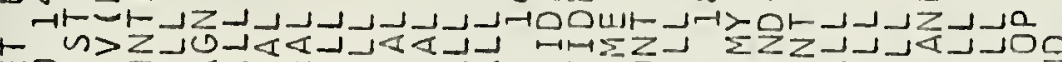

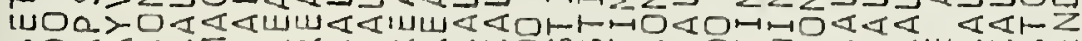

ज०
$0 \stackrel{4}{4}$

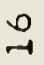
$\stackrel{\infty}{\rightarrow}$
$a$ 


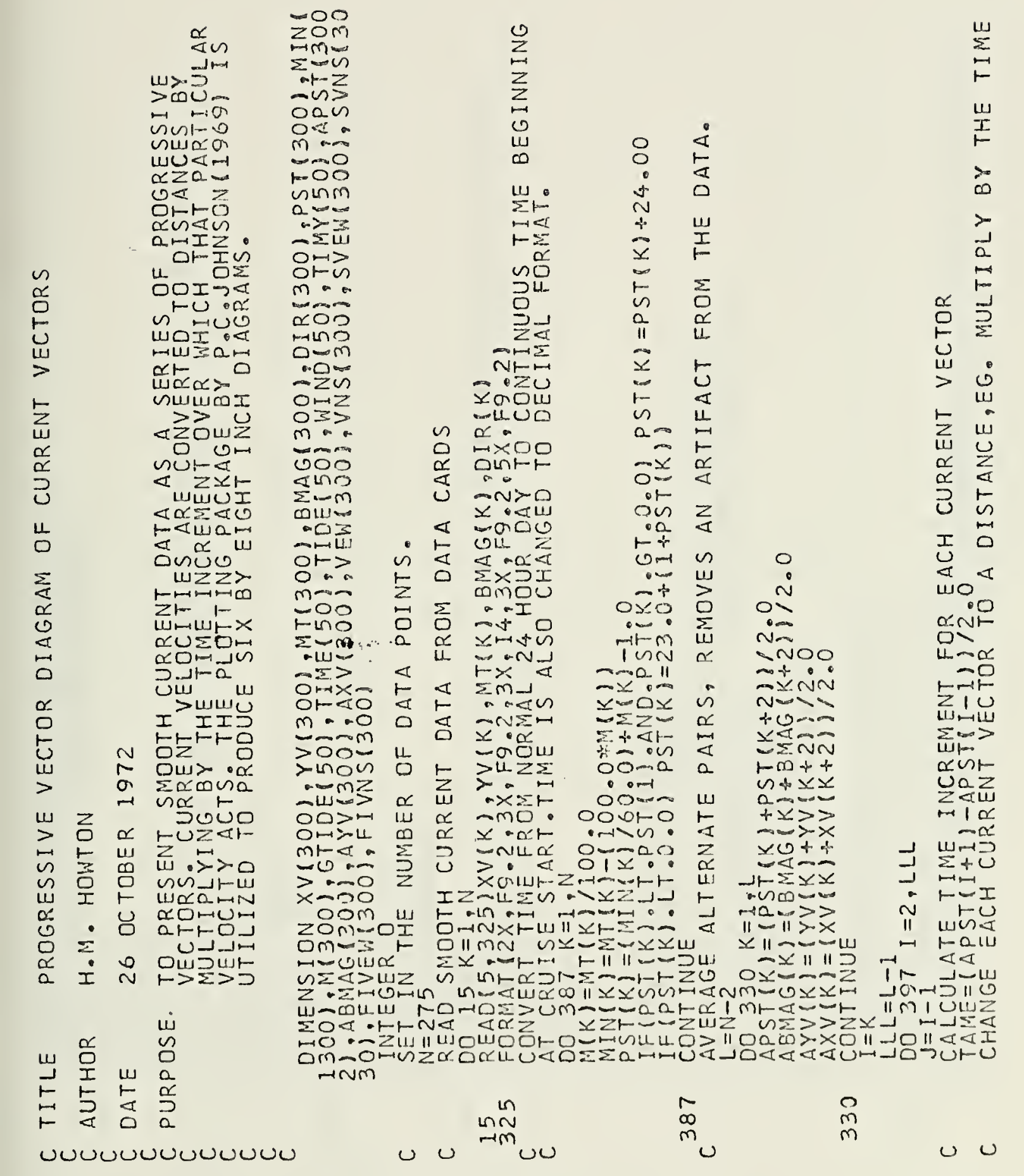




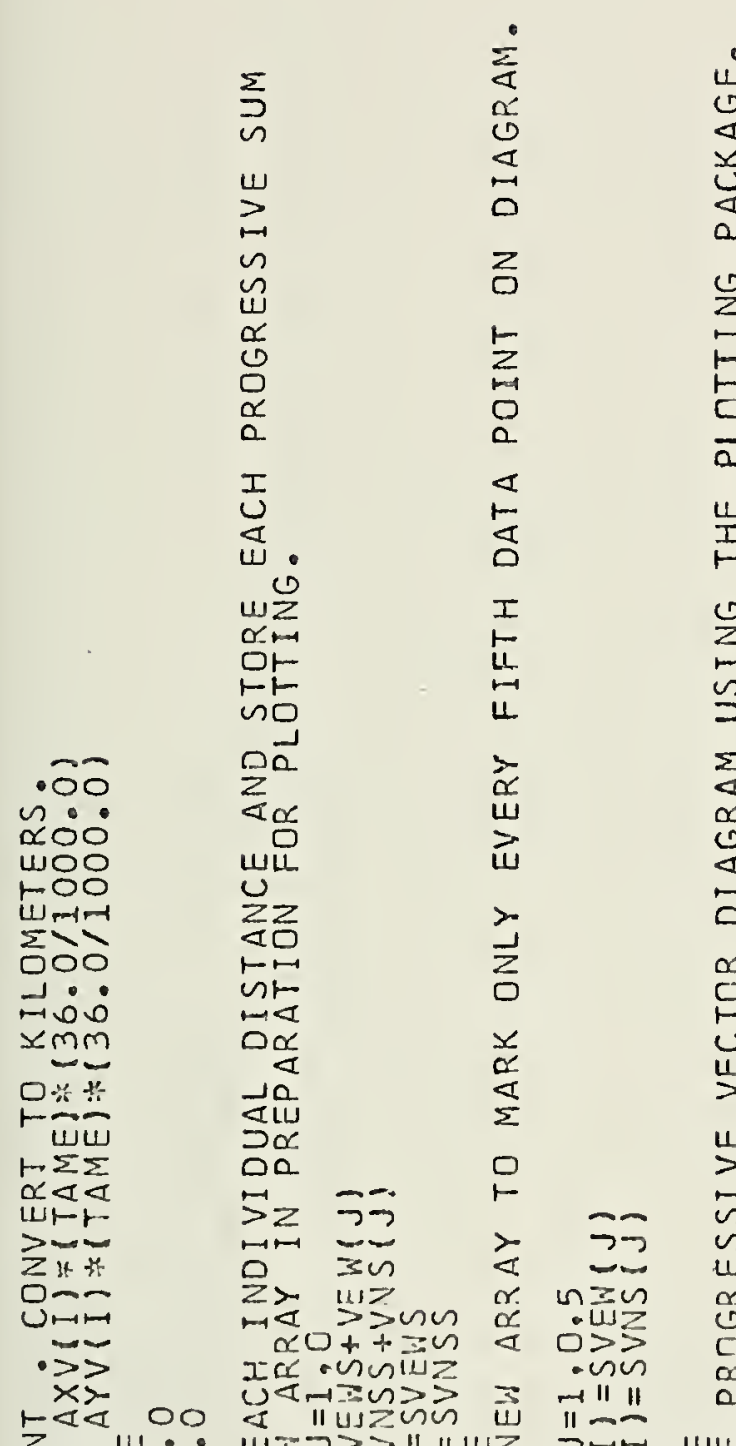

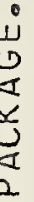

$\sum_{0}^{0}$

$\stackrel{0}{Z}$

$\alpha$

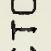

U

$\frac{1}{0}$

2

$x z$

एं

$I$

om

uz

I

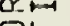

안

not

点

O

$\sum \sum$

$\sum_{x} 0$

no

on

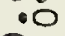

$\circ$

0.

$\div$

㐬

$\cup$

zzo

5

$\operatorname{sim}_{\rightarrow \rightarrow \infty}$

०ळ

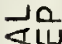

צtu

$\supset \alpha-\Sigma$

- $=2$.

$5 z$

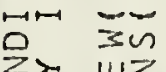

tid $>$ >nen

$\alpha 0++=\infty$

Ix unit)

is

U) II

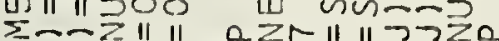

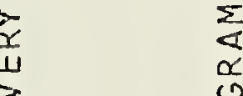

$\sum_{\substack{0 \\ 0}}^{0}$

ż

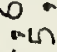

to?

일

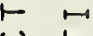

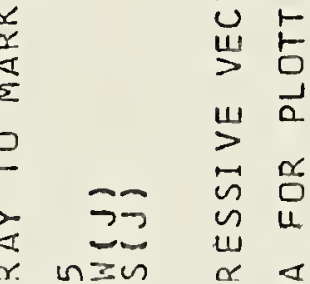

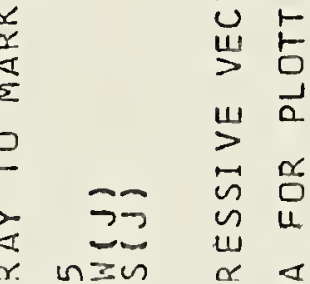

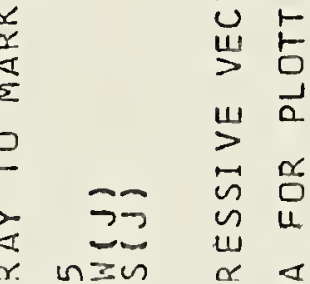

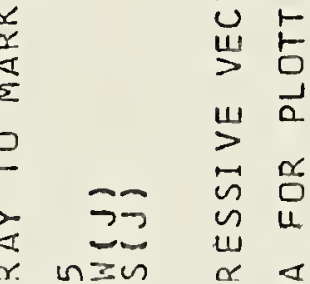

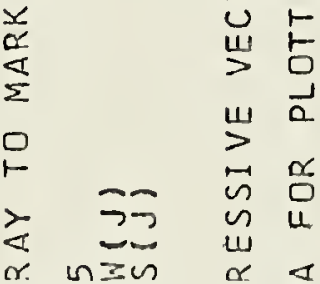

分分: ‘

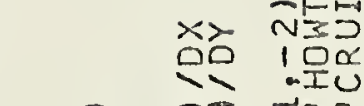

$\underset{\square}{0} \mathbb{1}$

$0>>$

- inar a 0

L 4 oü

an

-inis

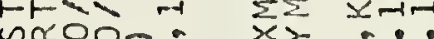

$3=$

$z z<0 \circ 0^{\circ}$

$\sum \sum \ldots+0000$

$x>0.00 \div z$

1100.000

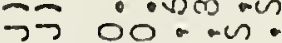

$-\infty 00>2=$

OO : *us

- ocons

ond

जिलिखिएँ

II-

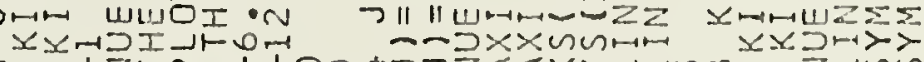

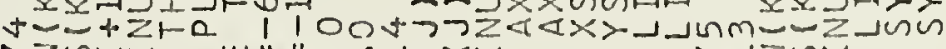

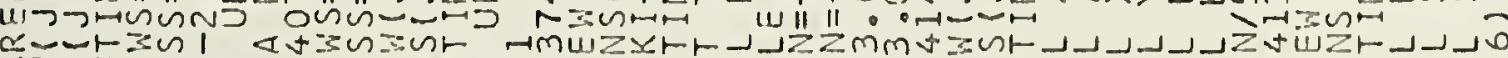

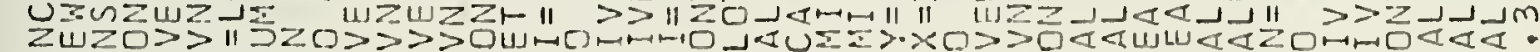

1 ino

$11 z$.

$\rightarrow \rightarrow+\infty$ in

$x x$ T0。

zen Uाँ $\leq 000$ z>> u.

- U H 드 U-J | $\|$ " -00

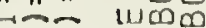
u

zw un

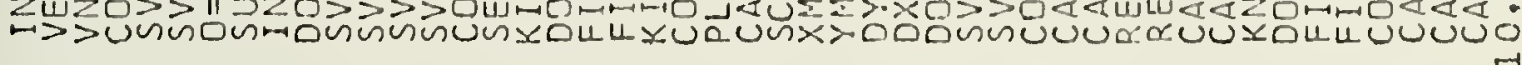

4

$\hat{n}$

U n. $\stackrel{2}{a}$

$\vec{v}$ 



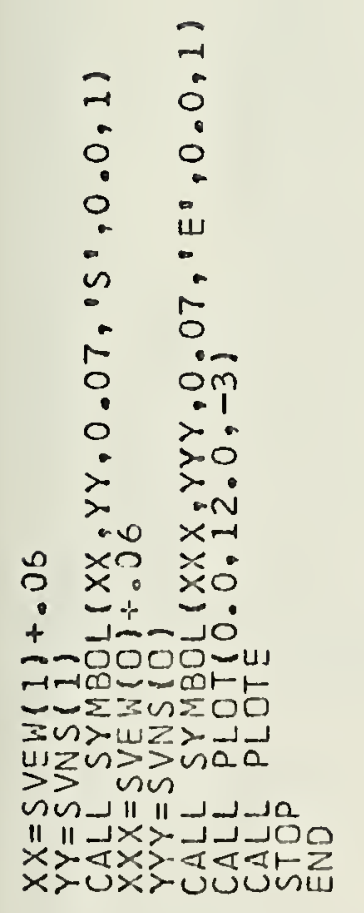

$a$
$a$ 



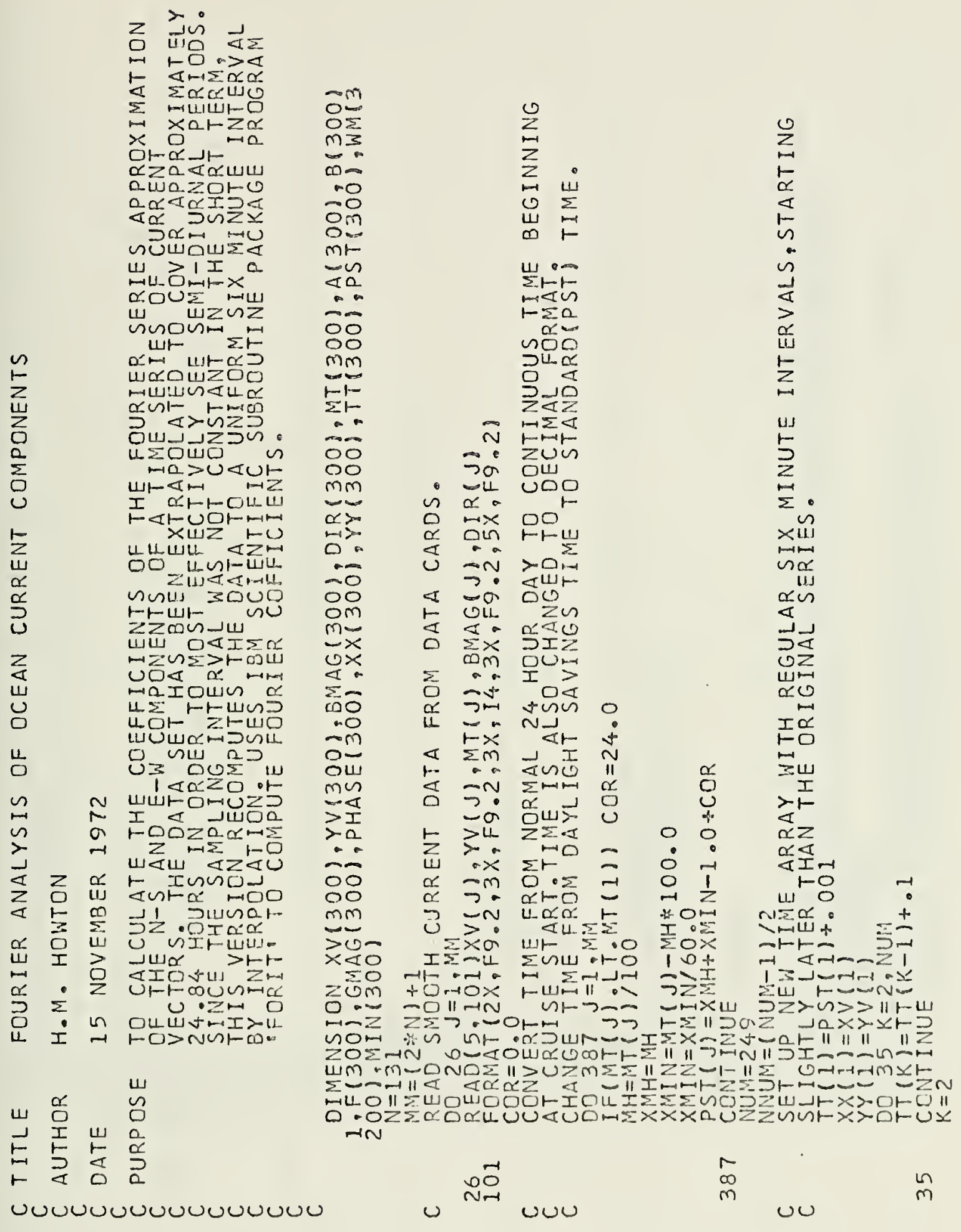





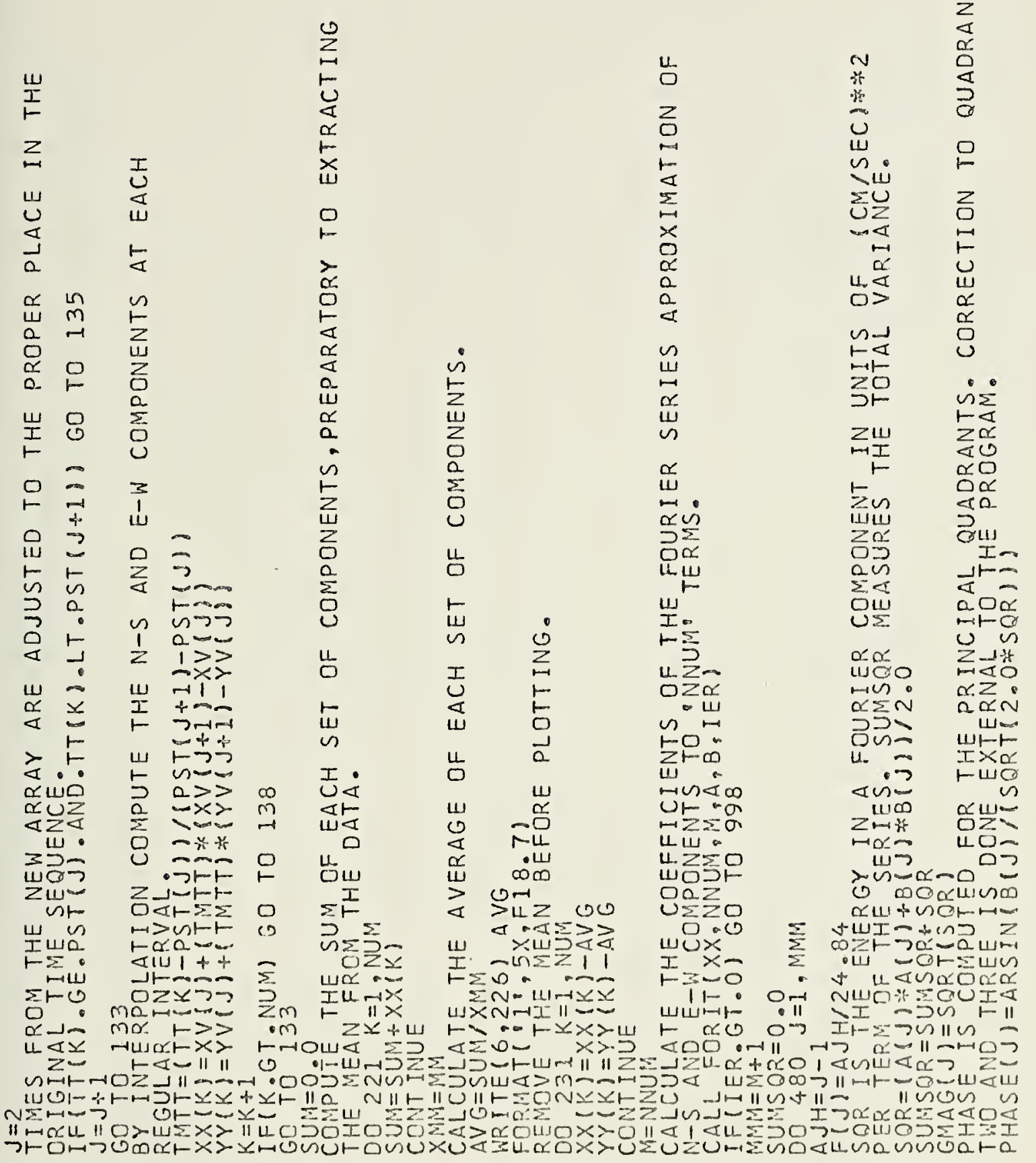

$u u^{m} \quad u^{\stackrel{m}{m}}$

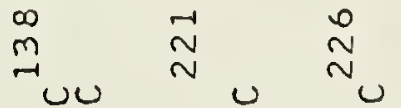

$\stackrel{-1}{n}$ uv

u

Uu 



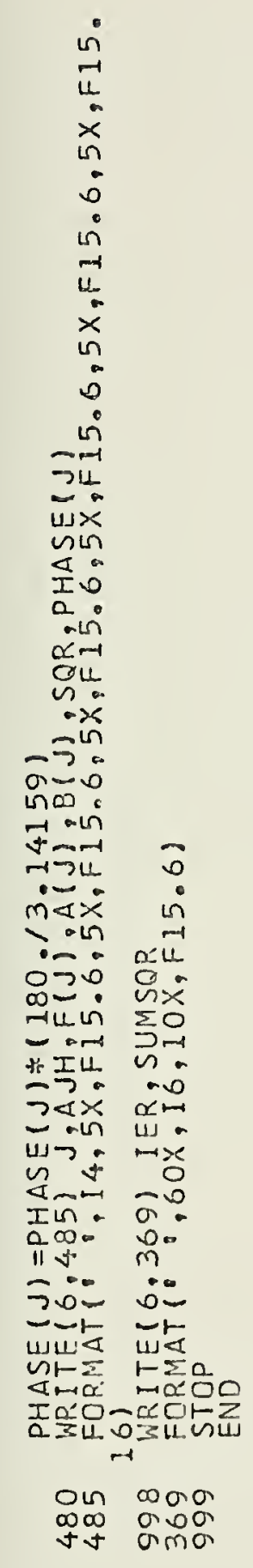





\section{APPENDIX B}

SAMPLE DATA FROM CRUISE I 

CRUISE I

$$
\begin{aligned}
& 10 \text { - } 11 \text { MAY } 1972 \\
& \text { WIND DATA }
\end{aligned}
$$

TIME

10 May 19721230

1415

1600

1715

1800

1955

2100

2300

11 May 19722400

0200

0400

0800

0905

1000

1100

1200

1300
WIND SPEED

8

11

12

16

20

14

10

8

8

2

4

4

6

7

8

8

9
WIND DIRECTION

NW

WNW

WNW

NW

WNW

NW

NW

NW

NW

VARIABLE

VARIABLE

VARIABL.E

WNW

WNW

NW

WNW

WNW 

CRUISE I

\section{0 - 11 MAY 1972 \\ TIDE DATA}

TIME

10 May 19721200

$1300-1.30$

$1400-1.30$

$1500 \quad-0.70$

$1600+0.30$

$1700+1.35$

$1800+2.40$

$1900+3.15$

$2000+3.40$

$2100+3.00$

$2200+2.00$

$2300+0.60$
TIME

11 May $1972 \quad 2400$

0100

$0200 \quad-2.85$

$0300-3.05$

$0400 \quad-2.65$

$0500 \quad-1.80$

$.0600 \quad-0.70$

$0700+0.40$

$0800+1.10$

$0900+1.45$

$1000+1.25$

$1100+0.80$

$1200+0.10$

$1300-0.50$ 

5

$-1 \geq$

$\infty<$

0 20

แ००

$\cup \alpha I$

马山u

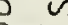

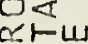

0<1

जा?

on

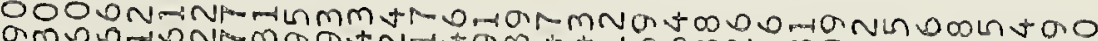

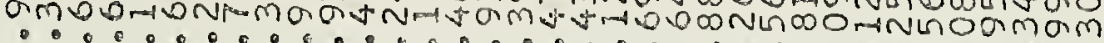
micom 0 -

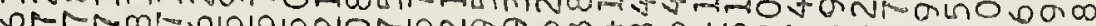
OR

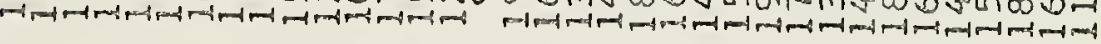

ய

Dis

FU

min

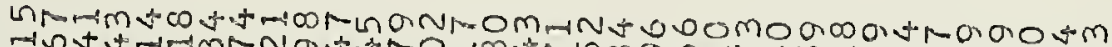
Hot t. Non

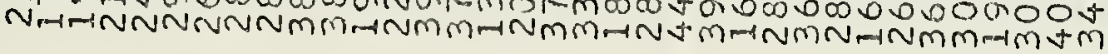
$\Sigma \cup$

000000000000000000000000000000000

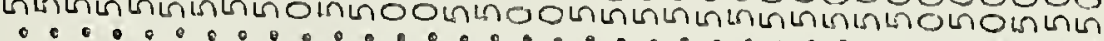

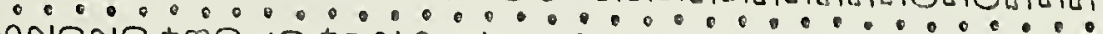
ONONO t OA HO

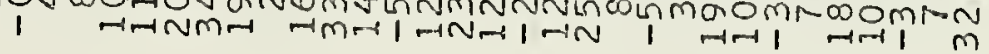
$\varangle 1$ $\sim \dot{\Sigma} \Sigma$

$\sum_{i=1}$

$\alpha \propto$

जण

10

$\sum_{i=10}$

30 에

$\sigma^{2} z$

ucra

Ju<

015 แ

шะ

İ̃u

$\vdash \cup \infty$

$\sum_{i=0}^{u \leftarrow}$
00000000000000000000000000000000000

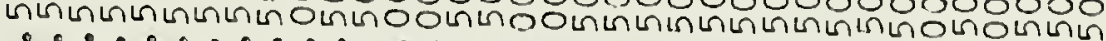
Nó: NTNNNMNNNMNI

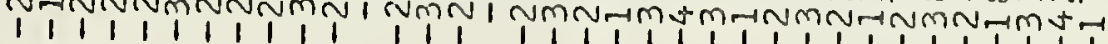

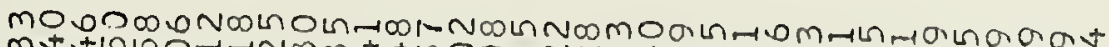

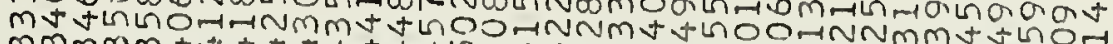

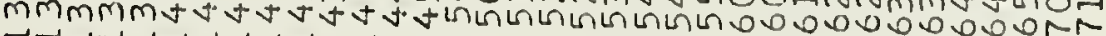





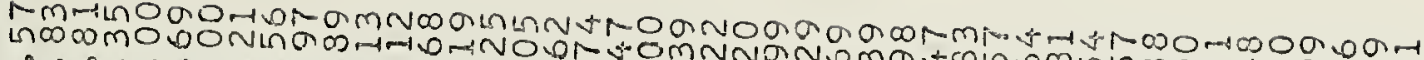

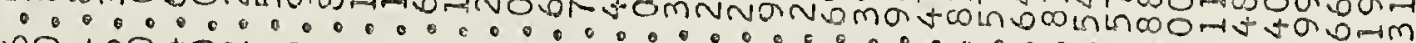
oOn Dotor.

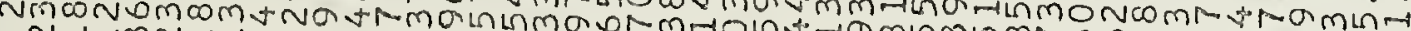

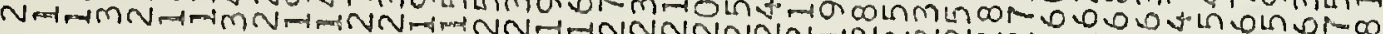

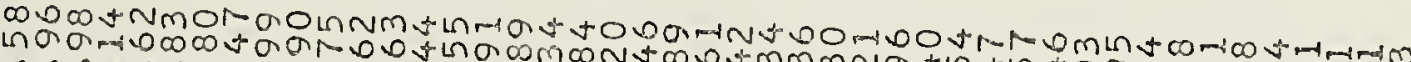

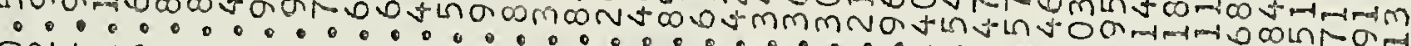

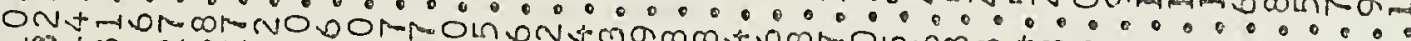

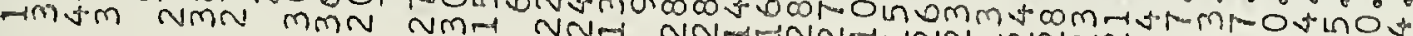

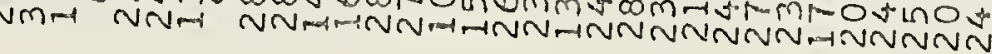

0000 O 00000000000000000000000000000000000000 .

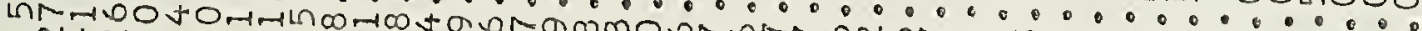

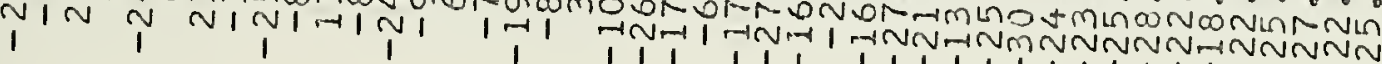

\section{0}

11111111111111111111111 



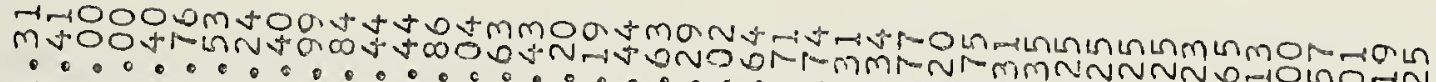

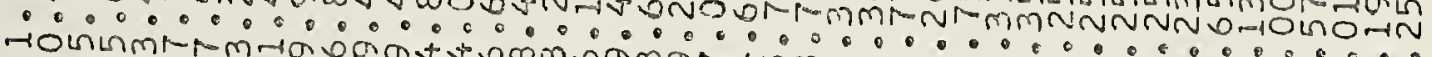

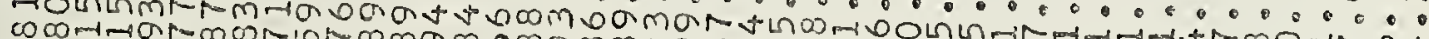
NNMm

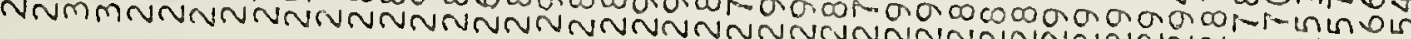

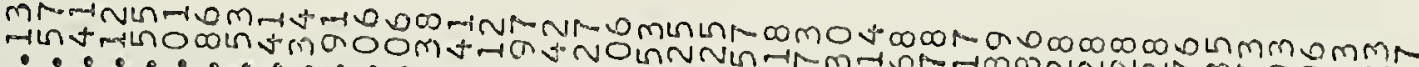
?. : : N

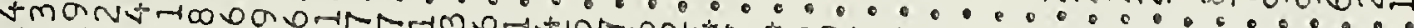

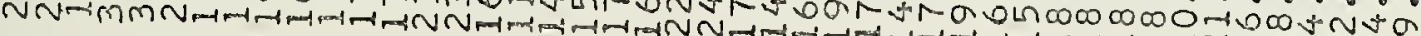
(1)

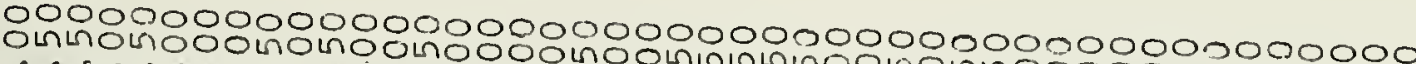
?

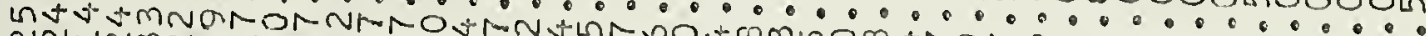

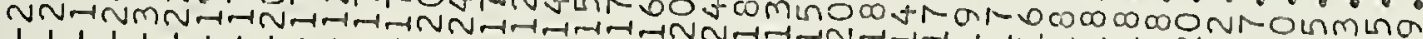

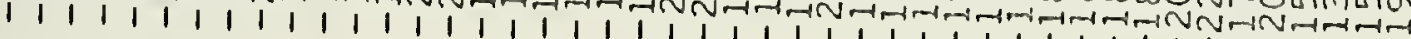

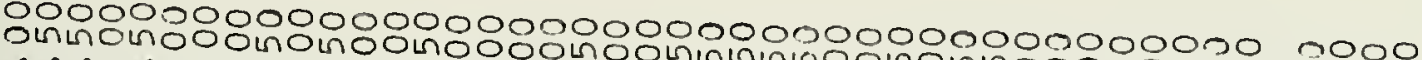

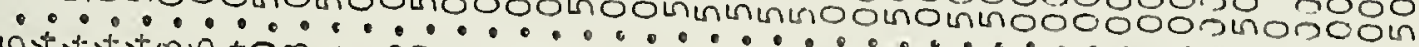

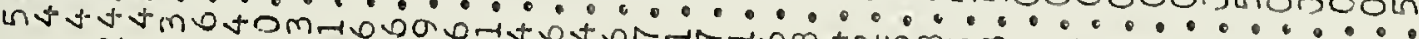
$\rightarrow \mathrm{Na}$

1

I $\rightarrow$

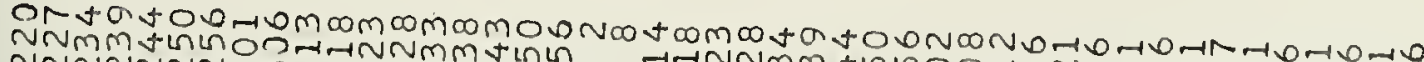

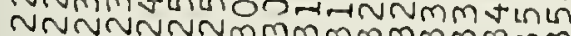

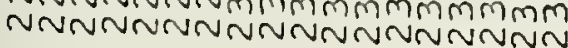
HANNmm tinioOn 



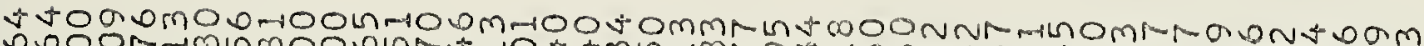

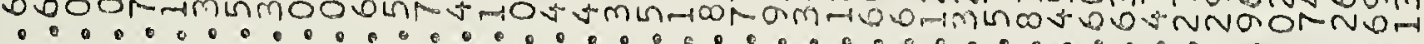
O

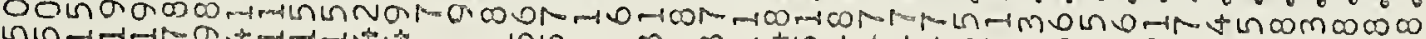
NNmmmovm mmmm $\mathrm{mm} m \mathrm{~mm}$ m $m$

m

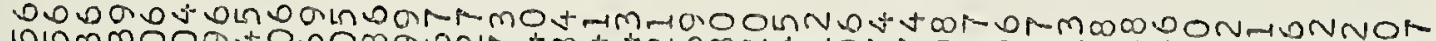

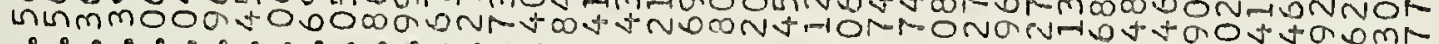

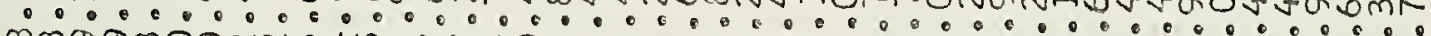

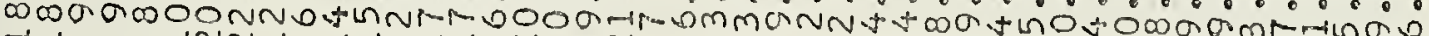

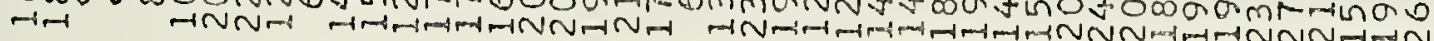

000000000000000000000000000000000000000000000

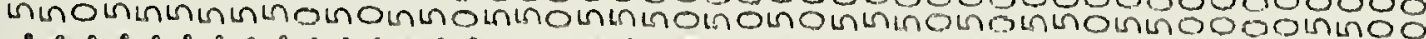

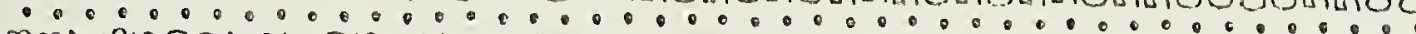

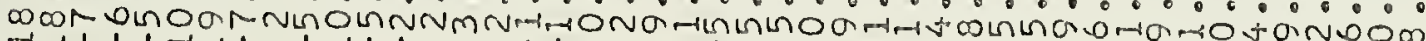

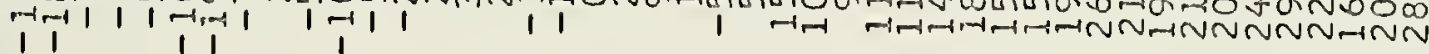

00000000000000000000000000000000000000000000

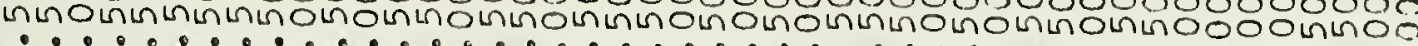
-

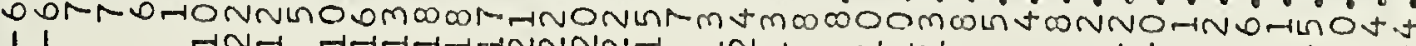

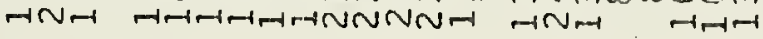

11

wi

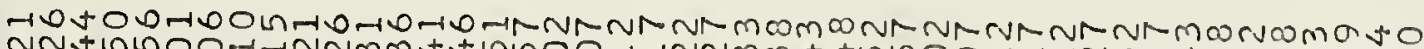

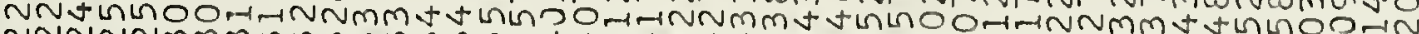

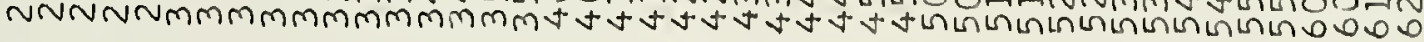





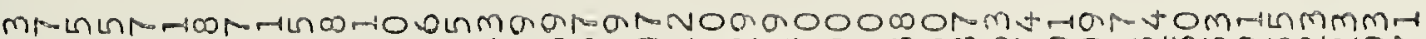

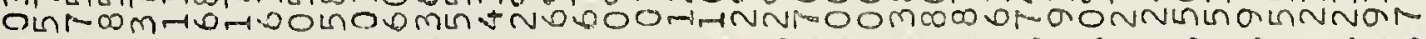

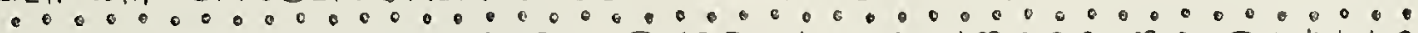

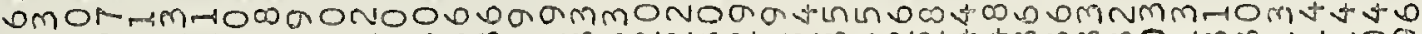

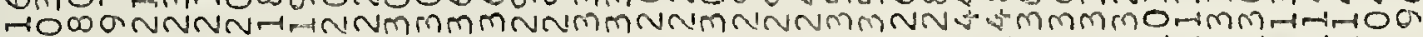

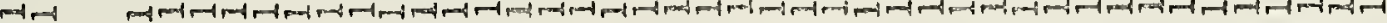

$山$

Sô

出

102

SO

$\Sigma-$

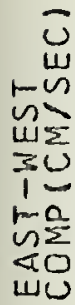

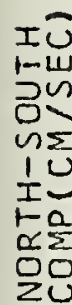

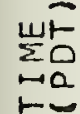

u

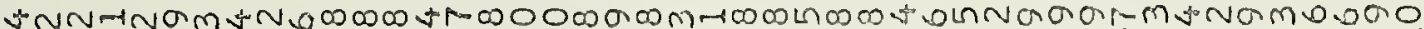

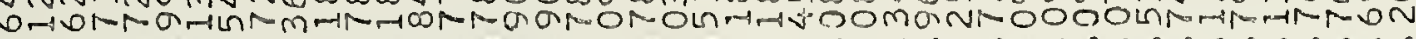

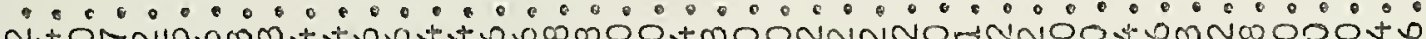

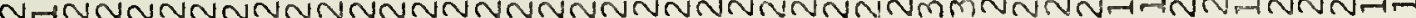

000000000000000000000000000000000000000000000

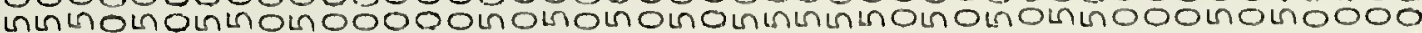

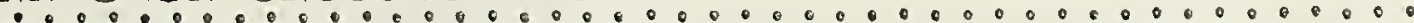

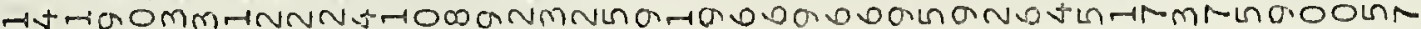

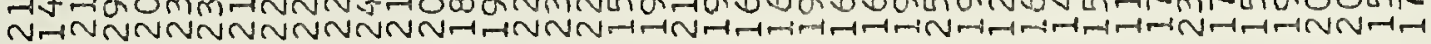

000000000000000000000000000000000000000000000

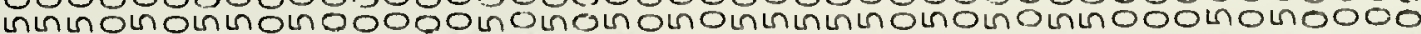
.

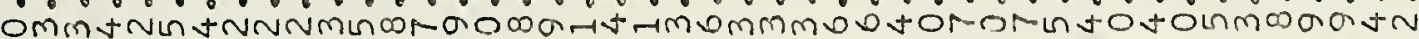

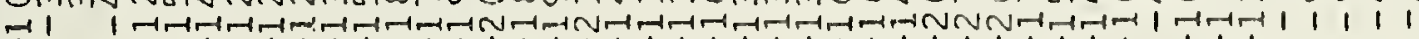

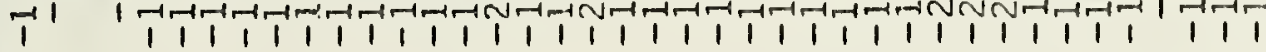

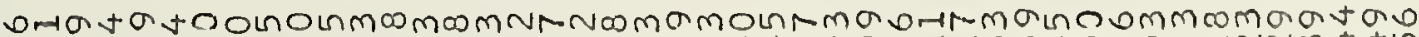

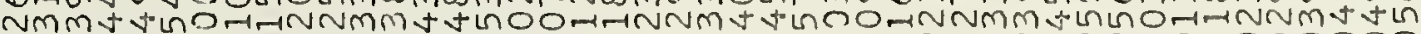

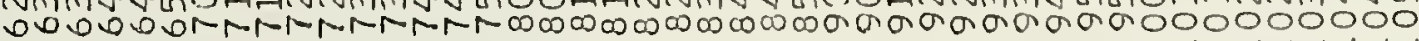





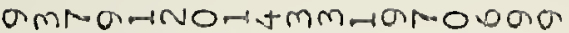

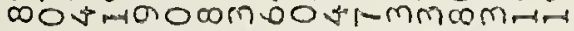

H

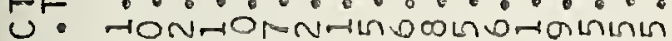

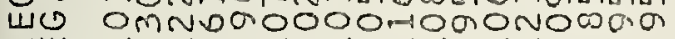

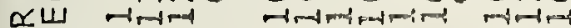

$+\infty$

U1

So

FU

$\Rightarrow$ m

खis

$\leq \omega$

$\sum$

岁

IU

†u

ơ

nI

1:3

Fo

$\alpha \sum$

00

zu

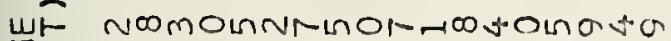

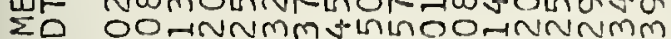

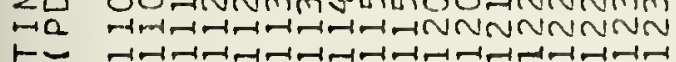

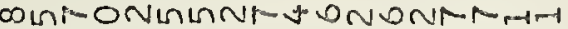
MtroconmAlnoso-ininara - $0: 0$ :

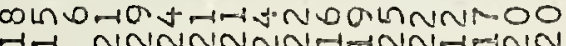

000000000000000000

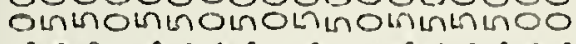
.

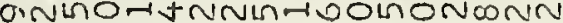

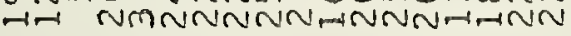

000000000000000000

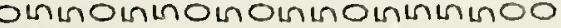

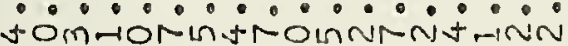
नाना $1111 \pi 111 \% 111$

u 



\section{APPENDIX C}

UNAVERAGED CURRENT DATA PLOTTED VERSUS WINDS AND TIDES 



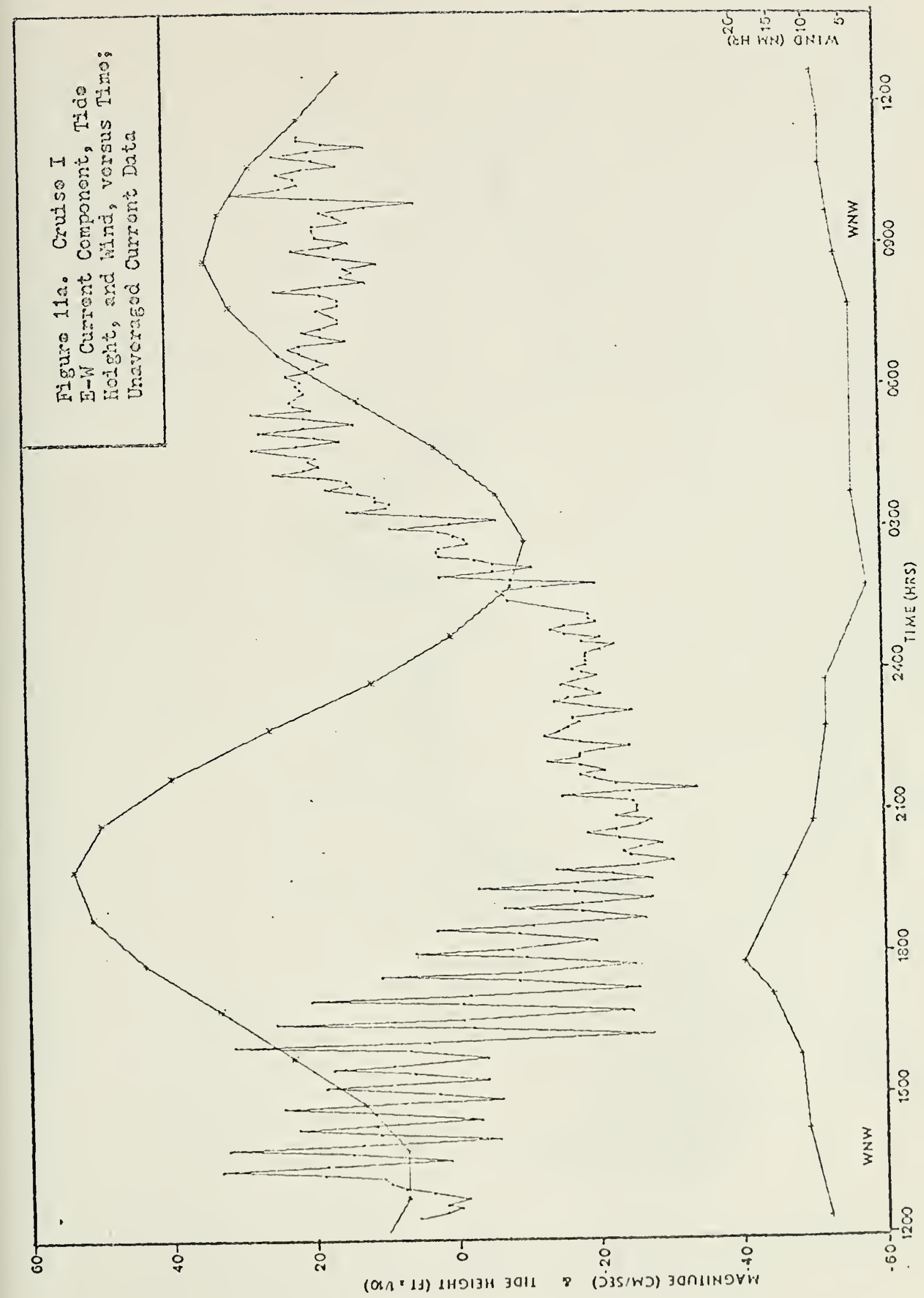





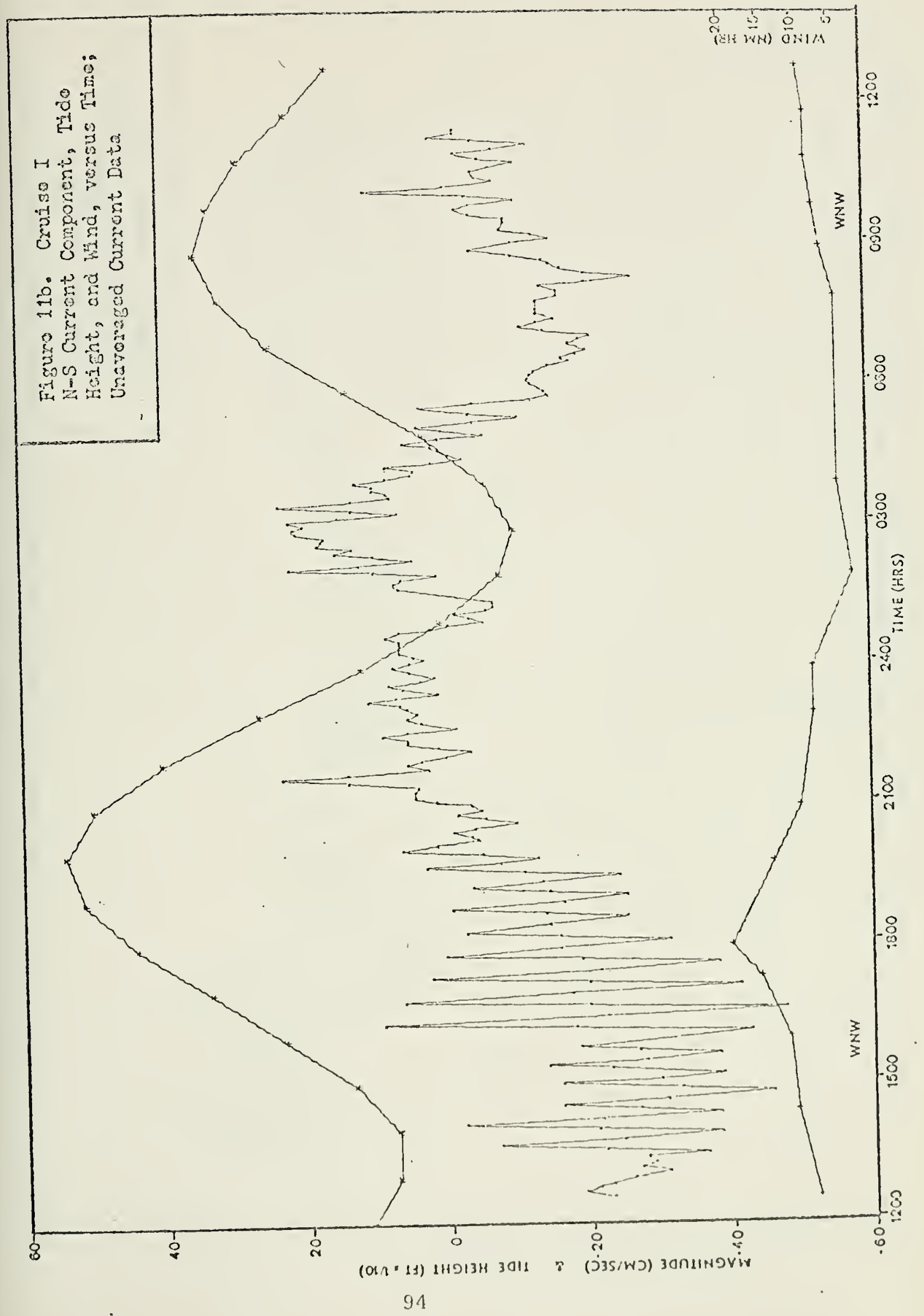





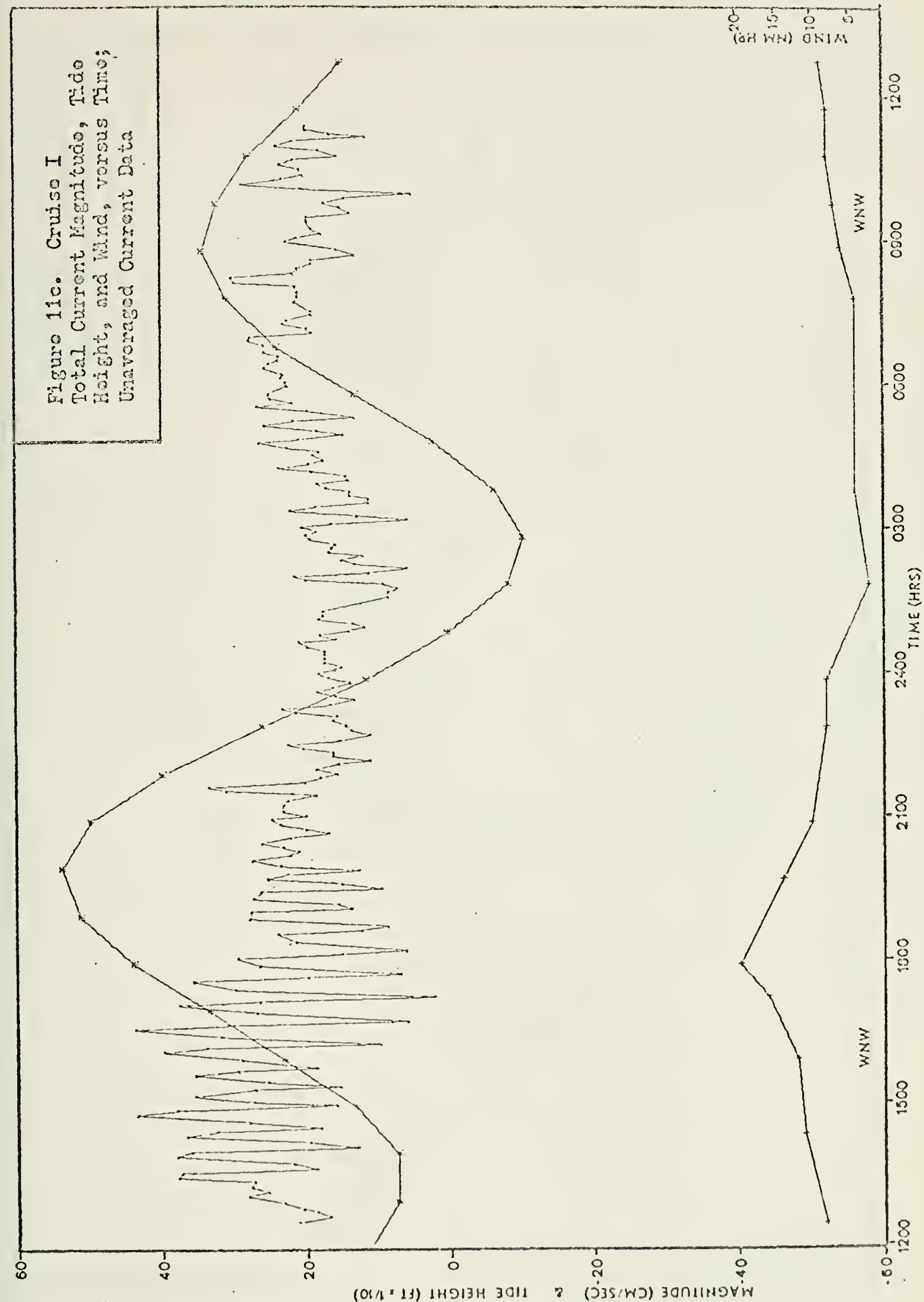





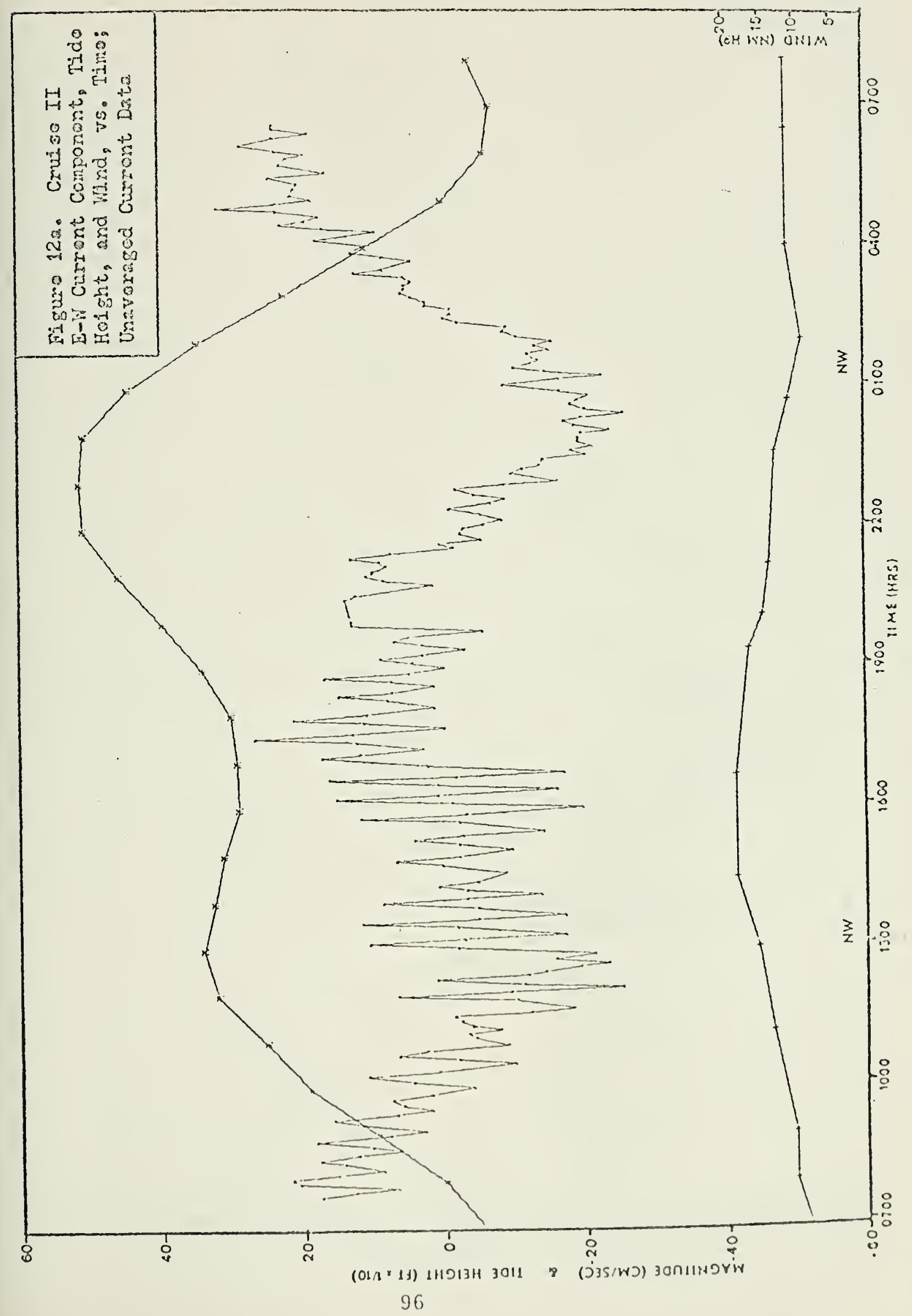





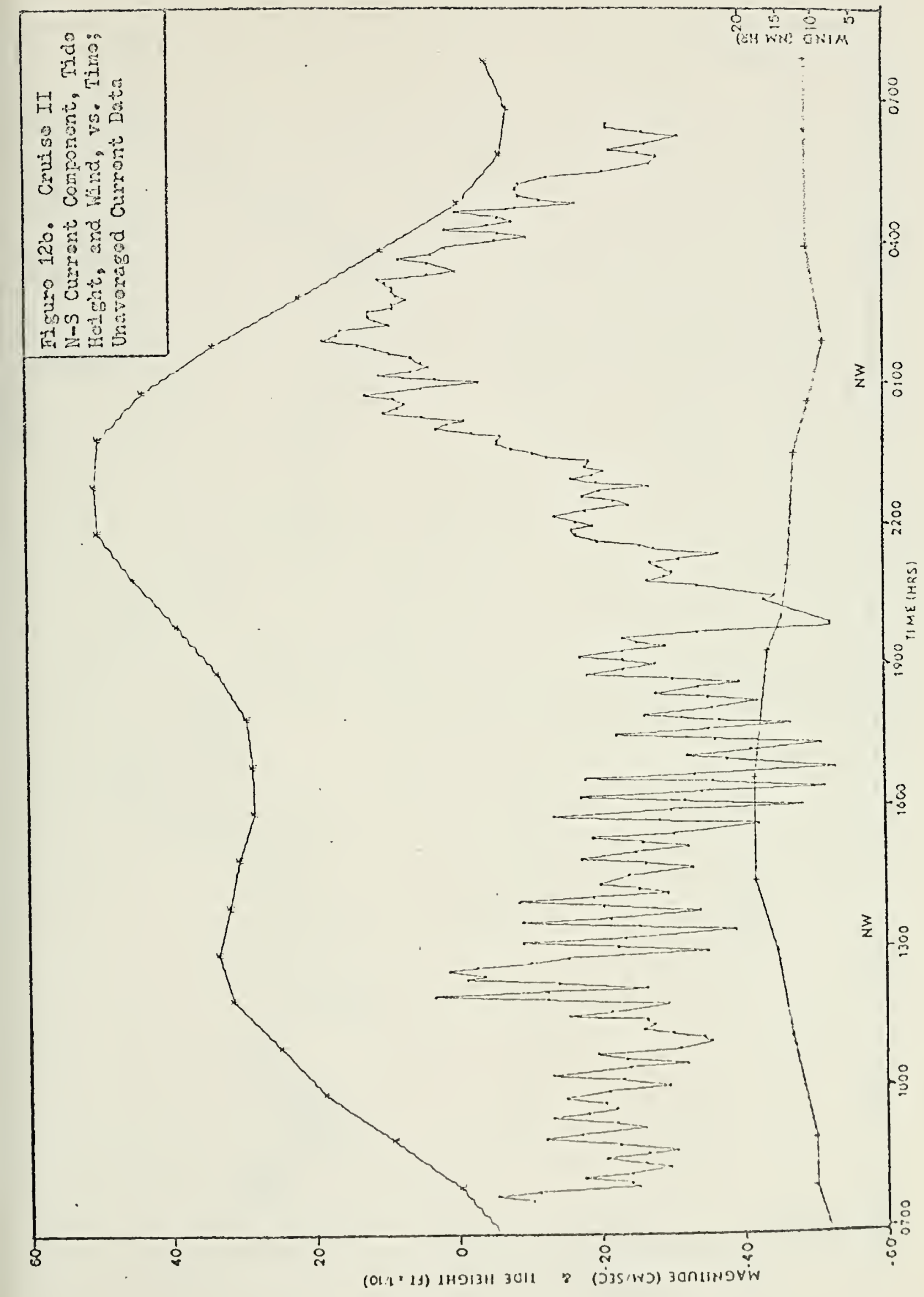





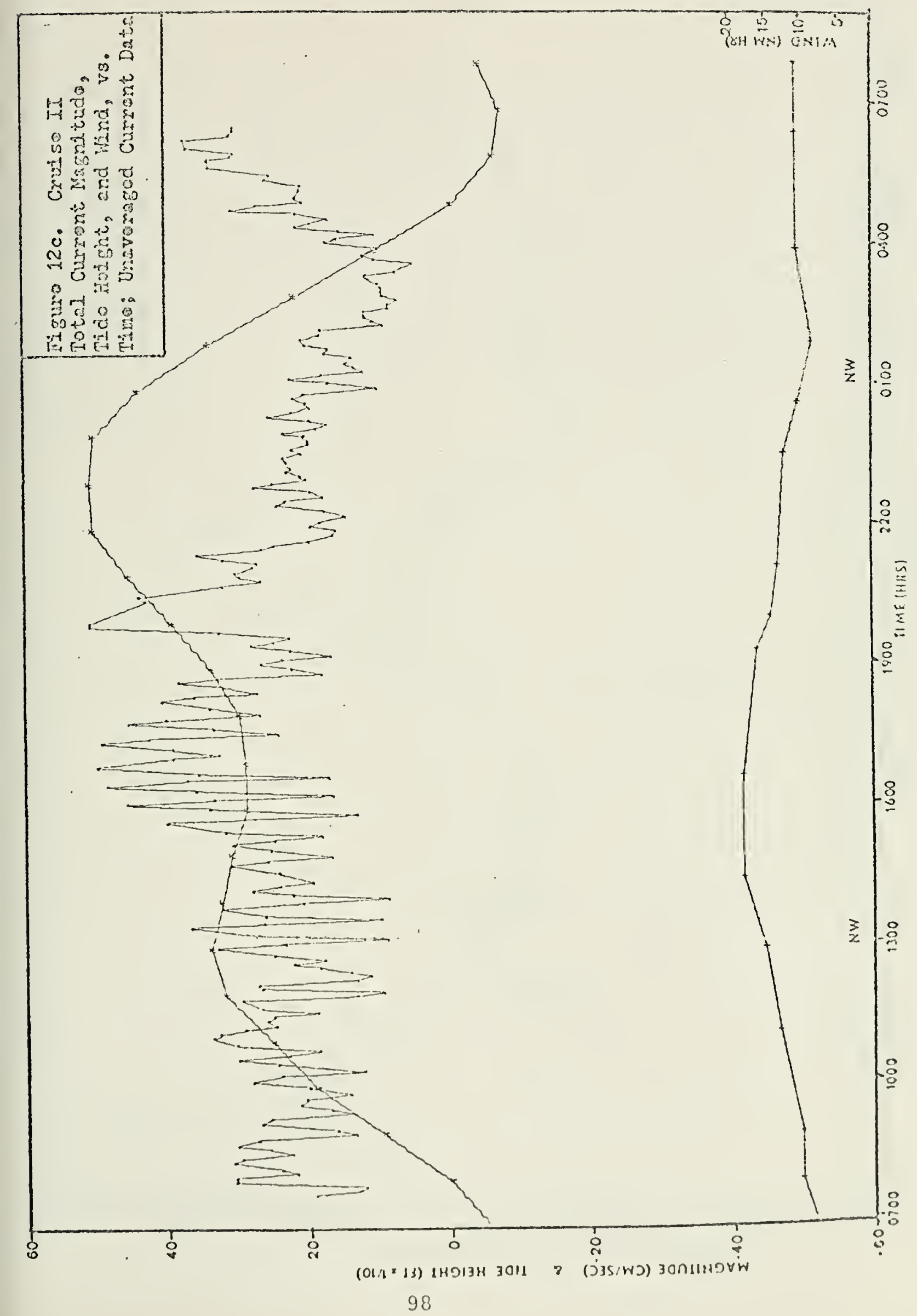





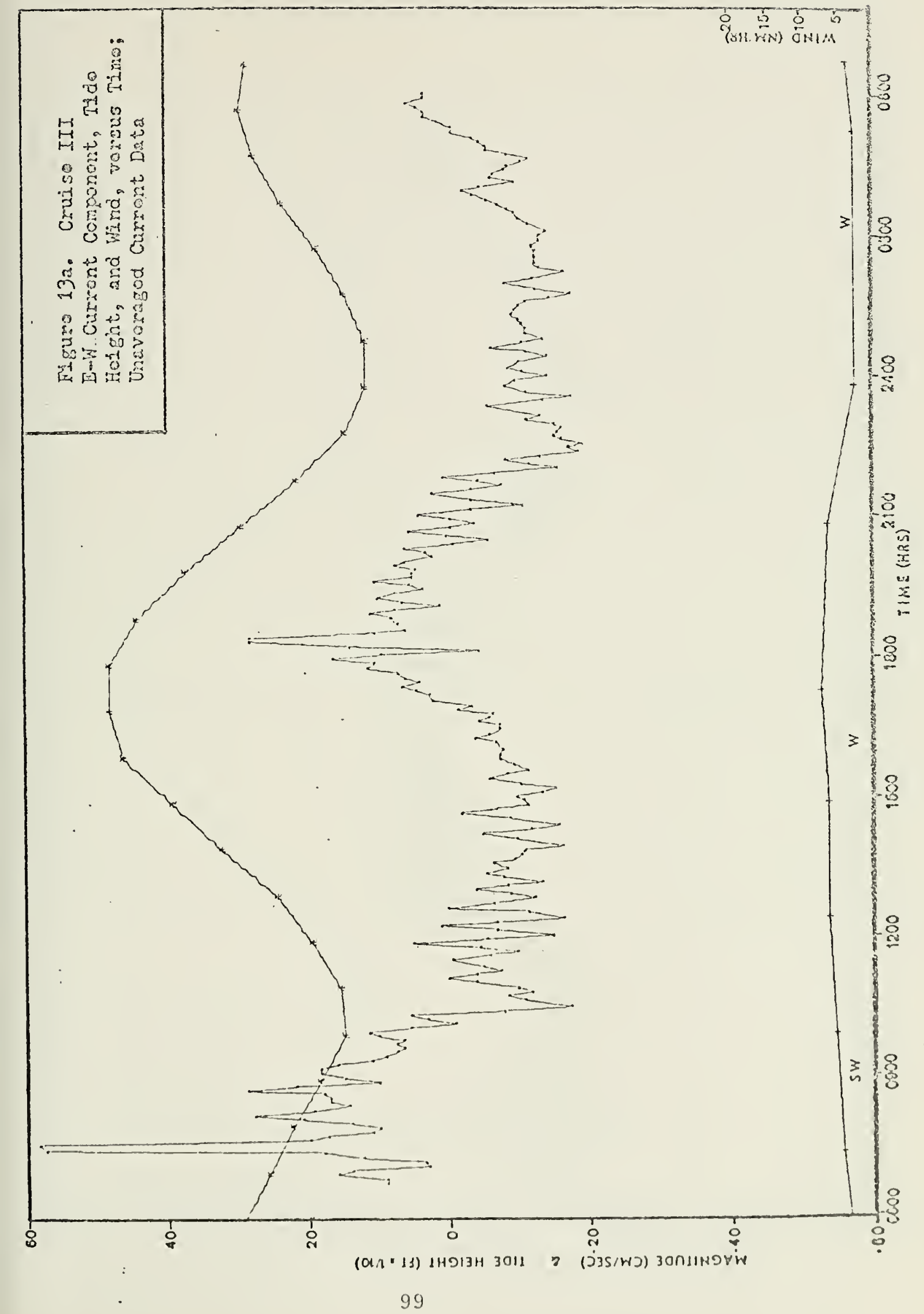





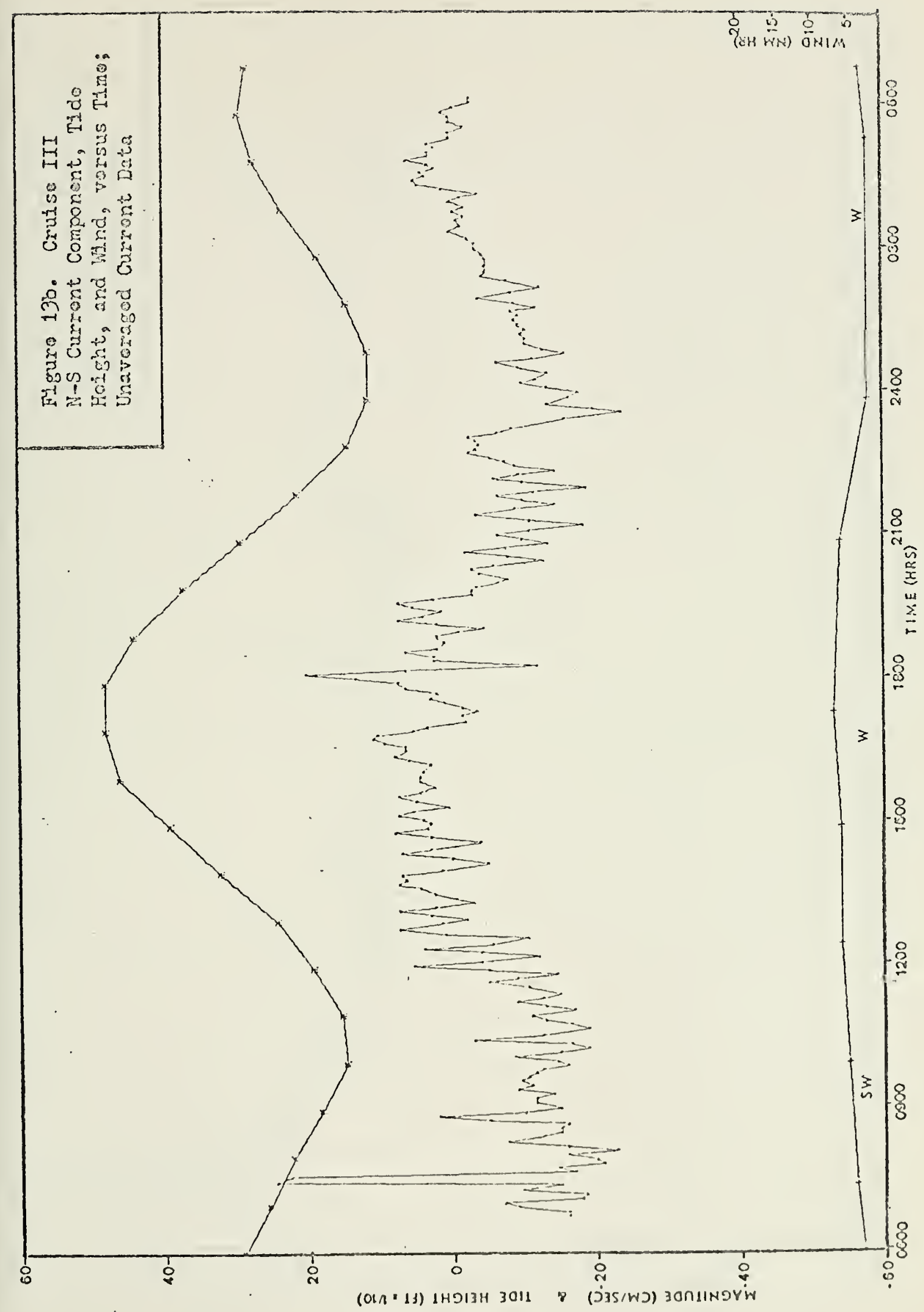






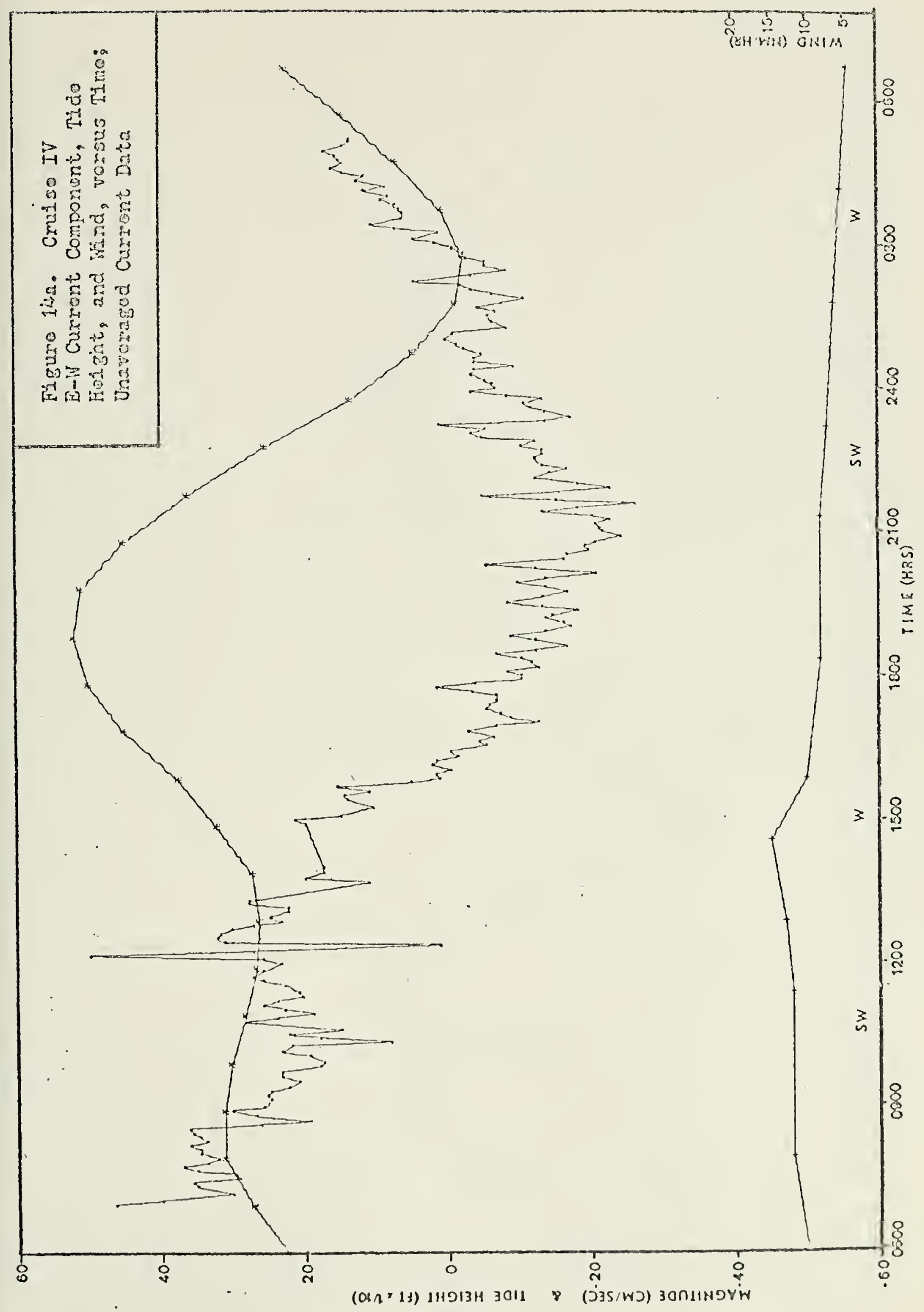

102 


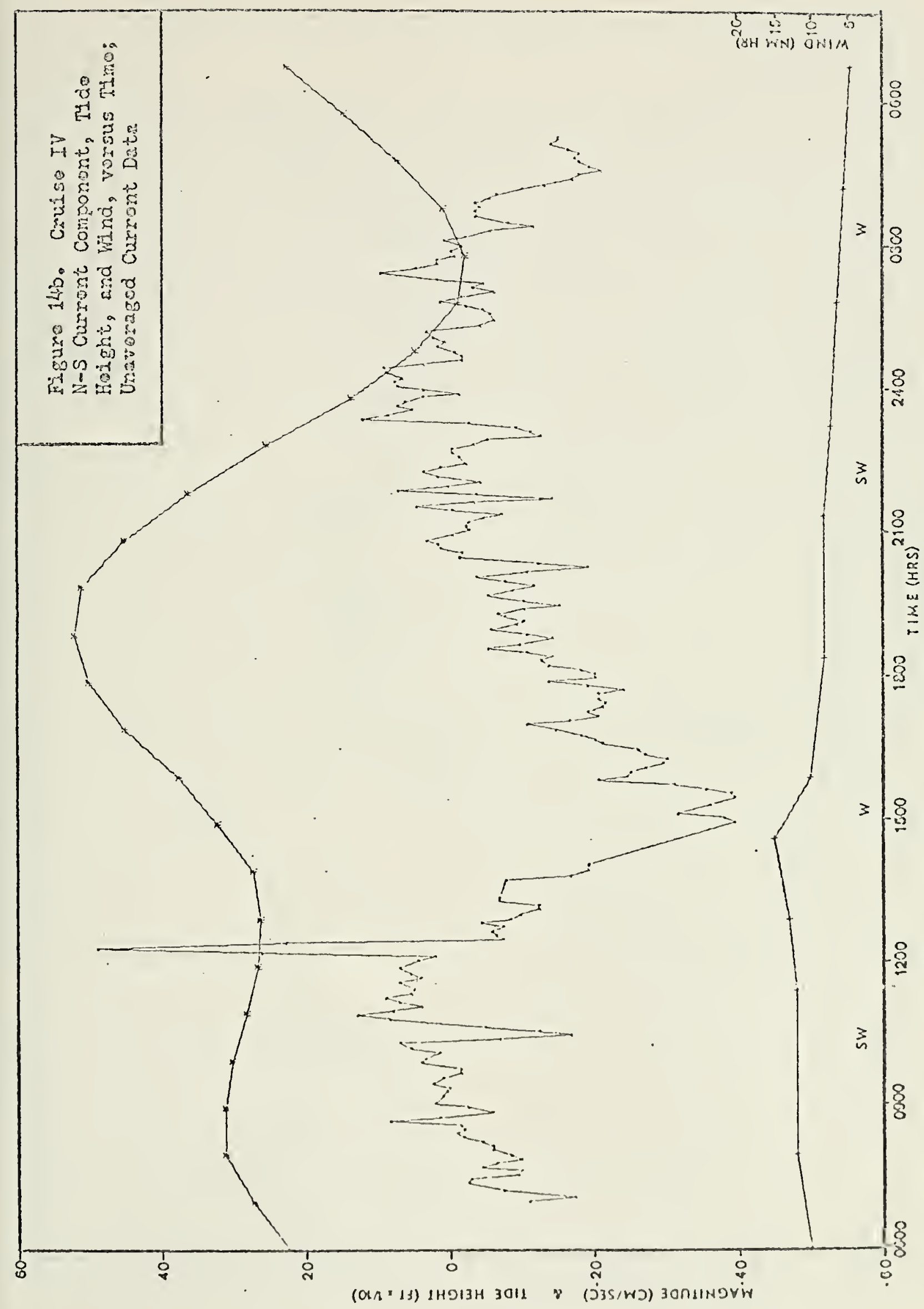





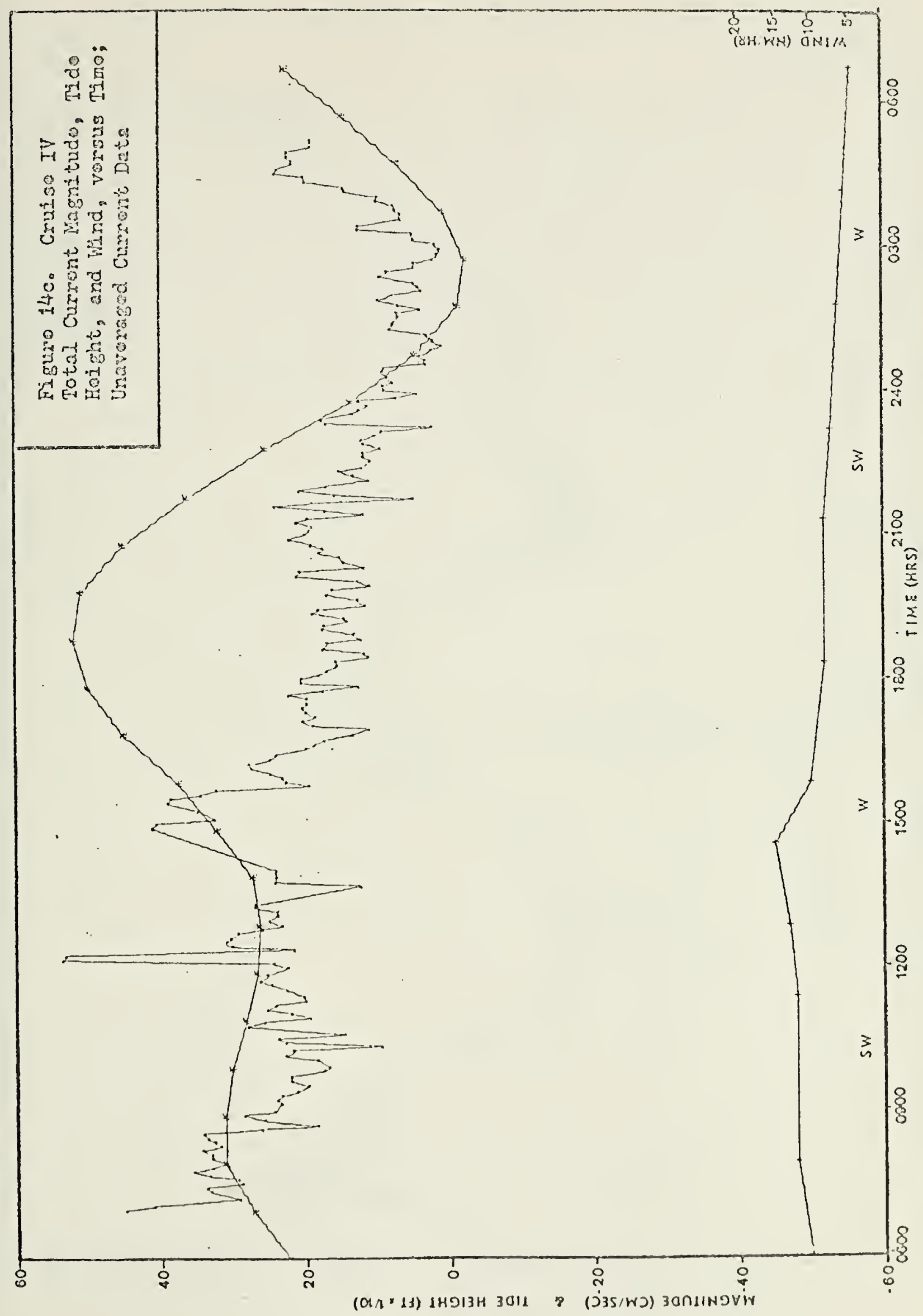





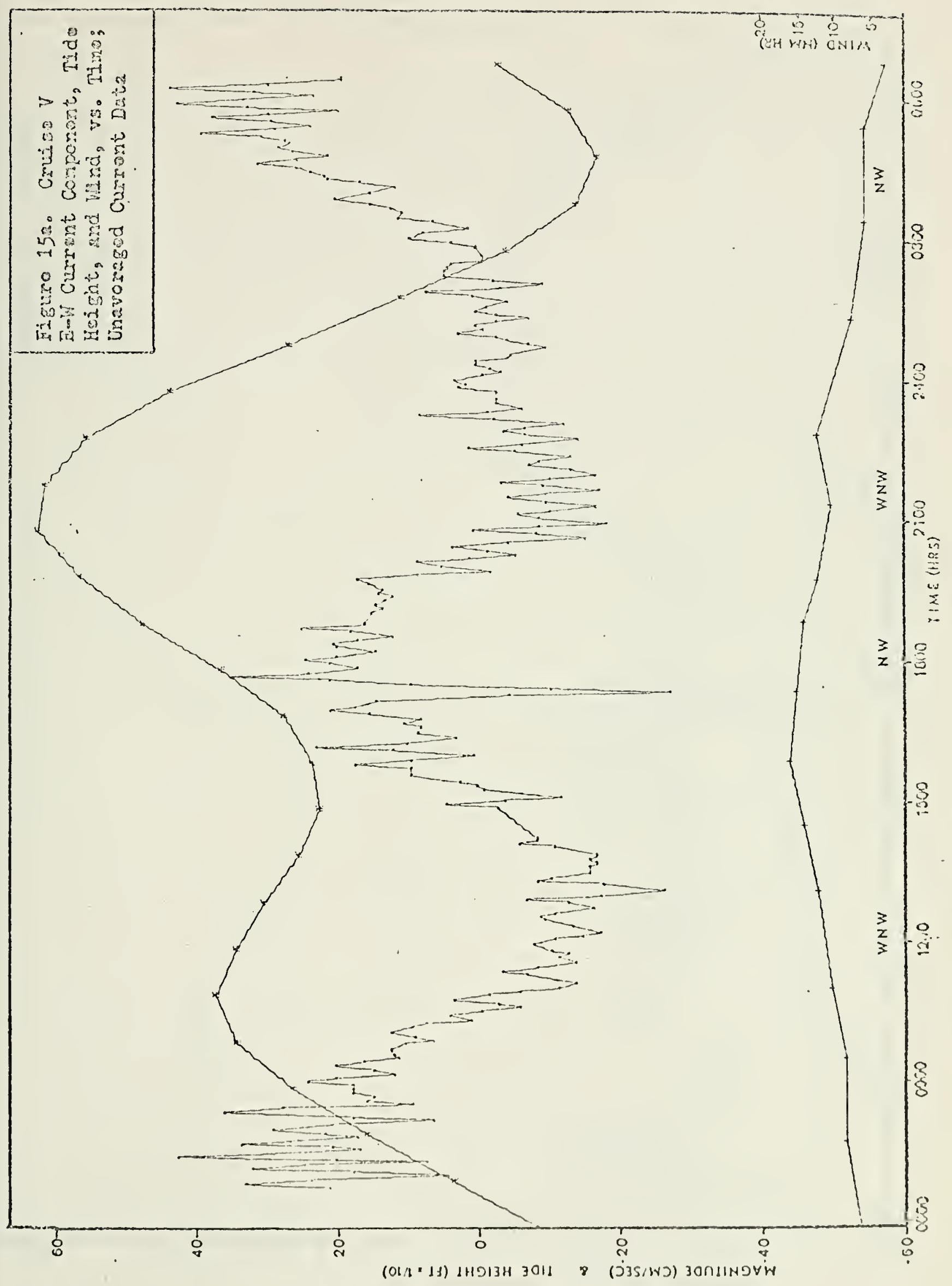





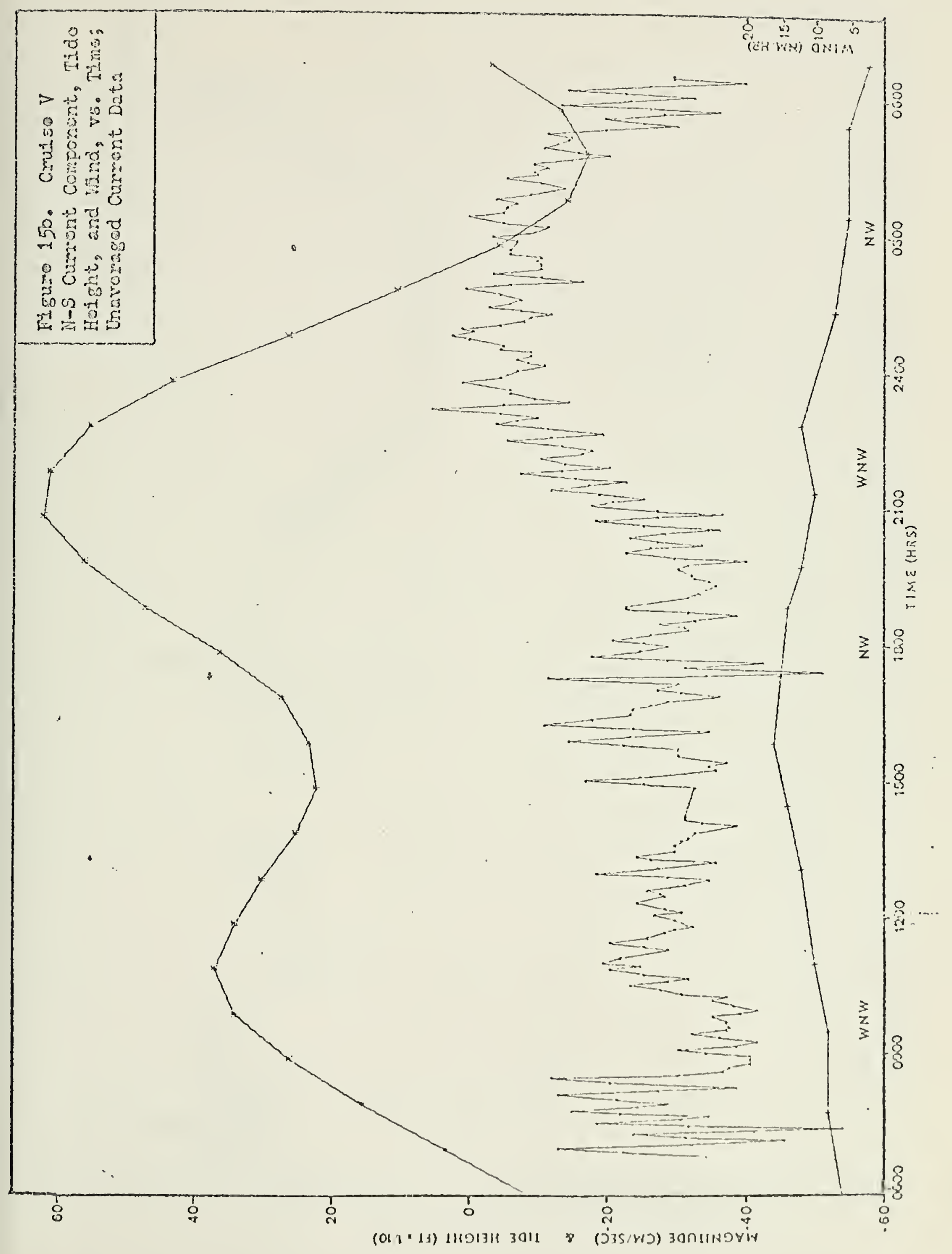





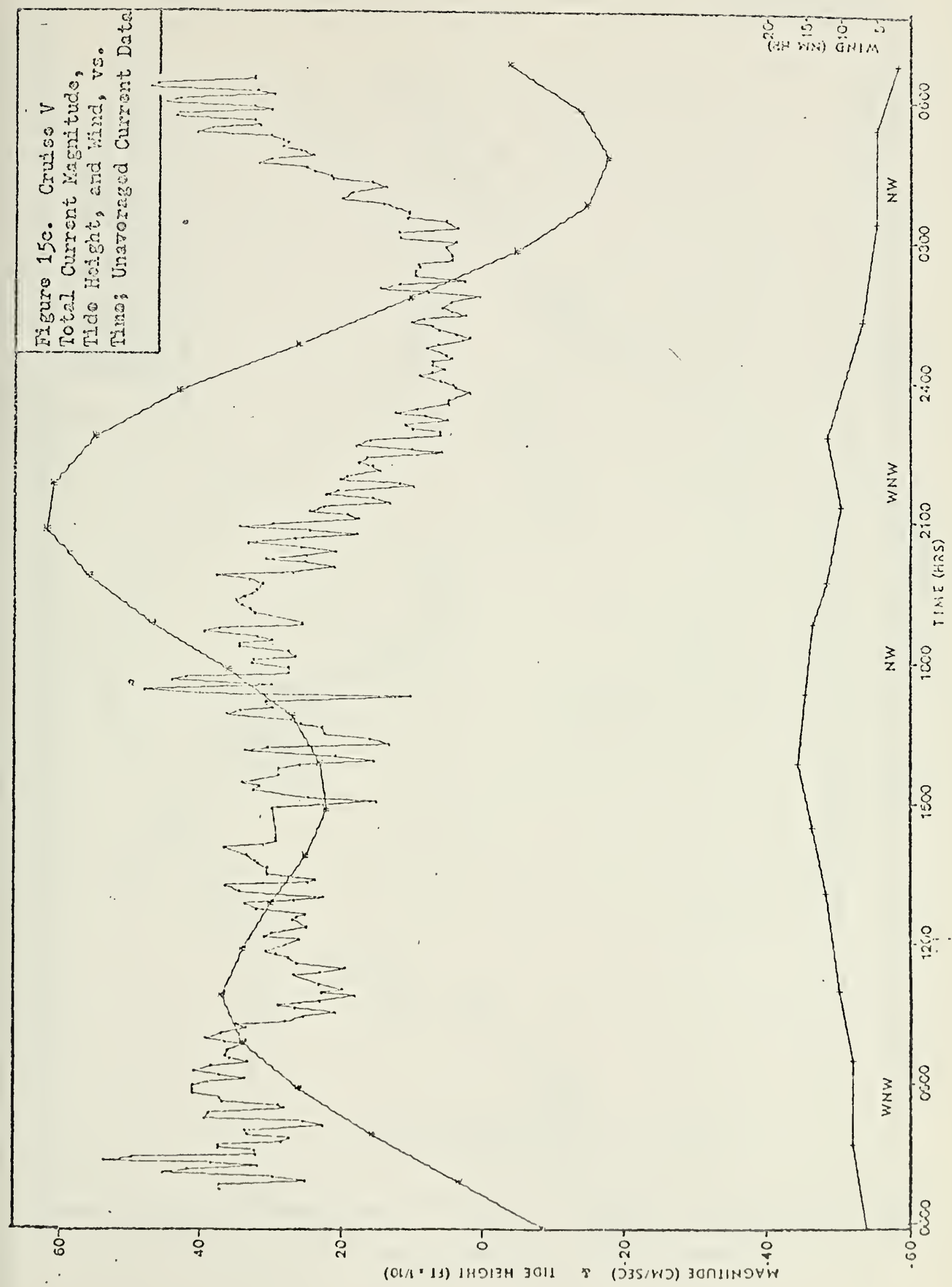





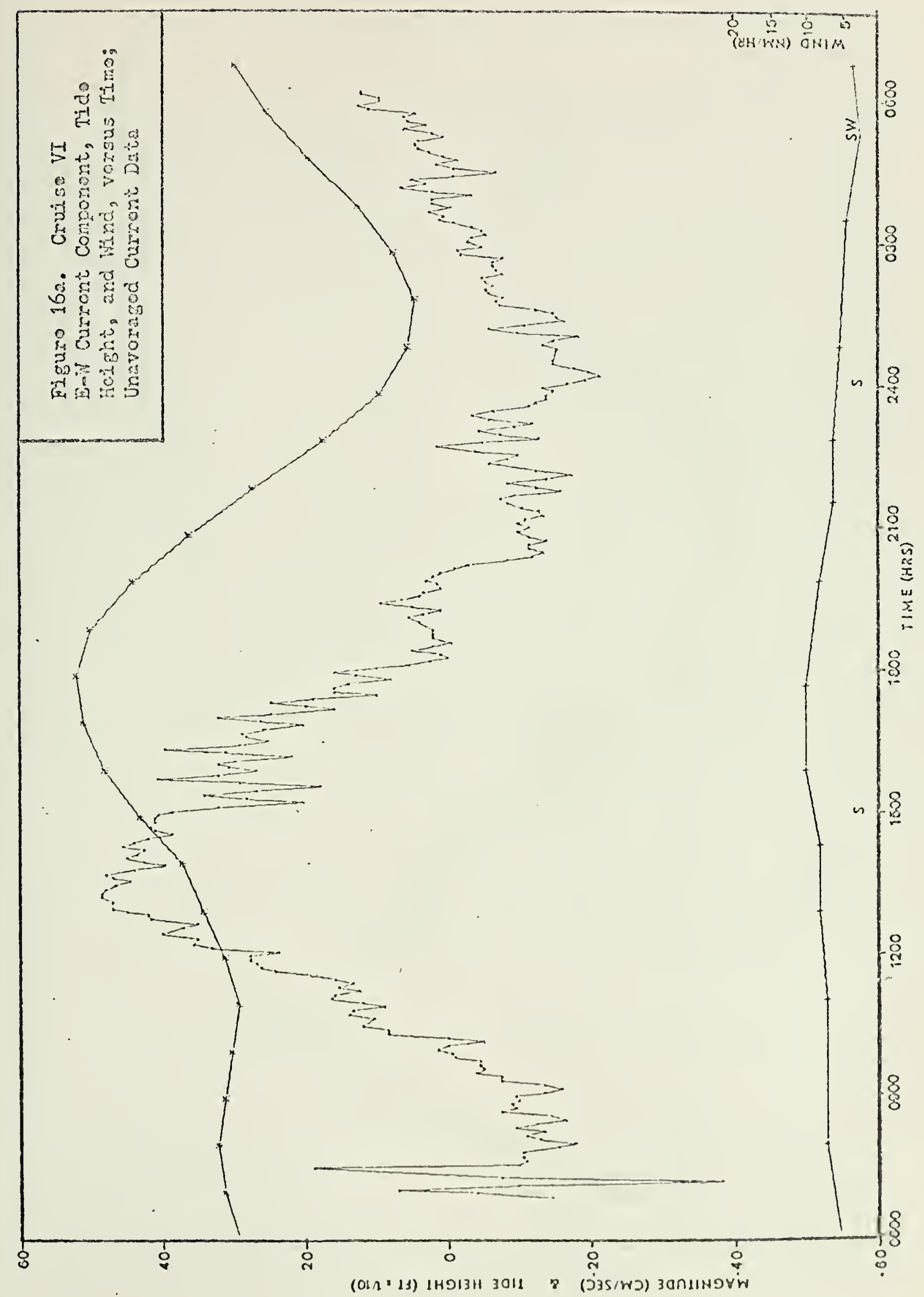





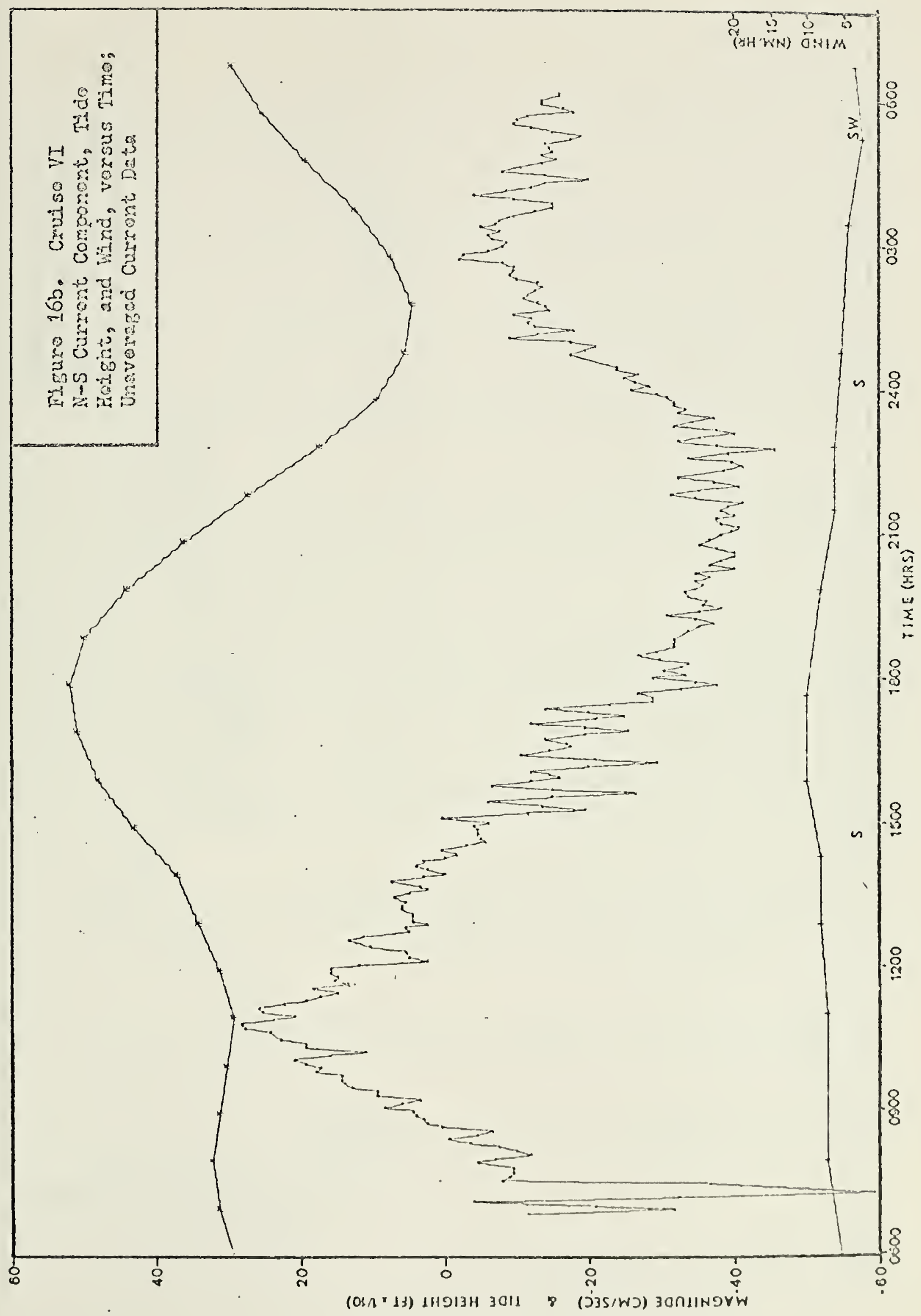





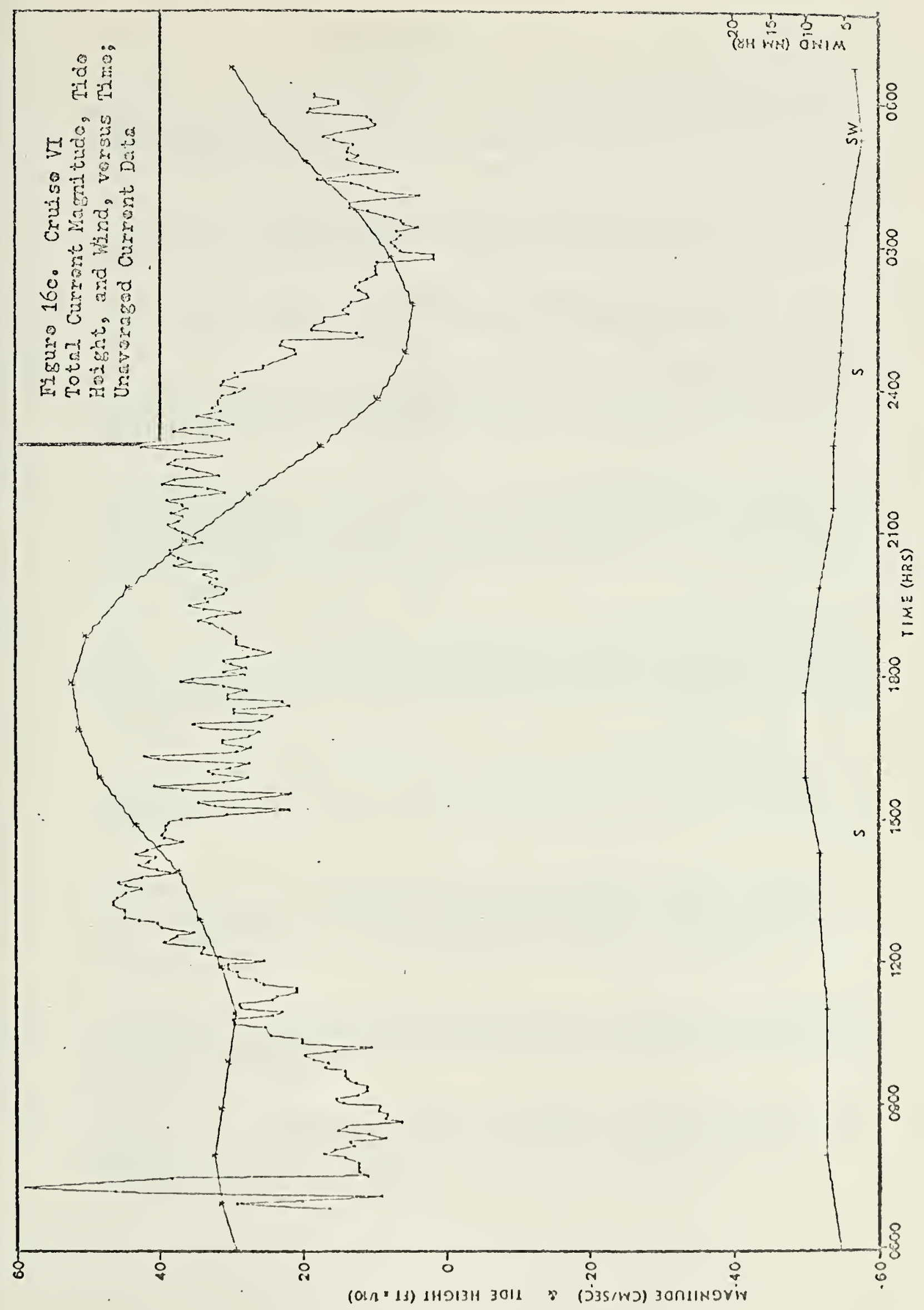



1. Barnes, C. A., and Paquette, R. G., Circulation near the Washington Coast, Proceedings of the Eighth Pacific Science Congress, III, pp. 585-608, 1957.

2. Bowden, K.F., Measurement of Wind Currents in the Sea by the Method of Towed Electrodes, Nature 171: 735, 1953.

3. Curtin, T. B., Towed Electrodes in the Sea: Theory and Use,

M. S. Thesis, Oregon State University, Corvalis, Oregon, 1970.

4. Lammers, L. L., A Study of Mean Monthly Thermal Conditions and Inferred Currents in Monterey Bay, M. S. Thesis, U. S. Naval Postgraduate School, Monterey, California, 1971.

5. Longuet-Higgins, M. S., Stern, M. E., and Stommel, H., The Electridal Field Induced by Ocean Currents and Waves, with Applications to the Mcthod of Towed Electrodes, M.I.T and Woods Hole Oceanographic Institution, Papers in Physical Oceanography and Meteorology, XIII(1), 1954 .

6. McKay, D. A., A Determination of Surface Currents in the Vicinity of the Monterey Submarine Canyon by the Electromagnetic Method, M. S. Thesis, U. S. Naval Postgraduate School, Monterey, California, 1970.

7. Reid, J. L. Ir ., A Comparison of Drogue and GEK Measurements in Deep Water, Limnology and Oceanography 3, No. 2, 160-165, 1958 .

8. Rodriguez, W. J., A Study of the Oceanographic Sea sons at a Single Station in the Monterey Submarine Canyon $1951-1955$ M. S. Thesis, U. S. Naval Postgraduate School, Monterey, California, 1970 .

9. Skogsberg, T., Hydrography of Monterey Bay, California, Thermal Conditions, 1929 - 1933, Transactions of the American Philosophical Society, 29, 1936.

10. Smith, T. D. , GEK Measurements of Surface Currents in Monterey Bay, 1971, M. S. Thesis, U. S. Naval Postgraduate School, Monterey, California, 1972. 

11. Stoddard, H. S. , Feasibility Study on the Utilization of Parachute Drogues and Shore-Based Radar to Investigate Surface Circulation in Monterey Bay, M. S. Thesis, U. S. Naval Postgraduate School, Monterey, California, 1971.

12. Sysoyev, N. N., and Volkev, V.S., A Guide to an Electromagnetic Method of Measuring the Velocity of Sea Currents from a Ship Under Way, Trudy Institituta Okeanologlii, Vol. XXIV: 173-199, 1957.

13. U. S. Department of Commerce Coast and Geodetic Survey, Tide Tables - West Coast North and South America, U. S. Government Printing Office, Washington, D. C., 1971.

14. U. S. Department of Commerce Coast and Geodetic Survey, Tidal Current Tables - Pacific Coast of North America and Asia, U.S. Government Printing Office, Washington, D. C., 1971.

15. U. S. Naval Oceanographic Office, Instruction Manual for Obtaining Oceanographic Data, Pub. No. 607, U. S. Government Printing Office, Washington, D. C., 1970.

16. von Arx, W. S., An Electromagnetic Method for Measuring the Velocities of Ocean Currents from a Ship Underway, M.I.T. and Woods Hole Oceanographic Institution, Papers in Physical Oceanography and Meteorology, XI(3), 1950.

17. Wyllie, J. G., CALCOFI ATLAS No. 4, Geostrophic Flow of the California Current at the Surface and at 200 Meters, State of California Marine Research Committee, 1966. 
1. Defense Documentation Center

Cameron Station

Alexandria, Virginia 22314

2. Library, Code 0212

Naval Postgraduate School

Monterey, California 93940

3. Department of Oceanography

Naval Postgraduate School

Monterey, California 93940

4. Dr. R. G. Paquette

Department of Oceanography

Naval Postgraduate School

Monterey, California 93940

5. Dr. J.J. von Schwind

Department of Oceanography

Naval Postgraduate School

Monterey, California 93940

6. Dr.W.C. Thompson

Department of Oceanography

Naval Postgraduate School

Monterey, California 93940

7. Dr. D.F. Leipper

Department of Oceanography

Naval Postgraduate School

Monterey, California 93940

8. Dr. E. B. Thornton

Department of Oceanography

Naval Postgraduate School

Monterey, California 93940

9. Dr. N.E. J. Boston

Department of Oceanography

Naval. Postgraduate School

Monterey, California 93940 

10. Dr. W. W. Denner

Department of Oceanography

Naval Postgraduate School

Monterey, California 93940

11. Chairman, Association of the Monterey Bay Area Governments (AMBAG)

Monterey, California 93940

12. Oceanographer of the Navy

The Madison Building

$732 \mathrm{~N}$. Washington Street

Alexandria, Virginia 22314

13. Lieutenant H. M. Howton, USN

149 Ferry Road, N.E.

Fort Walton Beach, Florida 32548 

Currents in Monterey Bay

Geomagnetic Electrokinetograph

Surface Currents 





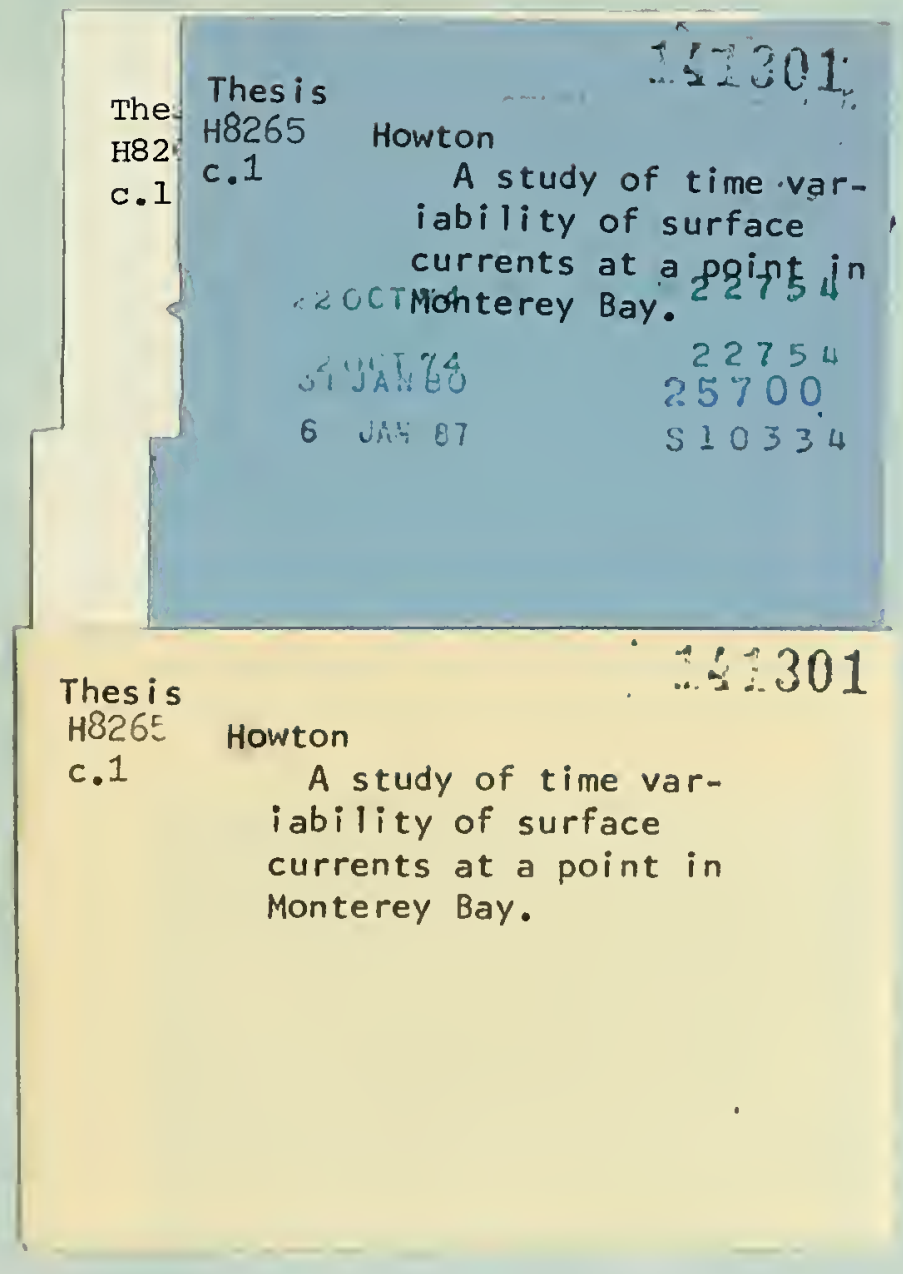


